\title{
WestVirginiaUniversity
}

THE RESEARCH REPOSITORY @ WVU

Graduate Theses, Dissertations, and Problem Reports

2006

\section{A geostatistical calculation of the Coal Mine Roof Rating}

Matthew A. Petrovich

West Virginia University

Follow this and additional works at: https://researchrepository.wvu.edu/etd

\section{Recommended Citation}

Petrovich, Matthew A., "A geostatistical calculation of the Coal Mine Roof Rating" (2006). Graduate Theses, Dissertations, and Problem Reports. 3264.

https://researchrepository.wvu.edu/etd/3264

This Thesis is protected by copyright and/or related rights. It has been brought to you by the The Research Repository @ WVU with permission from the rights-holder(s). You are free to use this Thesis in any way that is permitted by the copyright and related rights legislation that applies to your use. For other uses you must obtain permission from the rights-holder(s) directly, unless additional rights are indicated by a Creative Commons license in the record and/ or on the work itself. This Thesis has been accepted for inclusion in WVU Graduate Theses, Dissertations, and Problem Reports collection by an authorized administrator of The Research Repository @ WVU. For more information, please contact researchrepository@mail.wvu.edu. 


\title{
A Geostatistical Calculation of the Coal Mine Roof Rating
}

\author{
Matthew A. Petrovich \\ Thesis submitted to the \\ College of Engineering and Mineral Resources \\ at West Virginia University \\ in partial fulfillment of the requirements \\ for the degree of \\ Master of Science \\ in \\ Mining Engineering
}

Keith A. Heasley, Ph.D., P.E., Chair

Christopher J. Bise, Ph.D., P.E.

Syd S. Peng, Ph.D.

Department of Mining Engineering

Morgantown, West Virginia

2006

Keywords: CMRR, Coal Mine Roof Rating, Geologic factor, Stability mapping, Stability index

Copyright 2006 Matthew A. Petrovich 


\section{ABSTRACT \\ A Geostatistical Calculation of the Coal Mine Roof Rating}

\section{Matthew A. Petrovich}

In this thesis, the need for an efficient and easy to use program which calculates a Coal Mine Roof Rating (CMRR) over a spatial area is established. In response to this need, a program which enables for the geostatistical calculation of the CMRR over a spatial area was developed as an engineering tool to quantify the geo-mechanical stability of the roof rock within the bolted horizon of a coal mine through the utilization of one of the more widely available geologic model data formats.

The CMRR program utilizes the popular AutoCAD/SurvCADD platform and grid data format as a foundation for inputting the geologic characteristics necessary to calculate a CMRR. Through this feature the user can generate areal CMRR stability information from drill holes, SurvCADD geology grids and/or underground observations. This areal CMRR input can then be individually plotted for interpretation or combined with other geologic, structural and stress-based factors in order to generate an overall stability factor for the mine.

Upon completion of the program, a case study was performed in order to identify any shortcomings or additional needs that had not been previously identified. The case study utilized both the areal CMRR calculation and the integration of the CMRR program with a previously developed stability mapping package to create a stability map for the mine. Agreement was found between the resultant stability map and the field observations.

In the conclusion of this thesis it appears that the CMRR program can and will serve as a useful tool for the mining engineer in the evaluation of coal measure roof rock over a large spatial area. Through its application, both the mine engineer and the mine personnel can benefit from the increased knowledge of the coal measure roof rock being studied and the increased safety which that brings. 


\section{ACKNOWLEDGEMENTS}

Without the support of my advisor, colleagues, friends and family, the completion

of this thesis would have never been possible. Particularly, I would like to thank the following people:

Dr. Keith A. Heasley, my mentor and friend, for his unending patience, guidance and assistance during my time at West Virginia University.

Dr. Syd S. Peng and Dr. Christopher J. Bise for serving on my committee.

Olayemi Akinkugbe, for his help and support during the coding of the CMRR program.

More importantly, I want to thank my wife, Anna, for her ability to stay calm when I could not.

This work was performed under a project sponsored by the National Institute for Occupational Safety and Health (NIOSH). 


\section{TABLE OF CONTENT}

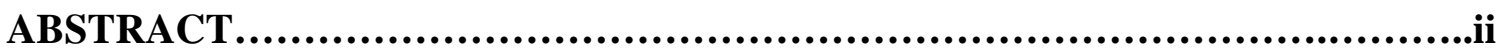

ACKNOWLEDGEMENTS..........................................................iii

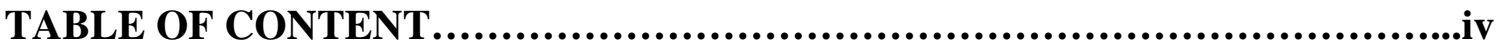

TABLE OF FIGURES...........................................................viii

TABLE OF TABLES...................................................................

Chapter 1. Introduction

1.1 General..........................................................................1

1.2 Statements of the Problem.......................................................3

1.3 Scope of Work...........................................................

Chapter 2. Literature Review.......................................................6

2.1 General.......................................................................6

2.2 The Coal Mine Roof Rating (CMRR) System..............................7

2.2.1 Introduction...........................................................

2.2.2 Components.........................................................

2.2.3 Discontinuities......................................................8

2.2.4 Discontinuity Intensity..............................................10

2.2.5 Compressive Strength..............................................11

2.2.6 Moisture Sensitivity.................................................12

2.2.7 Non-Unit Information...............................................12

2.2.8 Unit Rating Calculations................................................12

2.2.9 CMRR Calculations....................................................16

2.2.10 CMRR Summary....................................................19 
2.3 Calculating the CMRR from Core.........................................20

2.3.1 General..................................................................20

2.3.2 Compressive Strength from Core...................................20

2.3.3 Shear Strength........................................................21

2.3.4 Unit and CMRR Calculations.........................................23

2.3.5 CMRR Computer Program............................................23

2.4 Stability Mapping Systems..............................................25

2.4.1 Introduction........................................................25

2.4.2 Previous Work........................................................28

2.5 AutoCAD Program and Grids............................................43

Chapter 3. Design of the Coal Mine Roof Rating Program...........................45

3.1 General.........................................................................45

3.2 Data Format..................................................................45

3.3 Data Requirements.........................................................49

3.4 Program Creation $\quad$..........................................................50

Chapter 4. Implementation of the CMRR Program...............................51

4.1 General.................................................................51

4.2 User Interface..........................................................51

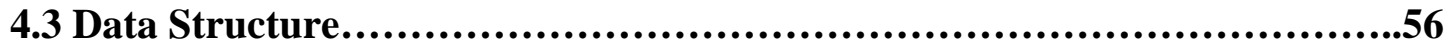

4.4 Unit Calculations..........................................................57

4.4.1 Observation Routines..................................................58

4.4.2 Core Data Routines..................................................61

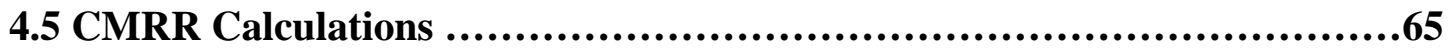

4.5.1 CMRR Calculations for One Unit.....................................65 
4.5.2 CMRR Calculations for Multiple Units...............................68

4.6 Major Secondary Support Routines.....................................70

4.6.1 Utility Calculations..................................................73

4.6.2 Grid Read and Write.................................................76

4.6.3 Working File Read and Write......................................78

Chapter 5. Program Verification....................................................81

5.1 Introduction..................................................................81

5.2 CMRR Program Verification...............................................81

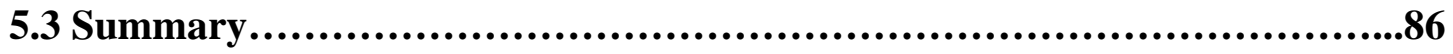

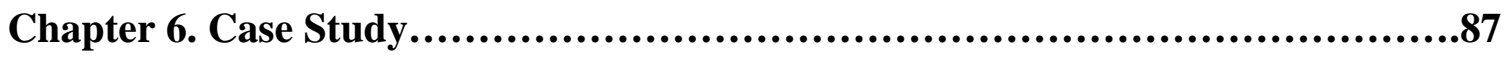

6.1 Introduction.............................................................87

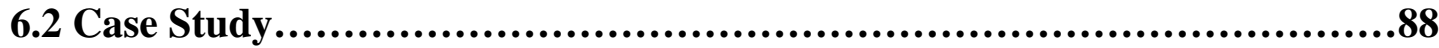

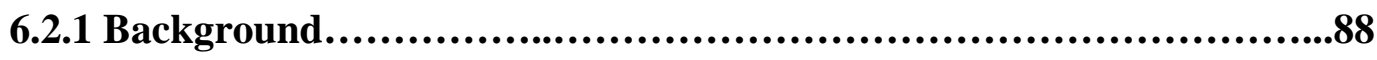

6.2.2 CMRR Application....................................................92

6.2.3 Stability Mapping...................................................96

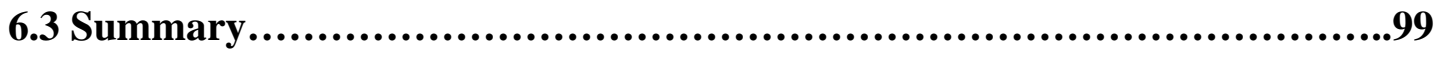

Chapter 7. Summary and Conclusions...........................................100

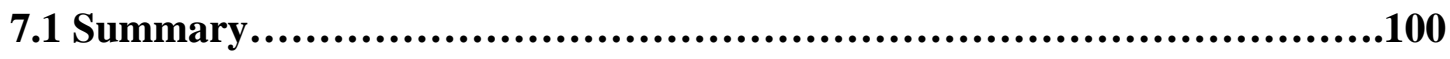

7.2 Conclusions..................................................................102

7.3 Ideas for Additional Research...........................................103

References..............................................................................106

Appendix A. Grid File Example..................................................109

Appendix B. Main Input Forms......................................................111

B.1 Loading the CMRR Program................................................111 
B.2 Primary forms of the CMRR program...................................112

B.3 Basic structure of the CMRR program forms............................119

B.4 Details of program execution..........................................120 


\section{TABLE OF FIGURES}

Figure 2.1 CMRR field data sheet (after Molinda and Mark, 1994)....................

Figure 2.2 Unit rating calculation sheet (after Molinda and Mark, 1994)...............14

Figure 2.3 CMRR calculation sheet (after Molinda and Mark, 1994)..................17

Figure 2.4 CMRR rating scale for diametral point load tests (after Mark et al., 2002)....22

Figure 2.5 Underground data entry screen from CMRR program......................24

Figure 2.6 Drill core data entry screen from CMRR program......................25

Figure 2.7 CMRR rating (after Riefenberg, 1994).............................. 30

Figure 2.8 CMRR and multiple seam stress (after Riefenberg, 1994).................31

Figure 2.9 Final hazard maps (after Riefenberg, 1994)...........................32

Figure 2.10 Sandstone rating (after Stankus et al., 2001)..........................................35

Figure 2.11 Stream valley influence (after Stankus et al., 2001).....................35

Figure 2.12 Tectonic stress distribution (after Stankus et al., 2001)...................36

Figure 2.13 Roof instability rating (after Stankus et al., 2001)......................37

Figure 2.14 Sandstone percentages in first $10 \mathrm{ft}$ of roof (after Wang, 2005) .............40

Figure 2.15 Index plot for interval thickness (after Wang, 2005) ...................41

Figure 2.16 Plot of overburden stress (after Wang, 2005) ........................41

Figure 2.17 Plot of final stability index (after Wang, 2005) .......................42

Figure 3.1 Overall structure of grid data format.................................46

Figure 4.1 General information form............................................53

Figure 4.2 Underground Observation Data form...................................54

Figure 4.3 Discontinuities form................................................54

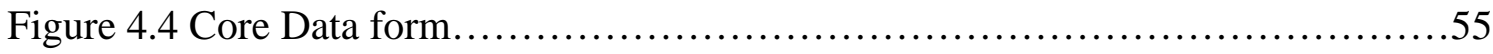

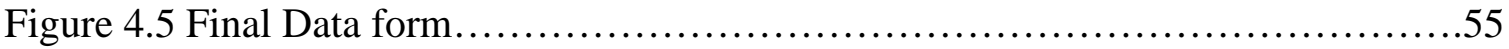




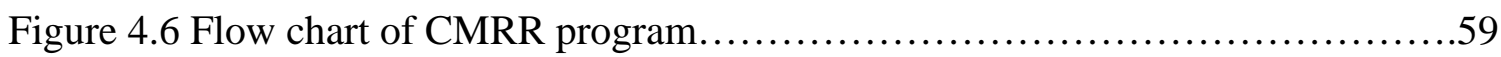

Figure 4.7 Unit rating calculation flow sheet for observation data with simple input......62

Figure 4.8 Unit rating calculation flow sheet for observation data with grid input........63

Figure 4.9 Unit rating calculation flow sheet for core hole data with simple input........64

Figure 4.10 Unit rating calculation flow sheet for core hole data with grid input........66

Figure 4.11 CMRR calculation flow sheet for simple input data and a single unit........67

Figure 4.12 CMRR calculation flow sheet for grid input data and a single unit...........68

Figure 4.13 CMRR calculation flow sheet for simple input data and multiple units......71

Figure 4.14 CMRR calculation flow sheet for grid input data and multiple units.........72

Figure 4.15 Grid read and write flow sheet.........................................79

Figure 4.16 Working file example.............................................. 80

Figure 6.1 Mine location (after Stewart et al., 2006).................................88

Figure 6.2 Southwest mining district longwall panels.................................89

Figure 6.3 Topography over B and D seam pillars....................................90

Figure 6.4 Sandstone channels and rider interburden thickness........................90

Figure 6.5 Faults, slumps, and warps in the southwest mining district..................91

Figure 6.6 Interburden thickness.................................................

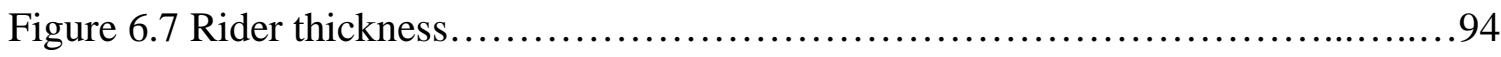

Figure 6.8 Sandy mudstone thickness..............................................

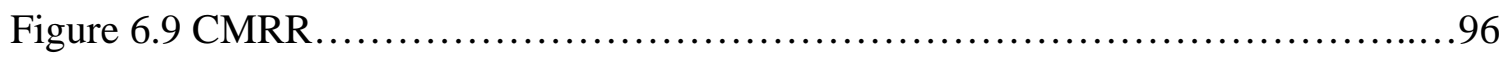

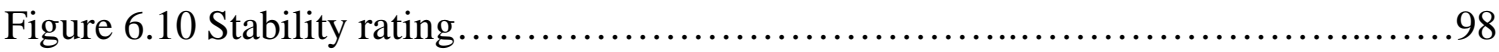

Figure B.1 Load/Unload application form......................................111

Figure B.2 General Information Form............................................113

Figure B.3 Browse Window Form...............................................114 
Figure B.4 Underground Observation Data Form...................................115

Figure B.5 Discontinuities Form.........................................116

Figure B.6 Core Hole Data Form..........................................118

Figure B.7 Final Data Form.................................................119

Figure B.8 General program flow sheet.....................................120

Figure B.9 Flow chart of CMRR program....................................122

Figure B.10 Unit rating calculation flow sheet for observation data with simple input..125

Figure B.11 Unit rating calculation flow sheet for observation data with grid input.....126

Figure B.12 Unit rating calculation flow sheet for core hole data with simple input.....127

Figure B.13 Unit rating calculation flow sheet for core hole data with grid input.......129

Figure B.14 CMRR calculation flow sheet for simple input data and a single unit.....130

Figure B.15 CMRR calculation flow sheet for grid input data and a single unit.........131

Figure B.16 CMRR calculation flow sheet for simple input data and multiple units.....134

Figure B.17 CMRR calculation flow sheet for grid input data and multiple units........135

Figure B.18 Grid read and write flow sheet...................................142

Figure B.19 Working file example.............................................143 


\section{TABLE OF TABLES}

Table 2.1 Cohesion-roughness rating (after Molinda and Mark, 1994)................15

Table 2.2 Spacing-persistence rating (after Molinda and Mark, 1994).................15

Table 2.3 Multiple discontinuity set adjustment (after Molinda and Mark, 1994)........15

Table 2.4 Strength rating (after Molinda and Mark, 1994).........................15

Table 2.5 Moisture sensitivity rating (after Molinda and Mark, 1994)................16

Table 2.6 Strong bed adjustment (after Molinda and Mark, 1994)...................18

Table 2.7 Weak bed adjustment (after Molinda and Mark, 1994).....................18

Table 2.8 Unit contact adjustment (after Molinda and Mark, 1994)..................18

Table 2.9 Groundwater adjustment (after Molinda and Mark, 1994)..................19

Table 2.10 Surcharge adjustment (after Molinda and Mark, 1994)....................19

Table 3.1 Unit Observation Data Types......................................48

Table 3.2 Unit Core Data Types...........................................49

Table 3.3 Overall Mine Data Types............................................49

Table 5.1 Observation test data............................................... 82

Table 5.2 Data for overall mine............................................82

Table 5.3 Unit 1 interpolated values..........................................83

Table 5.4 Unit 2 interpolated values.........................................83

Table 5.5 Unit 3 interpolated values......................................... 83

Table 5.6 Unit adjustment values.......................................... 84

Table 5.7 CMRR calculation values...........................................84

Table 5.8 Core test data.................................................... 85

Table 5.9 Data for overall mine.............................................. 85

Table 5.10 Unit rating values...............................................86 
Table 5.11 CMRR calculation values...........................................86

Table 6.1 Critical Factors (after Stewart et al., 2006)..............................89 


\section{Chapter 1}

\section{Introduction}

\subsection{General}

One of the main goals of a mining engineer is to guarantee the safety, stability, and productivity of the mine at which they work. The stability of the mine opening is of major concern because it directly influences both the safety and productivity of the entire mining system. A mining engineer's main concern regarding mine stability is with regard to reducing and or preventing roof and rib falls from occurring. In order to successfully accomplish this task, mine engineers must understand and work with the geology of the mine to the best of their ability. Many, if not all mines, have geology that varies throughout the extent of the mine workings and sometimes small variations can have a large effect on the competence and stability of the mine roof.

The ability of the mining engineer to observe and possibly predict the changing geology along with its effect on the roof stability is one of the most useful capabilities for increasing mine safety and productivity. With the ever increasing size of today’s coal mines, simple observation is normally not enough. The trends and information that the mine engineer and others observe must be recorded and thoroughly analyzed in order to gain the maximum information that will allow optimum decisions to be made regarding mine roof support and or mine stability design.

Over the years, many useful tools have been created to help aid the mine engineer in analyzing and interpreting geologic and structural mine features. One tool that was developed to specifically evaluate the competence of coal mine roof rock is the Coal Mine Roof Rating (CMRR) (Molinda and Mark, 1994; Molinda and Mark, 1996; Molinda et al., 2001; Mark et al., 2002). The CMRR has been successfully applied as a 
geotechnical feature in some stability maps and as an individual factor for evaluation of mine roof conditions (Riefenberg, 1994; Molinda et al., 2001). Initially, hazard maps were created which mainly considered geologic factors, but eventually stress analysis was added to these studies creating combined geologic and stress stability maps. Another recent development in mine evaluation technology is geologic mapping software. One of the more popular mapping packages is a program called SurvCADD (Richards, 2001). SurvCADD allows the user to develop a complete geologic model of the mine property containing strata thicknesses and selected properties. The SurvCADD program also allows the user to map or plot various geologic characteristics such as coal thickness or overburden onto the mine map for evaluation. Although each of these tools can be used individually, the greatest utility can be gained by bringing them together so that one system could easily supply the other with data.

As a reaction to the need for combining the CMRR with geologic mapping, a program was created that provides the ability to execute a geostatistical calculation of the CMRR. This program is able to use information from a SurvCADD geologic model as input for various factors that are needed for the CMRR calculation. Both observation data and core hole data are supported. The input factors can be entered as individual point values or as grids of points which cover a specified spatial area. The grid format that has been chosen is supported by both the SurvCADD geostatistical program and the newly developed stability mapping package (Wang, 2005). The creation of this application enables the mine engineer to take full advantage of geologic data that may be already available in the mine’s geologic model to optimize the CMRR calculation. By facilitating this quick, easy and comprehensive use of important data, the mine engineer is better able to design and foresee possible mining and safety hazards. 


\subsection{Statement of the Problem}

As it was stated in the previous section, one of the main concerns of a mining engineer is the safety and stability of the mine for which he or she is responsible. One way that the safety and stability can be ensured is to know and understand the coal mine geology and how it will react to the mining process. In today's mining industry there are often times large stores of geologic data available in a mine’s geologic model. Although these geologic data are available in their format for geologic analysis, it can be difficult to use this format to quantify the geology with respect to the stability of the mine opening. In order to be able to structurally evaluate the geologic information available, an appropriate method must be chosen and applied. One technique that has shown a lot of success in the coal mining industry for geologic technical evaluation purposes is the Coal Mine Roof Rating.

Since its inception, the Coal Mine Roof Rating (CMRR) has been used very successfully throughout the world in the evaluation of the competency of coal mine roof rock (Molinda and Mark, 1994; Molinda and Mark, 1996; Molinda et al., 2001; Mark et al., 2002). The data used to calculate the CMRR can come from a variety of sources including, but not limited to: underground observations such as overcasts and roof falls, outcrops on the surface, and data gathered from drilling that originates either from the surface or underground (Molinda and Mark, 1994; Mark et al., 2002). The main way in which the CMRR is used is to gather data for a specific point and calculate the CMRR for that point. The calculation of point CMRR values is then repeated throughout the mine where observations have been made. In order to get an accurate area representation of the CMRR when using point observations, numerous points must be individually 
analyzed (Mark et al., 2004). Making all of these individual observations can become quite tedious and time consuming for large areas of the mine and if insufficient observations have been made, the statistical interpretation of these CMRR values can be erroneous. Also, the straight statistical interpretation of the CMRR values often does not include knowledge about the geologic depositional environment, which can introduce additional errors.

With the ever increasing application of computer technology in the mining industry, the amount of data that are stored in a digitized or computer format has grown immensely. Many mines currently have geologic models that store important geologic and geotechnical data in formats such as grids and isopachs. These geologic models contain a large amount of geologic data that could be used to help calculate a CMRR over large areas of the mine. The problem with using these data for large scale CMRR calculations is that there is currently no easy and efficient way to make use of the current data format. A system or program that would allow the user to easily calculate a CMRR on a large scale by taking advantage of the geologic data and the geologic interpretation in its presently available format would be very useful.

This proposed CMRR calculation system could also be incorporated into a currently available stability mapping program (Wang, 2005). If the format of the data for the stability mapping program and the data for the CMRR are the same, it would be easy to use these two programs to support one another. A grid of CMRR values could be created as output and used in conjunction with other stability data to better take advantage of all of the geologic data available. Also, this application of the CMRR would add one more level of certainty to the overall stability map for a mine area. 


\subsection{Scope of Work}

The objective of this research is to create a program that will easily facilitate the calculation of the CMRR over a spatial area from data currently available in the geologic models used at coal mines. In comparison to previously developed CMRR programs, this system will allow for simultaneous calculation at multiple points by taking advantage of data in a grid format. Using the grid format will further increase the accuracy of CMRR calculations over a large area by individually interpolating the critical input data and not just interpreting the final CMRR values. Consequently, this will allow the program to accurately account for geologic and depositional changes in individual units over a large spatial area. By using gridded data, the program will be able to make use of the large amounts of computer-based geologic data that are already available and the program output will be compatible with all of the calculation and presentation capabilities of previous programs. The CMRR calculation program will be able to take input data from various sources and in multiple formats. Both point observation data and data taken from drill cores will be used, depending on what type is available. In order to make the program user friendly it will be Windows-based and be incorporated into one of the more popular drafting and mine modeling programs, AutoCAD/SurvCADD (Richards, 2001). This connection with AutoCAD and SurvCADD will facilitate easy transfer of data between geologic modeling software, SurvCADD and the program itself. To further increase the usefulness of the CMRR calculation program, it will be packaged along with a new stability mapping program that can be used to both create input data in grid format and to process the CMRR grid output for mine stability evaluation (Wang, 2005). 


\section{Chapter 2}

\section{Literature Review}

\section{$2.1 \quad$ General}

The objective of this research is to create a program that will easily facilitate the calculation of the CMRR over a spatial area from data currently available in the geologic models used at coal mines, in order to improve the overall design of safe and stable mines. Over the years there have been many developments in the tools that are used for mine stability evaluation. Initially, there were various tools used to simply evaluate coal mine geology. One of the more recent, most popular, and widely used is the Coal Mine Roof Rating (CMRR). The CMRR has been applied as a geotechnical feature in some stability maps and as an individual factor for evaluation of mine conditions. In one particular instance the CMRR and a stress map were combined to gain a greater understanding of the mine stability (Riefenberg, 1994). Also, over at least the last fifteen years, stability and hazard maps have been developed in an attempt to help assess a mine’s stability (Maleki, 1990). Initially, hazard maps were created which mainly considered geologic factors, but eventually stress analysis was added to these studies creating combined geologic and stress stability maps. Through the advent of computer applications the process of creating stability maps has become much easier. Another recent development in mine evaluation technology is geologic mapping software. One of the more popular mapping packages is a program called SurvCADD (Richards, 2001). SurvCADD allows the user to develop a complete geologic model of the mine property containing strata thicknesses and selected properties. The program also allows the user to map or plot various geologic characteristics such as coal thickness or overburden onto the mine map for evaluation. Although each of these tools can be used individually, the 
final goal is to bring them all together so that as many data as possible can be analyzed in the easiest and most time efficient manner.

\subsection{The Coal Mine Roof Rating (CMRR) System}

\subsubsection{Introduction}

The CMRR was developed by the USBM in 1994 as a means to mechanistically quantify bedded coal mine roof rock, and to improve the safety and design of U.S. coal mines (Molinda and Mark, 1994). Unlike many rating systems that have been developed in the past, the CMRR is coal mine specific and uses only coal mine geology data. This system quantitatively describes the geotechnical aspects of the mine roof rather than recording a detailed lithology. The information that is used to determine the rating focuses on discontinuities, which are considered to be any structure that interrupts the normal characteristics of the geology being investigated, and other aspects of the mine roof that will weaken the existing roof (Molinda and Mark, 1994).

\subsubsection{Components}

The CMRR was originally determined by using observations of the roof geology from underground roof falls and overcasts along with surface observations from high walls and outcrops. The CMRR is based on geotechnical data taken from the immediate roof layers within the mine. By definition, the immediate roof layers consist of the rock which is going to be suspended by the roof bolting system used in the mine. The first step to gathering information is to divide the immediate roof or bolting horizon into units. These units are distinct geotechnical breaks in the strength or behavior of the roof geology. They may include more than one type of rock in each unit as long as they all 
behave similarly. Each unit should be at least 6 in. thick to be considered an individual unit, although in some select cases a unit of less than 6 in. can be listed individually if that unit has shown exceptional strength. Once the bolting horizon is broken into units, simple tests and observations are used to gather all pertinent information for calculation of the final CMRR (Molinda and Mark, 1994). The field data can be easily recorded on a data sheet like the one found in Figure 2.1. The field data sheet was developed to help assist the mine engineer or geologist in gathering the appropriate information for each area where a CMRR would like to be determined. Each piece of necessary information has a place on the data sheet so that mistakes and errors may be minimized.

\subsubsection{Discontinuities}

One of the main factors that determine whether a mine roof will be difficult to support is the number and severity of discontinuity sets that are present. A discontinuity can be any feature such as a fault, fracture, bedding plane, or joint that may weaken the rock; and a discontinuity set is a group of these similar discontinuities within a unit. In order to determine how much a discontinuity will affect the strength of the coal mine roof, both the cohesion and roughness of the discontinuity surface must be found. A low cohesion or a planar contact, and a low roughness value of a discontinuity surface can greatly reduce the ability of the rock to resist lateral movement. 


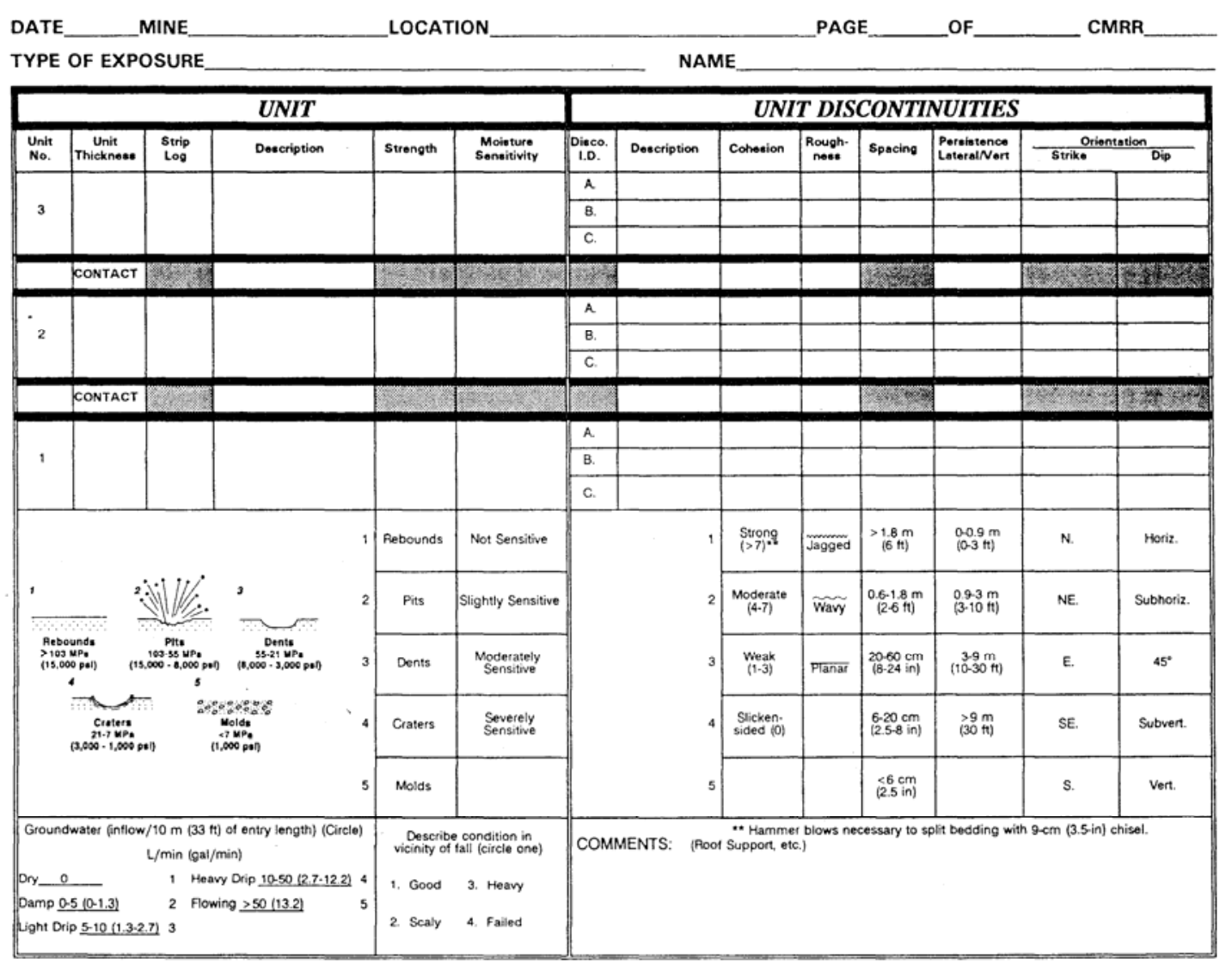

Figure 2.1 CMRR field data sheet (after Molinda and Mark, 1994)

The shear strength of the discontinuities is so important that it may account for up to $35 \%$ of the overall CMRR (Molinda and Mark, 1994).

There are two parameters in the CMRR (see Figure 2.1) that measure the ability of a discontinuity surface to resist shearing movement. The first of the two measures of a discontinuity's strength is the amount of cohesion that is present between the discontinuity surfaces. Cohesion is the measure of the ability of two surfaces to resist sliding when no normal force is being applied. Because there are many different types of rock found in coal mine roof, the variability of the cohesion can be quite high. For a rock with platy grains such as mica or clay, like a shale or mudstone, the cohesion value is normally low. On the other side of the spectrum are rocks with silt or sand cemented in 
them such as sandstone and limestone. These rough grains help to hold and interlock the discontinuity surface in resistance to shearing movement.

In the field, the cohesion is measured using a 3.5 in. mason's chisel and a hammer. Based on the number of blows it takes to separate the discontinuity, the cohesion is given a rating from $1-4$. The highest rating is given to surfaces that are well cemented and the lowest rating given to those such as slickensides that have little or no ability to hold themselves together (see Figure 2.1).

The second discontinuity parameter that measures the ability to resist shearing of the discontinuity surface is the roughness. The roughness is determined by visually inspecting the discontinuity and assigning it a visual description of jagged, wavy, or planar. Although the roughness can greatly affect the shear strength of the surface, it can only do so when the cohesion values are in the middle of the range. This is true because if the cohesion is a very high value then the roughness will not matter because it will never have a chance to come into play. On the other hand, if the cohesion is very low and the surface easily separates, it will not matter how rough the surface is, it will be inherently weak (Molinda and Mark, 1994).

Along with the cohesion and roughness of each discontinuity set the user should record the strength of the contact between each of the units. This surface should be listed as either weak or strong, and this observation will only have an effect on the final CMRR if the contact is weak.

\subsubsection{Discontinuity Intensity}

As stated above, the cohesion and roughness of a discontinuity surface can have a great affect on the overall strength of the roof rock. Along with those two parameters, the 
"intensity" of the discontinuity set is also very important. The intensity of the discontinuities is determined by measuring the spacing and the persistence of the similar discontinuities within a unit.

The spacing is measured by finding the average distance between each discontinuity within a discontinuity set. The persistence of a discontinuity set is the measure of the size of the discontinuity set plane in both a vertical and horizontal direction. A discontinuity set with very wide spacing that does not cover much area has little consequence to the mine roof, whereas a discontinuity set that is either closely spaced or covers a wide area can cause severe problems regarding roof control. Similar to the roughness and cohesion parameters, the intensity of the discontinuities can also account for up to $35 \%$ of the final CMRR.

\subsubsection{Compressive Strength}

One of the other critical parameters of the CMRR is the measure of the compressive strength of each unit. This measure is important because the compressive strength determines the ability of the unit to anchor a bolt and to allow fractures to form within the unit. Not unlike the procedure for determining cohesion, the compressive strength is found using a simple $3 \mathrm{lb}$. ball-peen hammer. The test is done by striking the rock to be rated and inspecting the nature of the indentation made. The shape of the indentation is the important aspect to be recorded, not the magnitude. The indentation can be classified in one of five ways; from having the hammer rebound and not leave a mark to the rock molding and crumbling under the force of the blow (see Figure 2.1). Anywhere from 5 - 30 points of the CMRR can be assigned based on this test. 


\subsubsection{Moisture Sensitivity}

The moisture sensitivity of the rocks present in the mine roof can greatly affect their competence when water and/or high humidity is present in the mining environment. Although some roof rock has little or no reaction to water, some clay stones and mud stones react poorly to the presence of water. They may swell or lose all competence as a roof material. The moisture sensitivity is determined through visual estimation along with water immersion testing over a 24 hour period, and a moisture adjustment to the CMRR is assigned accordingly.

\subsubsection{Non-Unit Information}

After all of the information is gathered for each unit, two parameters regarding the overall mine area should be recorded. These two parameters are the ground water in flow and the strength of the bed above the highest unit in the bolting horizon, also known as the "surcharge adjustment". The amount of groundwater is rated on a scale of $1-5$, one being no water and five being a situation where water is flowing into the area of interest. The surcharge is rated according to the relative strength of the bed overlying the uppermost unit in the CMRR. Combined, the amount of groundwater present and the surcharge can account for a total deduction of 15 points from the final CMRR.

\subsubsection{Unit Rating Calculations}

The unit rating, which is the major building block of the CMRR, is based on the discontinuity data, the strength of the unit, and the sensitivity of the unit to moisture as seen in the field data sheet in Figure 2.1. The easiest way to manually perform the unit rating calculation procedure is to use the Unit Rating Calculation Sheet developed by 
Molinda and Mark (1994) and illustrated in Figure 2.2. The calculation sheet helps to simplify the calculation process and ensures that important data are not omitted.

The first step in calculating the unit rating is determining the adjustment values for the combined cohesion-roughness values and the combined spacing-persistence values that were gathered during field observations. By referencing the field data sheet in Figure 2.1 and relating the values to the look-up tables in Tables 2.1 and 2.2 the adjustments for the cohesion-roughness and the spacing-persistence data can be determined. The next step is to find the appropriate adjustments for the strength and the moisture sensitivity data collected. This process is the same as described above, but instead uses Table 2.4 for the strength adjustment and Table 2.5 for the moisture data. It should be noted that the moisture adjustment should only be applied when calculating a unit rating for the first unit or a unit that is exposed to water. If more than one discontinuity set is found, the multiple discontinuity adjustment from Table 2.3 should be determined and applied to the unit rating calculation. The final step in calculating the unit rating is to add the lowest individual discontinuity rating with the multiple discontinuity adjustment, strength adjustment, and moisture adjustment. This procedure should be carried out for each individual unit, and the resulting unit rating recorded on the final CMRR calculation sheet found in Figure 2.3 


\section{CALCULATION SHEET}

Mine Name

Location

1) Calculate the Individual Discontinuity Rating

Date

Data Collected by

Unit No.

\section{Discontinuity}

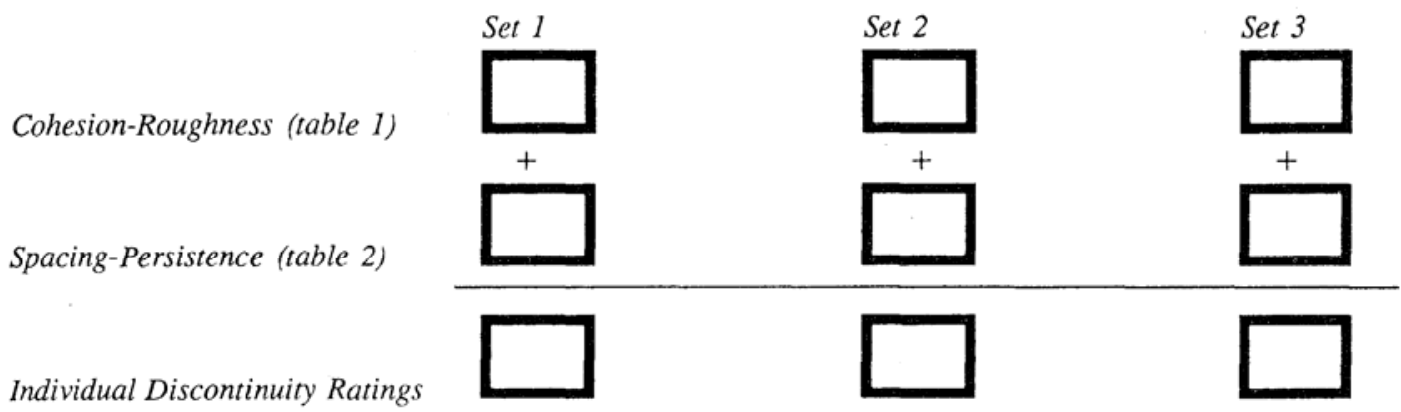

2) Enter the lowest of the Individual Discontinuity Ratings

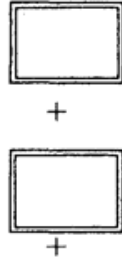
set, enter the Multiple Discontinuity Adjustment from table 3. Otherwise, enter 0.

4) Calculate the Unit Strength (table 4)

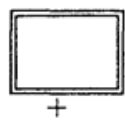

5) Calculate the Unit Moisture Sensitivity (table 5) (this applies only to Unit 1, or if upper Unit is exposed to water)

$=$ Unit Rating (UR)

Figure 2.2 Unit Rating Calculation Sheet (after Molinda and Mark, 1994) 
Table 2.1 Cohesion - roughness rating (after Molinda and Mark, 1994)

(1) Strong cohesion
(2) Moderate cohesion
(3) Weak Slickensided cohesion

(4)

\begin{tabular}{lcccc} 
Roughness & $\begin{array}{c}\text { Strong } \\
\text { cohesion }\end{array}$ & $\begin{array}{c}\text { Moderate } \\
\text { cohesion }\end{array}$ & $\begin{array}{c}\text { Weak } \\
\text { cohesion }\end{array}$ & Slickensided \\
\hline (1) Jagged.. & 35 & 29 & 24 & 10 \\
(2) Wavy... & 35 & 27 & 20 & 10 \\
(3) Planar... & 35 & 25 & 16 & 10 \\
\hline
\end{tabular}

Table 2.2 Spacing - persistence rating (after Molinda and Mark, 1994)

\begin{tabular}{|c|c|c|c|c|c|}
\hline $\begin{array}{c}\text { Persistence } \\
\mathrm{m}(\mathrm{ft})\end{array}$ & $\begin{aligned} &(1) \\
&> 1.8 \mathrm{~m} \\
&(>6 \mathrm{ft}) \\
&\end{aligned}$ & $\begin{array}{c}(2) \\
0.6 \text { to } 1.8 \mathrm{~m} \\
(2 \text { to } 6 \mathrm{ft}) \\
\end{array}$ & $\begin{array}{c}(3) \\
20 \text { to } 61 \mathrm{~cm} \\
(8 \text { to } 24 \mathrm{in}) \\
\end{array}$ & $\begin{array}{c}(4) \\
<6 \text { to } 20 \mathrm{~cm} \\
(2.5 \text { to } 8 \mathrm{in})\end{array}$ & $\begin{aligned} & (5) \\
< & 6 \mathrm{~cm} \\
(< & 2.5 \mathrm{in})\end{aligned}$ \\
\hline (1) 0 to 0.9 (0 to 3 ) & 35 & 30 & 24 & 17 & 9 \\
\hline (2) 0.9 to 3 (3 to 10 ) & 32 & 27 & 21 & 15 & 9 \\
\hline (3) 3 to 9 (10 to 30$)$ & 30 & 25 & 20 & 13 & 9 \\
\hline$(4)>9(>30)$ & 30 & 25 & 20 & 13 & 9 \\
\hline
\end{tabular}

Table 2.3 Multiple discontinuity set adjustment (after Molinda and Mark, 1994)

$\begin{gathered}\text { Two lowest individual } \\ \text { discontinuity ratings } \\ \text { both lower than-- }\end{gathered}$
$\begin{gathered} \\ 30 \ldots \ldots \ldots \ldots \ldots \ldots \ldots \ldots\end{gathered}$
$40 \ldots \ldots \ldots \ldots \ldots \ldots \ldots \ldots$

Table 2.4 Strength rating (after Molinda and Mark, 1994)

$$
\text { Strength, Mpa (psi) Rating }
$$

(1) $>103(>15,000) \ldots \ldots \ldots \ldots \ldots \ldots$

(2) 55 to $103(8,000$ to 15,000$)$

(3) 21 to $55(3,000$ to 8,000$) \ldots . \quad 15$

(4) 7 to $21(1,000$ to 3,000$) \ldots \ldots . \quad 10$

(5) $<7(<1,000) \ldots \ldots \ldots \ldots \ldots \ldots \ldots$ 
Table 2.5 Moisture sensitivity rating (after Molinda and Mark, 1994).

$\begin{array}{lc}\text { Moisture Sensitivity } & \text { Rating } \\ & \\ \text { (1) Not sensitive ........... } & 0 \\ \text { (2) Slightly sensitive...... } & -3 \\ \text { (3) Moderately sensitive } & -10 \\ \text { (4) Severely sensitive..... } & -25\end{array}$

\subsubsection{CMRR Calculations}

Now that the each of the individual unit rating values have been transferred to the final calculation sheet in Figure 2.3, the process of calculating the final CMRR can begin. The final "raw" CMRR calculation essentially consists of determining the thicknessweighted average of the individual unit ratings (called the $R R_{w}$ ), by using the unit thickness in the bolted horizon as the weighting factor for the unit rating. Specifically, the raw CMRR value is calculated by multiplying the thickness of each unit with the calculated unit rating, adding this contribution from all of the units and dividing the resultant summation by the total bolted thickness (see Figure 2.3).

It should be noted that the total thickness used in the $\mathrm{RR}_{\mathrm{w}}$ calculation should be no longer than the length of the bolt that is being used at this particular location. Once the $R_{\mathrm{w}}$ is calculated, then the strong bed difference (SBD) can be found by subtracting the $\mathrm{RR}_{\mathrm{w}}$ from the strongest unit. The SBD is important because it has been found that the strongest unit within the bolting horizon plays a large part in the overall competence of the roof strata. Using the SBD, the thickness of the strongest bed, and Table 2.6, the initial strong bed adjustment can be determined. The final strong bed adjustment can be changed based on the amount of rock hanging from the strong bed. 
ROOF RATING (CMRR)

CALCULATION SHEET

Mine Name Date

Location Data Collected by

1) Calculate the weighted average of the Unit Ratings $\left(R R_{w}\right)$

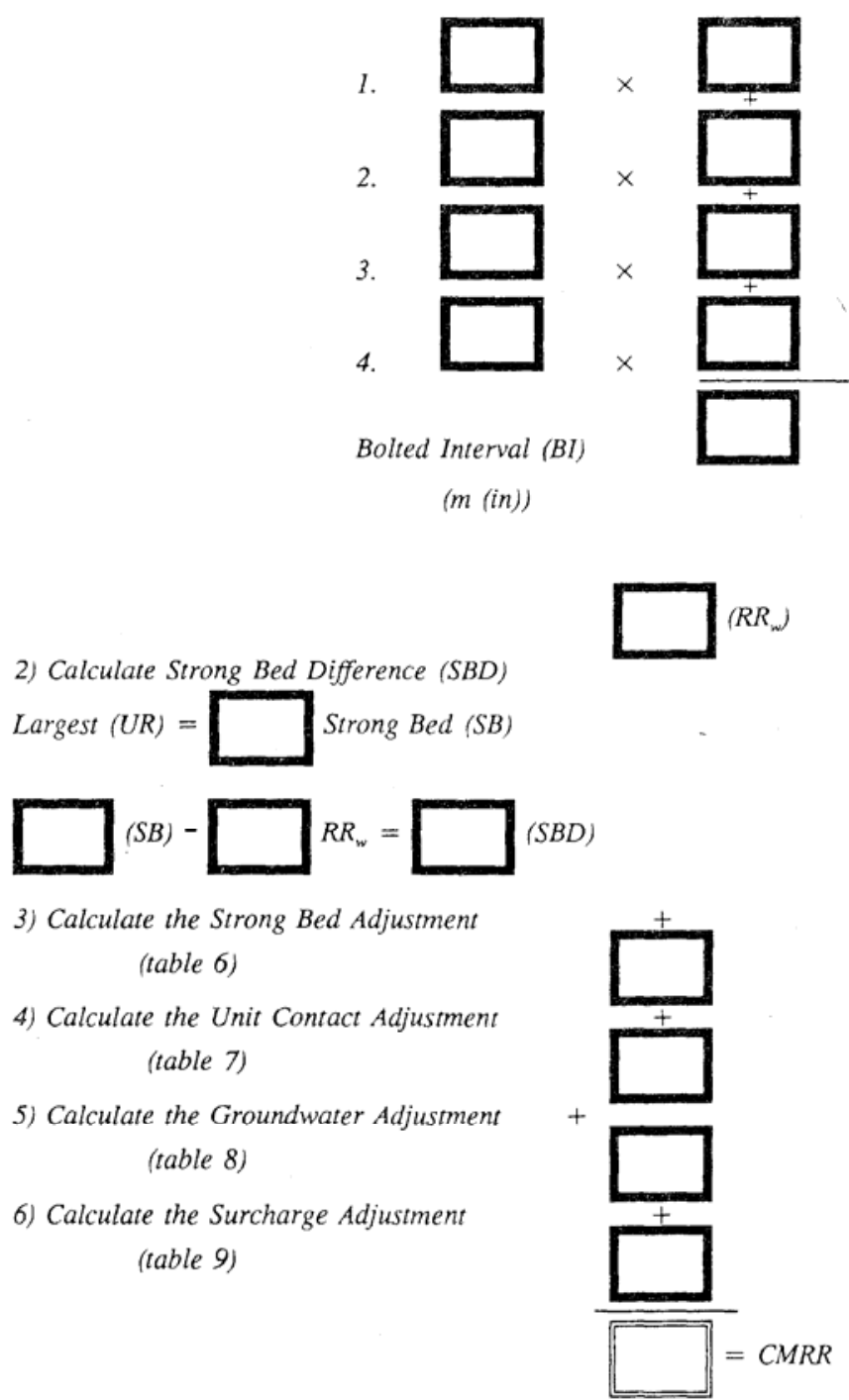

Figure 2.3 CMRR calculation sheet (after Molinda and Mark, 1994)

This change accounts for the weight of the weaker rock that is being suspended from the stronger bed. If the thickness of weaker rock suspended from the strong bed is from $3-6$ ft., the initial strong bed adjustment is multiplied by 0.7 and, if the weaker rock is greater 
than $6 \mathrm{ft}$. thick, the initial strong bed adjustment is multiplied by 0.3 (see Table 2.7). Following the format shown in Figure 2.3, the final adjustment factors that need to be included are the contacts, groundwater, and surcharge. The three adjustments for these factors can be found in Tables 2.8, 2.9, and 2.10 respectively. The final CMRR is calculated by adding the raw CMRR $\left(\mathrm{RR}_{\mathrm{w}}\right)$ and the adjustments for the strong bed, contact, groundwater, and surcharge.

Table 2.6 Strong bed adjustment (after Molinda and Mark, 1994)

\begin{tabular}{lccccccccc} 
Thickness of strong bed, & \multicolumn{7}{c}{ Strong bed difference } \\
\cline { 2 - 9 } m (ft) & $5-9$ & $10-14$ & $15-19$ & $20-24$ & $25-29$ & $30-34$ & $35-40$ & $>40$ \\
\hline 0.3 to 0.6 (1 to 2) & 0 & 2 & 4 & 5 & 7 & 8 & 9 & 10 \\
0.6 to 0.9 (2 to 3) & 2 & 4 & 7 & 9 & 12 & 14 & 17 & 20 \\
0.9 to 1.2 (3 to 4) & 3 & 5 & 10 & 14 & 18 & 21 & 25 & 30 \\
$>1.2(>4)$ & 4 & 8 & 13 & 18 & 23 & 28 & 34 & 40 \\
\hline
\end{tabular}

Table 2.7 Weak bed adjustment (after Molinda and Mark, 1994).

$\begin{array}{cc}\begin{array}{c}\text { Thickness of weaker } \\ \text { rock, m(ft) }\end{array} & \begin{array}{c}\text { Multiply strong bed } \\ \text { adjustment by-- }\end{array} \\ 0-0.9(0-3) \ldots \ldots \ldots \ldots \ldots \ldots & 1.0 \\ 0.9-1.8(3-6) \ldots \ldots \ldots \ldots \ldots & 0.7 \\ >1.8(>6) \ldots \ldots \ldots \ldots \ldots \ldots & 0.3\end{array}$

Table 2.8 Unit contacts adjustment (after Molinda and Mark, 1994).

$\begin{array}{lc}\begin{array}{c}\text { Number of major } \\ \text { contacts }\end{array} & \text { Adjustment } \\ & \\ 0 \ldots \ldots \ldots \ldots \ldots \ldots \ldots \ldots & 0 \\ 1 \text { to } 2 \ldots \ldots \ldots \ldots \ldots \ldots \ldots & -2 \\ 3 \text { to } 4 \ldots \ldots \ldots \ldots \ldots \ldots \ldots & -4 \\ >4 \ldots \ldots \ldots \ldots \ldots \ldots \ldots & -5\end{array}$


Table 2.9 Groundwater adjustment (after Molinda and Mark, 1994).

$\begin{array}{lc}\text { Condition } & \text { Adjustment } \\ & \\ \text { Dry ................ } & 0 \\ \text { Damp............. } & -2 \\ \text { Light Drip......... } & -4 \\ \text { Heavy Drip....... } & -7 \\ \text { Flowing ........... } & -10\end{array}$

Table 2.10 Surcharge adjustment (after Molinda and Mark, 1994).

Condition

Upper units approximately equal in strength to bolter interval.

Upper units significantly weaker than bolted interval ....
Adjustment

0

-2 to -5

\subsubsection{CMRR Summary}

The CMRR can be a very useful technique for evaluating the immediate roof strength within a coal mine. It is an easy evaluation tool with input data that can be either collected all in the field or partially evaluated in a lab. It allows the user to develop a single value for evaluating the strength of the coal mine roof. This value, the CMRR, is comparable between different seams and different geologies, and has been used around the world. There has been a lot of research with regard to the utility and repeatability of the CMRR and it has been found to be a consistent and accurate measure of coal measure roof strata (Riefenberg, 1994; Molinda and Mark, 1994; Molinda and Mark, 1996). The CMRR has also been incorporated into both stability mapping studies and pillar sizing evaluation with successful results in almost all cases (Riefenberg, 1994; Molinda and Mark, 1994; Mark et at., 2001; Mark et al., 2002). The CMRR has been used in both ALPS and ARBS which can aid the mine engineer in designing both pillar sizes and roof support densities for a given condition. Because of all of these positive aspects of the 
CMRR, it seems to be the optimum technique for the evaluation of coal mine roof rock using the stores of geologic data that are available in current mine geologic models.

\subsection{Calculating the CMRR from Core}

\subsubsection{General}

Since the original development of the CMRR some changes and updates have been implemented in order to make the system easier to use and to allow for the use of drill core data. The overall structure of the CMRR remains the same, but the data used to calculate the CMRR can now also come from drill cores along with the original underground and surface observations.

The procedure for calculating the final CMRR remains the same, but the unit rating calculations have changed based on the new and different source of data. The unit rating calculation still includes a measure of the compressive strength of the rock, which now comes from either a traditional Unconfined Compressive Strength (UCS) lab test or from a field point load test. Unlike the observation data, discontinuity sets cannot be identified very well when using core samples. Because of this shortcoming, the shear strength of the unit is now determined either by a diametral point load test rating or a discontinuity spacing rating, depending on which value is lower; this then becomes the discontinuity rating. The final unit rating from the core is simply the discontinuity rating plus the UCS rating (Mark et al., 2002).

\subsubsection{Compressive Strength from Core}

As stated above, either a traditional laboratory UCS test or a point load test can be used to find the UCS value used to determine the compressive strength rating in the 
CMRR from a core sample. If a point load test is the preferred method, the result can be converted to a UCS by multiplying by a factor of 21 (Mark et al., 2002). Once the conversion is complete, the UCS rating for the unit can be calculated by using one of the three following formulas, depending on the strength of the rock. For a UCS value less than 5,000 psi, the first formula should be used; if the UCS is greater than 5,000 psi and less than 21,300 psi, the second formula should be used; and if the value is greater than 21,300 the UCS rating is equal to 30 (Mark et al., 2002).

$$
\begin{gathered}
\text { For a UCS }<\mathbf{5 0 0 0} \text { psi - UCSrating }=5+1.5(U C S / 1000) \\
\text { For } \mathbf{5 0 0 0} \mathbf{p s i}<\mathbf{U C S}<\mathbf{2 1 , 3 0 0} \mathbf{p s i}-\text { UCSrating }=7+1.08(U C S / 1000) \\
\text { For a UCS }>\mathbf{2 1 , 3 0 0 ~ p s i - ~ U C S r a t i n g ~}=30
\end{gathered}
$$

\subsubsection{Shear Strength}

In order to account for the shear strength of the unit along with the discontinuities, a set of two tests are performed to determine the discontinuity rating. The first of the two tests is to measure the amount of fracture in a length of core using either a fracture spacing measurement or a rock quality designation (RQD). If the core is not highly fractured and the breaks are spaced apart by at least one foot it is recommended to use the fracture spacing method. This can be done by counting the breaks in a unit and dividing by the overall thickness of that unit. On the other hand, if the core is highly fractured, then the RQD is a better measure of the overall rock quality. The RQD is calculated by adding all of the pieces within the core greater than 4 inches and dividing this length by the total length of the unit. The following two equations are used to determine the discontinuity spacing rating based on either the fracture spacing in inches or the RQD rating (Mark et al., 2002). 


$$
\begin{gathered}
D S R=5.64 \ln (\text { fracture spacing in inches })+24 \\
D S R=10.5 \ln (R Q D)-11.6
\end{gathered}
$$

The second test for the shear strength is a diametral point load test. This test is carried out similar to the UCS point load test but it is done parallel to the bedding plane instead of perpendicular. From the diametral point load test, a diametral rating can be calculated using one of the four sections on the curve in Figure 2.4. Each equation fits a particular section of the curve that relates the diametral point load test result to the final diametral rating. After the discontinuity spacing rating and the diametral PLT rating are determined, the lower of the two should be selected and used as the discontinuity rating.

$$
\text { When PLT }<34.7 \text { - DiametralRating }=25
$$

$$
\begin{gathered}
\text { When } 187>\text { PLT }>34.7 \text { - DiametralRating }=0.144 x+20 \\
\text { When } 312.5>\text { PLT }>187 \text { - DiametralRating }=0.104 x+27.5 \\
\text { When PLT }>\text { 312.5 DiametralRating }=60
\end{gathered}
$$

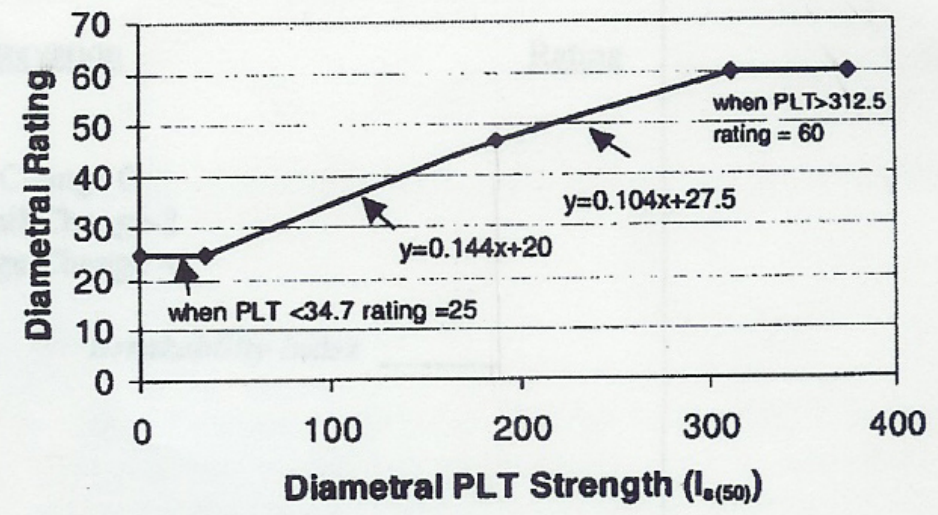

Figure 2.4 CMRR rating scale for diametral point load tests (after Mark et al., 2002) 


\subsubsection{Unit and CMRR Calculation}

As stated above, the final unit rating is the UCS rating plus the discontinuity rating. These two aspects account for the rock behavior in both a shear and uniaxial manner along with the discontinuities that would result in the weakening of the rock mass. Calculation of the final CMRR does not change from the original version, but some additions have been made to make some of the calculation process easier. Instead of using a table to determine the strong bed adjustment, the following equation was developed through regression analysis to calculate the value (Mark et al., 2002). Not only can this equation be used with drill core data, but it is also possible to apply it to observation data.

$$
\begin{aligned}
& \text { SBADJ }=[(0.22 S B D * T H S B)-2.5] *[1-(0.1(T H W R-1.7))] \\
& \text { Given that: } \\
& \text { SBD = Strong Bed Difference } \\
& \text { THSB = Thickness of the Strong Bed } \\
& \text { THWR }=\text { Thickness of the Weak Rock }
\end{aligned}
$$

\subsubsection{CMRR Computer Program}

Because of the popularity of the CMRR calculation, a simple computer program was developed by NIOSH to aid users in calculating the CMRR (Mark et al., 2002). This program allows the user to calculate the traditional CMRR and to calculate a CMRR from drill core data. The program also enables the user to calculate and store the coal mine roof data. It allows the user to calculate and store individual CMRR data points along with their geologic information and export the data for that one point to AutoCAD. Data 
for each point that are to be calculated must be entered individually from mine observation information or core log data. The data interface shown in Figures 2.5 and 2.6 is similar to the CMRR worksheets and incorporates pull down menus and data boxes for all information that is necessary to calculate the final CMRR.

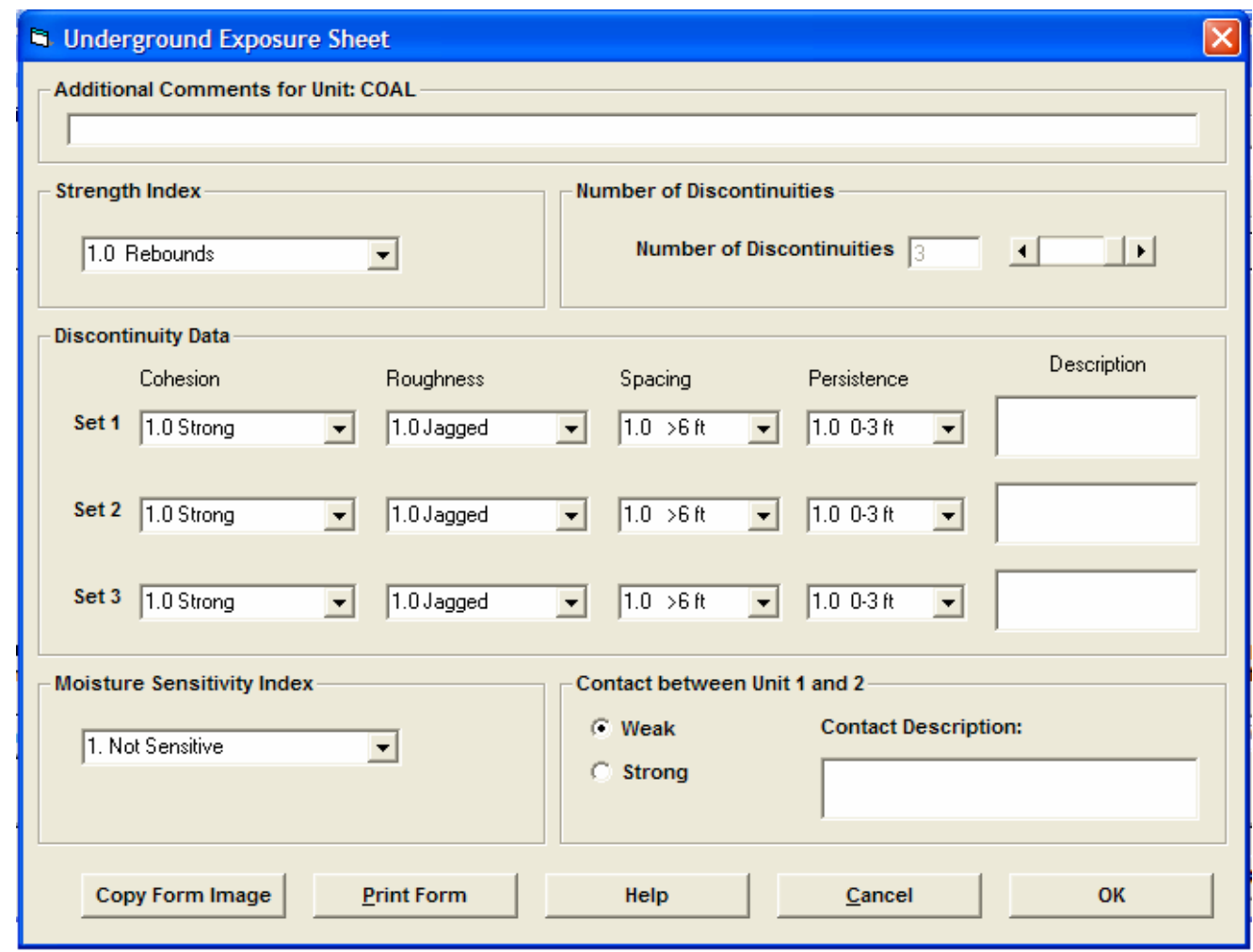

Figure 2.5 Underground data entry screen from CMRR program 


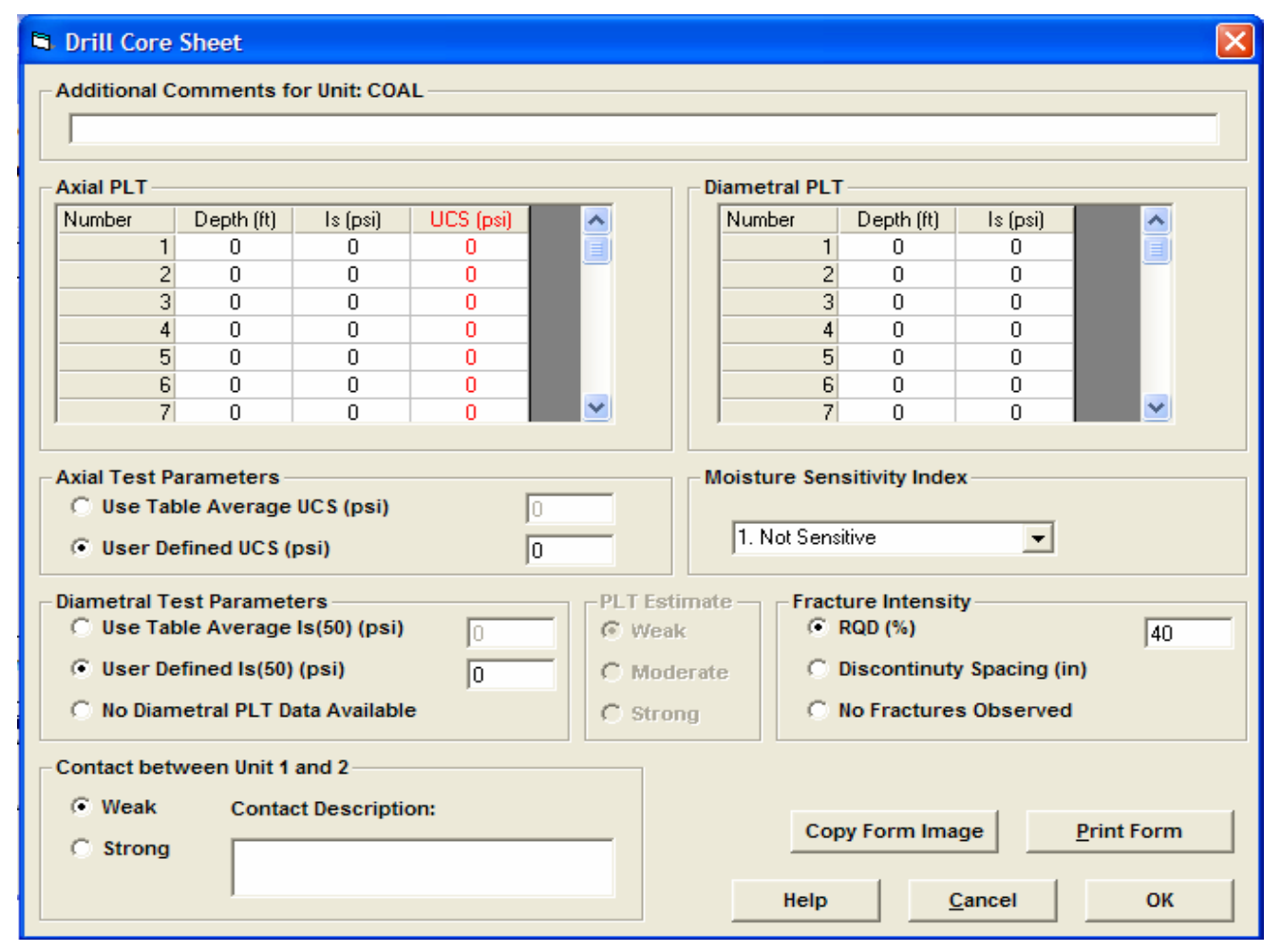

Figure 2.6 Drill core data entry screen from CMRR program

\subsection{Stability Mapping Systems}

\subsubsection{Introduction}

The mitigation of roof control problems has been an essential part of the development and smooth operation of coal mines since their inception. One of the key elements to predicting and controlling roof control problems is the identification of the mechanisms and circumstance which promote their existence (Maleki, 1990). The establishment of a link between the ground control problems and the geology and mechanisms which cause them can be a tedious and drawn out process depending on the resources available. It is essential to keep a detailed record of observed ground conditions along with the geology and other factors over a period of time in order to establish this critical link. The mine engineer and geologist are responsible for gathering 
data through underground observation along with drill data, roof coring, depositional modeling and other such sources to be used in the formation of a hazard or stability map.

Traditionally, hazard maps were created by hand and were quite simple or they involved large amounts of time and many steps before coming to a final result. Initial hazard maps may have only looked at one or two parameters such as: highlighting the areas below stream valleys (Molinda et al., 1991); or noting areas of weak roof (or floor); or marking areas under overlying barrier pillars. Initially, the majority of the data being collected were geologic and structural in nature. Many different types of geologic and structural data can be important to a mine's stability depending on the individual mine itself. Near seam geology data such as the thickness and competence of the rock making up the coal mine roof can have a large effect on the overall stability of the mine opening. Underground structural features such as faults, joints and fractures, stream channels, rolls, and lineaments are also important. Also, some obvious surface/stress features including stream valleys, topography and overburden thickness could also be of great interest. Normally this information was gained through underground observation, drill cores, and identification of surface features on the mine property.

The practice of creating a hazard map by hand, based solely on geologic or geophysical data has become less prominent with the introduction of computer-aided drafting, computer-aided geologic modeling, and computer-aided numerical modeling methods in the mining industry. Instead, it is more likely to see a stability map that takes both geology and stresses into account. This is the major difference between the hazard maps of old and the new and more complex stability maps of today.

One of the more popular mining computer applications is that of computer aided design or CAD. The great majority of U.S. coal mines, around 90\%, use a CAD program 
know as AutoCAD developed by Autodesk to carry out their drafting and mapping needs (Heasley and Wang, 2001). One of the advantages to using AutoCAD is that there are multiple add-on applications that can be used for mining specific work. One such add on is SurvCADD, developed by Carlson Software, that can be used for geologic mapping, mine planning, and surveying. Between $75 \%$ and $80 \%$ of U.S. coal mines are currently using this application package for their mine planning and related work (Richards, 2001). The main advantage to using software as mentioned above is the ability to store large amounts of geologic, geotechnical, structural, and mine plan data in a single and easy to access, modify and distribute format.

There are also numerous modeling packages that can be used to evaluate the stresses within and around a coal mine; some of these include, but are not limited to, LaModel, FLAC, and LaM2D. These types of programs allow the mining engineer to analyze one more dimensions of the mining environment that were previously unknown. Some aspects that can be evaluated include, but are not limited to, overburden stress, multiple-seam stress, two-dimensional planar stresses, and three dimensional stresses.

Although basic geologic hazard maps can be of some use to a mining engineer, it is possible to improve the accuracy of a hazard detection system by combining other types of geotechnical information with geologic features (Riefenberg, 1994). There are many factors other than geology which may affect the competency of a mine opening and the more that can be included in a hazard map the more accurate the prediction of the mine stability will be (Stankus et al., 2001; Maleki, 1990; Jiang and Wells, 1998; Newman et al., 2001). 


\subsubsection{Previous Work}

A mine stability evaluation was carried out by Maleki (1990) at an underground longwall coal mine located in Utah. At that time, the mine was experiencing floor heave on the tailgate entry that was becoming problematic. The reason for the study was to determine whether or not the mine would need to redesign its tailgate pillar system, and if the floor heave would increase once the mining depth increased from 1,000 to $1,800 \mathrm{ft}$. This mine stability evaluation was based on geotechnical monitoring and numerical modeling analysis. The study focused mainly on stress evaluation and determining insitu coal and rock properties. These properties were determined through monitoring and identification of failure mechanisms, deformation of roof, and monitoring of roof to floor convergence. Pillar stress measurements and gob pressure cells were also used to investigate the local and regional stress fields that changed as the longwall advanced. Coal measure strata strength was determined by comparing the failure mechanisms within the mine to calculated values obtained by using Mohr-Coulomb failure criteria.

Once the stresses and material properties were identified, a three-dimensional displacement discontinuity code was used to identify areas of high stress within the large area of the longwall tailgate and other areas of interest to the mine personnel. Once these areas of interest were identified, a two-dimensional displacement discontinuity code was used to generate input for a two-dimensional finite element code that could identify the potential failure zones within the roof and floor at the tailgate entry. Final results showed that the floor heave is likely to increase with the increase in cover from 1,000 to $1,800 \mathrm{ft}$. The modeling was in agreement with the experience of the current mine operations and it was determined that there was definitely a need for a new gate pillar layout to be designed. 
Although the study was successful, it seems as though it was quite difficult and cumbersome. Many different analysis tools were used and various databases were compiled and compared to get to the final conclusions. There was also very limited geologic mapping and evaluation that was taken into consideration. A more thorough geologic analysis may have helped to give a more comprehensive analysis of the tailgate stability. The numerical modeling was also done with a few completely separate programs which must have made for a very long and arduous process. Even though this study did focus mainly on stress analysis, it could have benefited from an integrated stability mapping system that included a geo-mechanical evaluation tool such as the CMRR.

Another hazard mapping study was carried out by Riefenberg and the USBM in 1994 that illustrated how the CMRR and multiple seam mining stresses could be used to create stability ratings (Riefenberg, 1994). This conceptual study was begun by gathering data from 10 bore scopes at an underground coal mine. The data were then used in the computation of CMRR values, ranging from 57 to 77, for each location. The mine area was then broken into a grid of 25 x 50 points covering an area of 500 by $1000 \mathrm{ft}$. The individual grid point values for the CMRR were determined by carrying out a geostatistical analysis that involved the creation of a variogram and then kriging the entire area (Figure 2.7). 


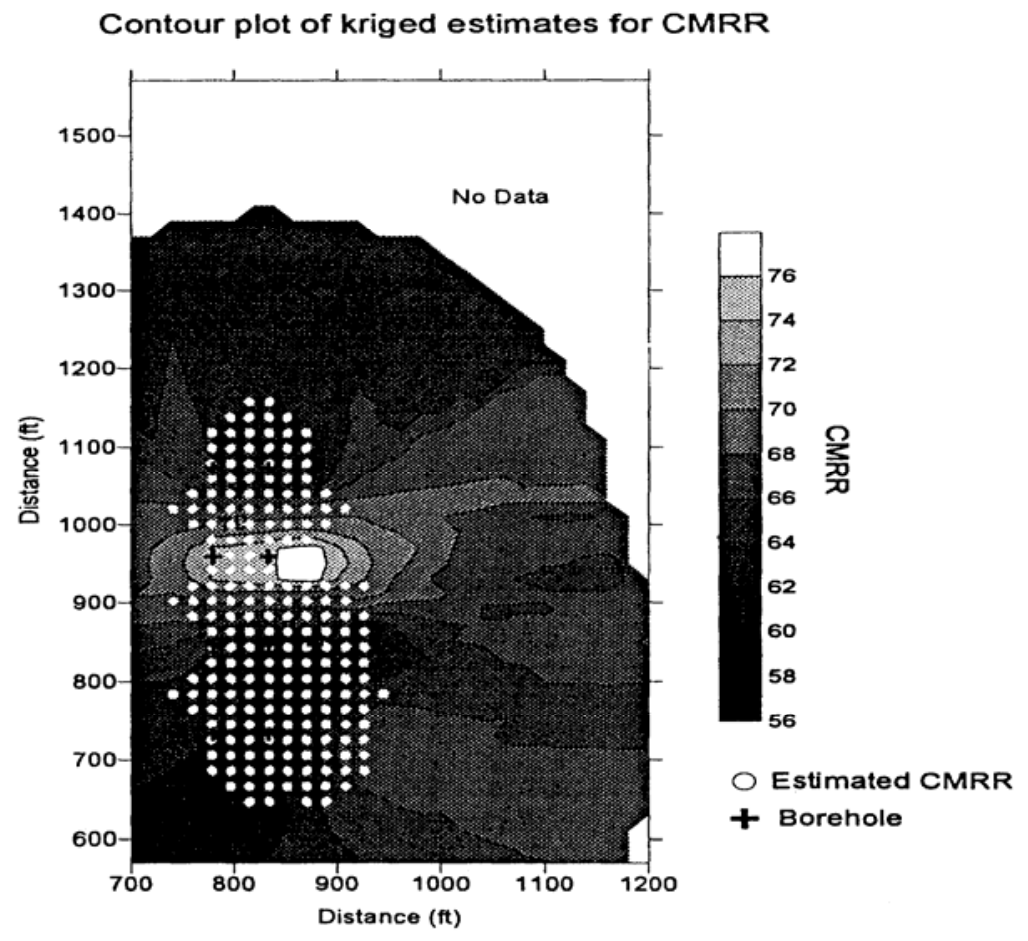

Figure 2.7 CMRR rating (after Riefenberg, 1994)

The process of creating a grid of critical parameters, such as the CMRR in this example, is an important part of present stability analysis techniques. The idea behind this process is to choose an area of interest; in this case it is an area of 500 by $1,000 \mathrm{ft}$ broken up into a grid of 25 by 50 points. In this example each of the 10 bore hole values are statistically analyzed so that interpolated vales for each grid point can be determined.

The multiple seam mining stresses were determined by using the modeling software MULSIM which is a homogeneous elastic boundary element program. The multiple seam stresses were determined by creating a model of the lower seam without the influence of the upper seam along with a model of the lower seam with the influence of the upper seam. The two sets of values were then subtracted from one another to single out the multiple seam stresses (Figure 2.8). 


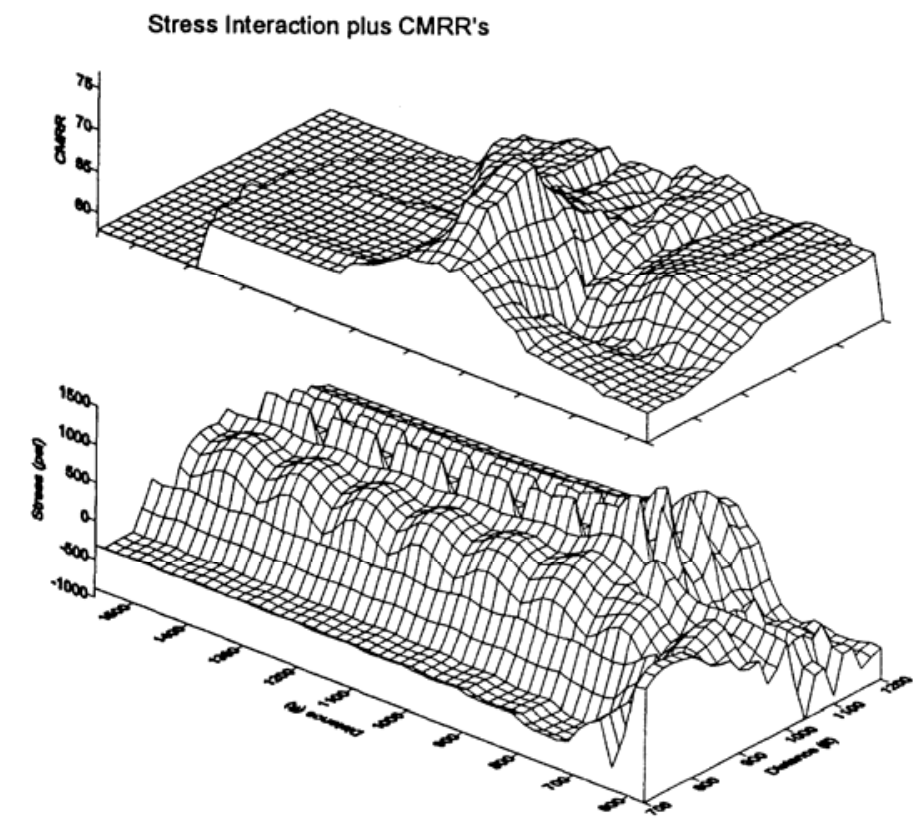

Figure 2.8 CMRR and multiple seam stresses (after Riefenberg, 1994)

The CMRR data were converted to an inverse of the original values by subtracting the value from 100 and the multiple seam stresses were changes from a psi scale to a scale from $0-100$. After both grids were created and normalized they were combined to create the final hazard maps (Figure 2.9). The normalization or creation of an index is simply a method of being able to place different types of data with varying data ranges on the same scale so that they may be combined to form one overall stability index. In this example the multiple seam stress and the CMRR data were weighted equally. In many instances, especially studies with more than two variables, different individual factors may affect the mine stability to different degrees. 

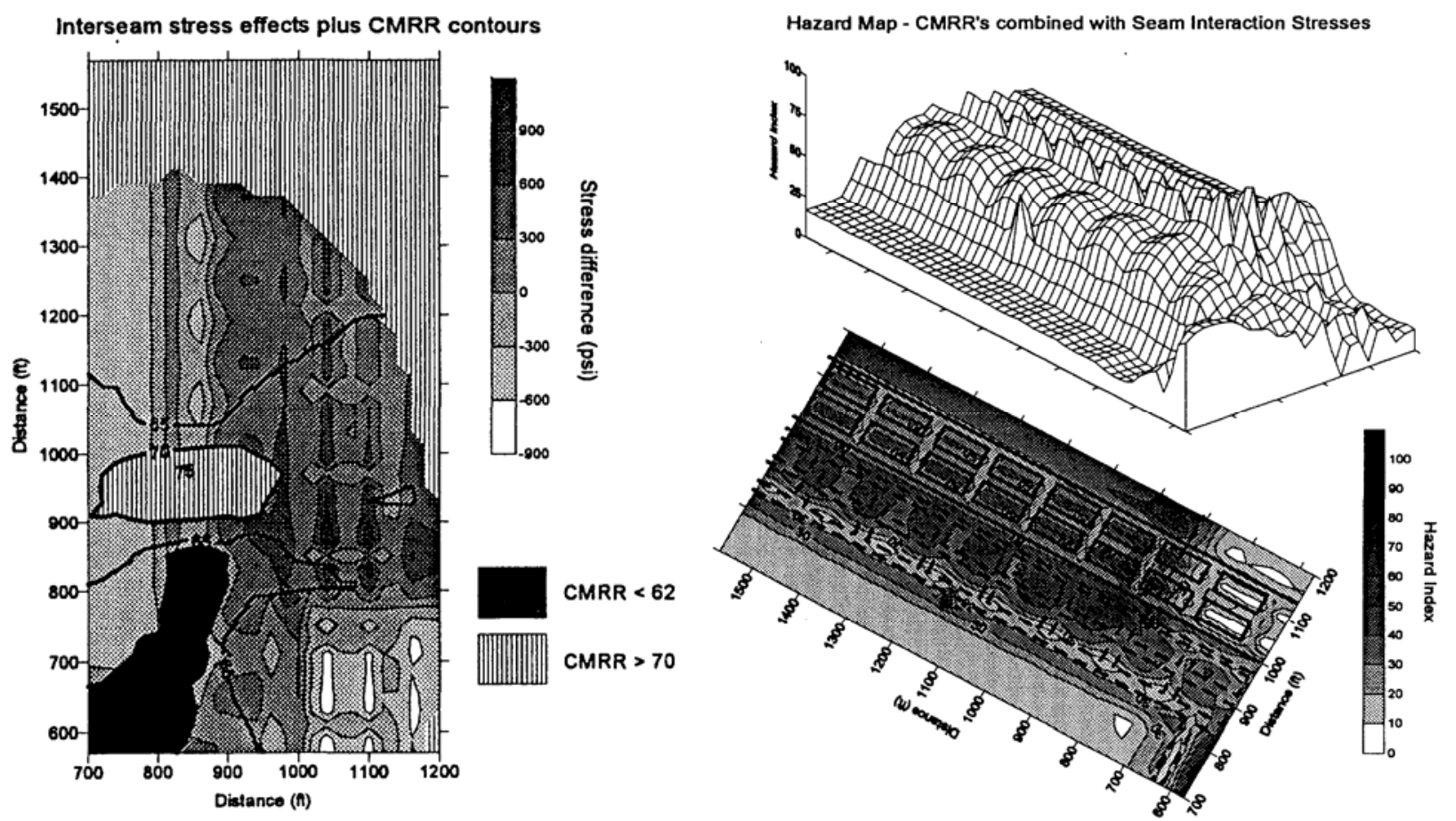

Figure 2.9 Final hazard maps (after Riefenberg, 1994)

Although this study was limited to two parameters and the amount of available CMRR data were minimal, the overall result seems promising. As the author stated:

“The hazard mapping approach presented in this preliminary study appears to be a promising development for understanding and delineating interactions between many geologic and geotechnical parameters that affect ground control stability” (Riefenberg, 1994).

This study is a good illustration of how a geotechnical tool such as the CMRR can be combined with stress analysis to determine mine stability. A more thorough examination of this situation could have been done if the analytical tools available to the user had been more substantial and easier to use. Both the kriging process and the multiple seam stress analysis seemed to be very time consuming and tedious.

A very thorough study was done to investigate various geologic and geotechnical factors and their effect on a longwall panel's performance at a mine in Alabama (Jiang 
and Wells, 1998). These factors included, but were not limited to, coal thickness, undulation in mine floor, massive sandstone channels, faults, joints, and cleat orientation. Much of the data were gathered through surface and underground drilling programs.

The effect on the longwall due to these geologic factors was studied through the use of a real-time monitoring system that kept a log of the longwall pressure data. It was found that three separate things could have an effect on the loading of the longwall shields. These three things were: the sandstone channel in the roof and its thickness, the sometimes extreme floor undulation, and the joint sets in the roof. Along with various loading that occurs due to the geology, the orientation of the coal cleats with respect to the face line was determined to be very important when observing face failures.

After observation of all of the above, it was found that the sandstone channel thickness, the floor undulation, coal cleat orientation, and the parting thickness had the most effect on the longwall performance. It was also found that mining under the parting helped to reduce falls and the overall downtime of the longwall system.

Each of the important factors identified in this study could be easily entered into a comprehensive stability mapping package such as the one developed by Wang and Heasley (2005). Also, with the addition of the CMRR to the package another input parameter would be present that could give more insight into the effect of the immediate roof with respect to the longwall loading.

Another example of a stability mapping system was developed by Jenmar in cooperation with Consol Energy and tested at their Enlow Fork mine (Stankus et al., 2001). A case study was carried out to show the effectiveness of what they listed as a Roof Instability Rating (RIR) system. The system takes various geologic and geotechnical factors and uses them to determine the final RIR. Each factor is quantified 
and weighed based on past experience and then combined with the other factors to determine the final instability rating. Factors such as sandstone channels, stream valleys, tectonic stresses, and mica percentage were studied and recorded on detailed maps to be used in the creation of the final stability map.

The influence of the sandstone was determined by giving a rating based on the thickness of the sandstone along with its proximity to the seam. It was observed that as the sandstone became more massive and more closely approached the coal seam, the roof conditions would deteriorate. Therefore, the highest possible sandstone rating occurs when the sandstone is greater than 20 feet thick and has protruded into or is right against the top of the coal seam. Figure 2.10 illustrates how the sandstone rating varied across a section of the mine.

The stream valleys were included by applying an influence zone that reached 500 linear ft. from each side of the stream valley bottom. The stream valley was applied as a linear feature and the influence zone carried out in a perpendicular direction from the bottom of the valley (Figure 2.11). If an area is within the influence zone then the stream valley rating is 100 and if it is outside then the rating is zero. 


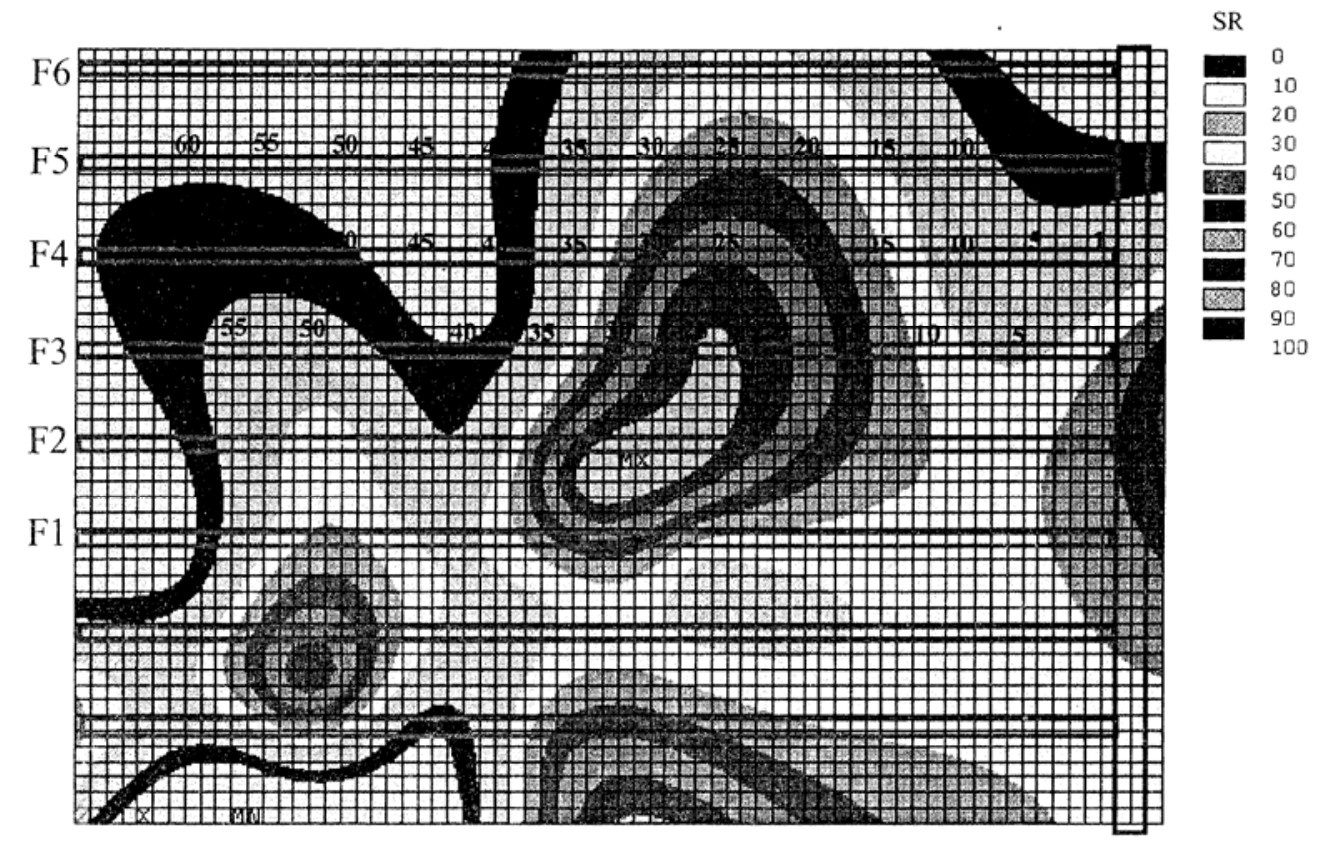

Figure 2.10 Sandstone Rating (after Stankus et al., 2001)

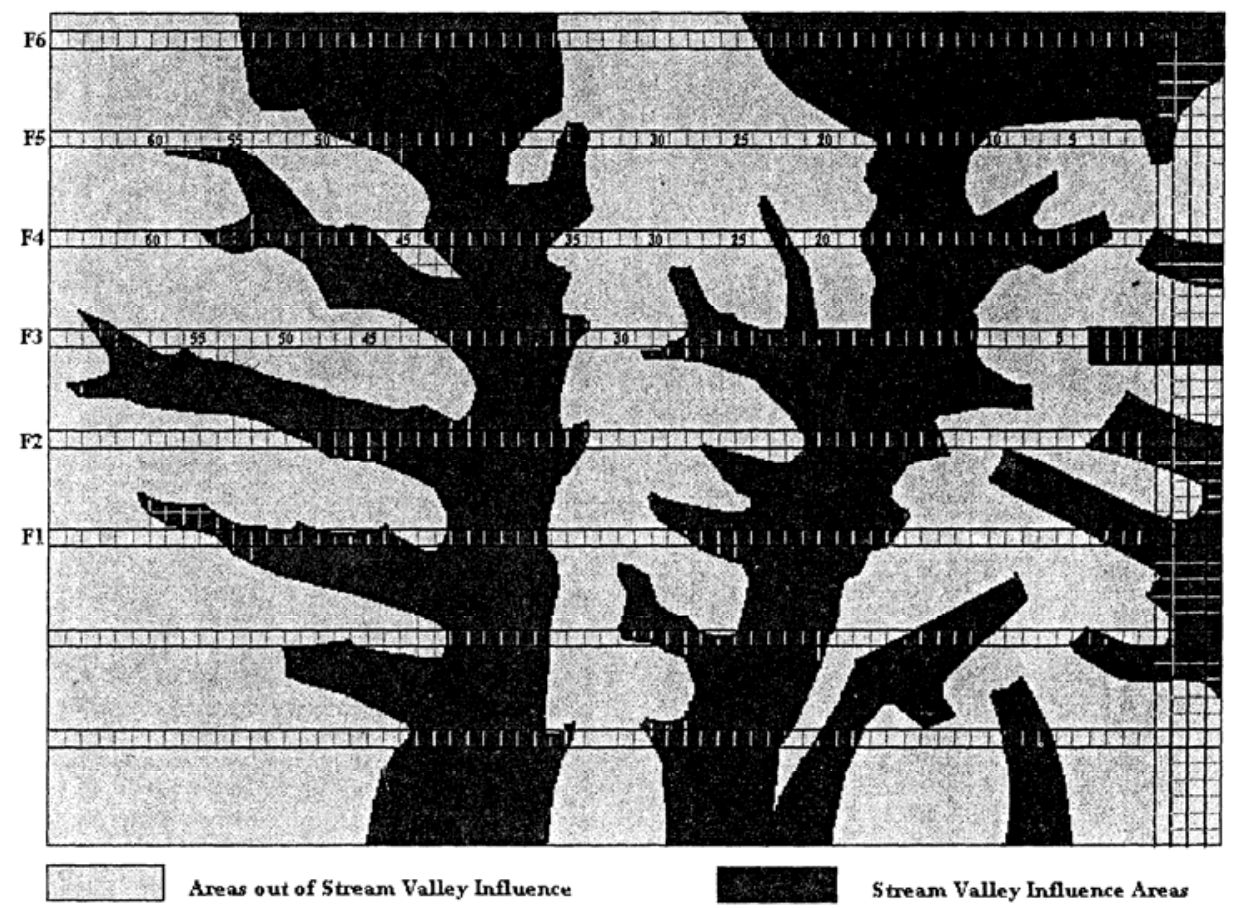

Figure 2.11 Stream valley influence (after Stankus et al., 2001)

Along with the sandstone channels and stream valleys, the presence of tectonic stresses were found to affect the mine stability. The tectonic stresses were determined by using a finite element program. From the finite element output (Figure 2.12) a tectonic 
stress rating was determined based on the tectonic influence area. It is not specified at what point the stress is considered important, but one would assume there is some critical value where stability problems begin to occur. As with the stream valleys, if an area is within the tectonic influence zone then a tectonic stress rating of 100 is given and if it is out of the area a rating of zero is applied.

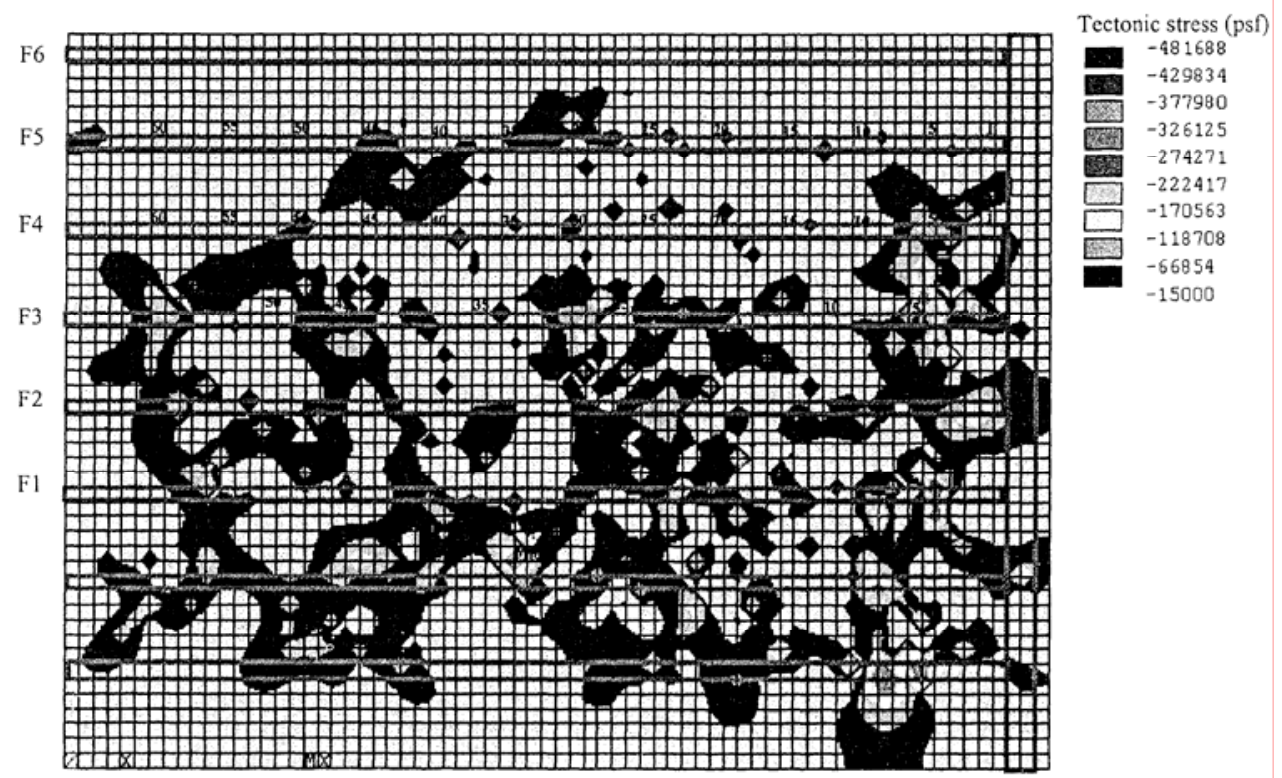

Figure 2.12 Tectonic stress distribution (after Stankus et al., 2001)

The last important stability feature, and maybe the most difficult one to identify, is the presence of mica within the sandstone. If mica was found to be present in the sandstone a mica rating of 100 is applied and if no mica is found a rating of zero is applied.

From the sandstone, stream valleys, tectonic stress, and mica ratings a final stability map was composed (Figure 2.13). From this map, the mine engineer was able to determine where and how much additional roof support was needed. Overall it was found that where the RIR was greater than 60 the supplemental support would need to be very heavy. 


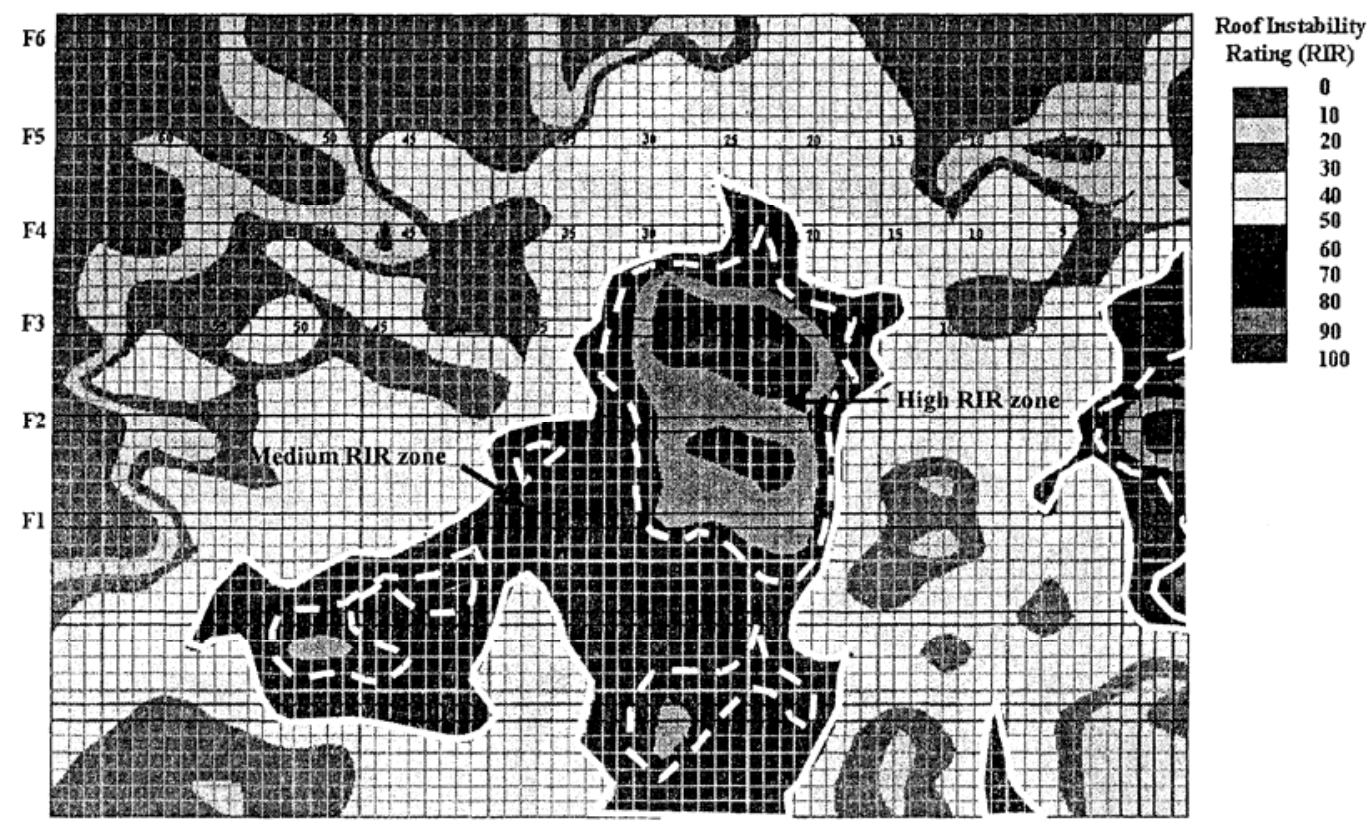

Figure 2.13 Roof Instability Rating (after Stankus et al., 2001)

The use of both cable bolts and trusses was needed in these areas and they were installed immediately after development. For an RIR of 50-60 the supplemental support should be installed before the longwall mines through the area of concern. If the RIR was less than 50, it was determined that little to no supplemental support was needed other than in the intersections or if problems where encountered. Application of this system was found to be successful in predicting and mitigating roof problems within the mine (Stankus et al., 2001).

This example perfectly illustrates the need for a fully integrated stability mapping system. Both geology and stress were taken into account and used to determine a stability map. Given that there was extensive knowledge with regard to the geology at the mine location the CMRR calculation could have been an easy addition to the stability map that was created. 
Another example of determining risk in a mining situation based on geologic and geotechnical data was the work done by Appalachian Mining and Engineering Inc. at an underground limestone mine located in Tennessee (Newman et al., 2001). The main objective of this project was to evaluate the stability of various levels of a multilevel limestone mine in order to help with the planning of future mine development.

At the time of the study, two levels of the mine had already been developed and a third was being planned. Geologic features such as calcite veins, joints, and fractures were mapped in the active mining zone and the rock strength was also recorded through the use of a few drill cores.

Underground observations of general stability were observed and correlated with the different geologic conditions such as the fracture and calcite vein orientation. Also, analytical calculations of the pillar safety factors and opening stability were performed. Another tool that was used was the LaModel boundary element program. It was used to determine the stress interaction between the different levels that have already been mined along with the proposed mine development. The LaModel software was used because it allows the user to determine multiple seam stresses that are caused by the mining in an adjacent level.

Through the use of geologic mapping, analytical analysis, and computer modeling, the mine operators were able to better plan the proposed area of mine development. Through the use of discontinuity mapping a preferred orientation of the mine was found and crosscuts could be planned so that roof conditions would also improve. The LaModel analysis results correlated well with the pillar conditions found in the mine. It was also discovered that the preferred layout is a case in which the rows of 
pillars in the mine overlay each other from level to level. This study seemed to be very beneficial for the mine personnel.

Even though the previous example was not a coal mine situation, the same methods were employed in determining the stability of the mine openings. Although the CMRR could not be applied to this situation, a comprehensive stability mapping package would still have been advantageous.

Part of the solution to some of the more tedious tasks that were undertaken in the previous studies could possibly be solved through the use of a new stability mapping package that has been developed by Heasley and Wang of West Virginia University (Wang, 2005). This stability mapping system uses the windows-based program SurvCADD/AutoCAD as a platform and has added various calculations and utilities to aid in the creation of a stability map. The program enables the user to investigate geologic features, structural factors, and mining stress elements and analyze them to create a stability rating for a mine area.

The majority of the data for this system are stored in a matrix or grid format developed by SurvCADD. The data that are used to create the geologic grids can be taken from sources such as drill logs and underground samples. Also, various structural features such as sandstone channels and stream valleys can be gridded with utilities in the program and used in the creation of the overall stability rating. Also, stress analysis can be carried out with the built-in boundary element program which can determine grids for vertical stress, multiple seam stress, pillar safety factors, etc.

Each feature is added to the database and given a weighting value based on how important it is to the mine stability. One of the biggest advantages of this system is that it can analyze many different types of geologic, structural or stress data and combine them 
to reach one final set of output. It allows the user to easily optimize the weighting of each specific feature and determine the most representative model for the mine of interest.

A case study was carried out to evaluate the effectiveness of this system when it is used in a mining situation. At this mine site, it was determined that the sandstone thickness along with its proximity to the seam and the overburden stress were of the most importance to the pillar/rib stability (Wang, 2005). The first step was to determine the thickness of the sandstone within the immediate $10 \mathrm{ft}$. of roof. These data were gathered from 67 core holes drilled up into the roof from within intersections in the mine. Once all of the geologic data were collected and modeled in SurvCADD, a plot of the sandstone percentage within the immediate roof was compiled (Figure 2.14)

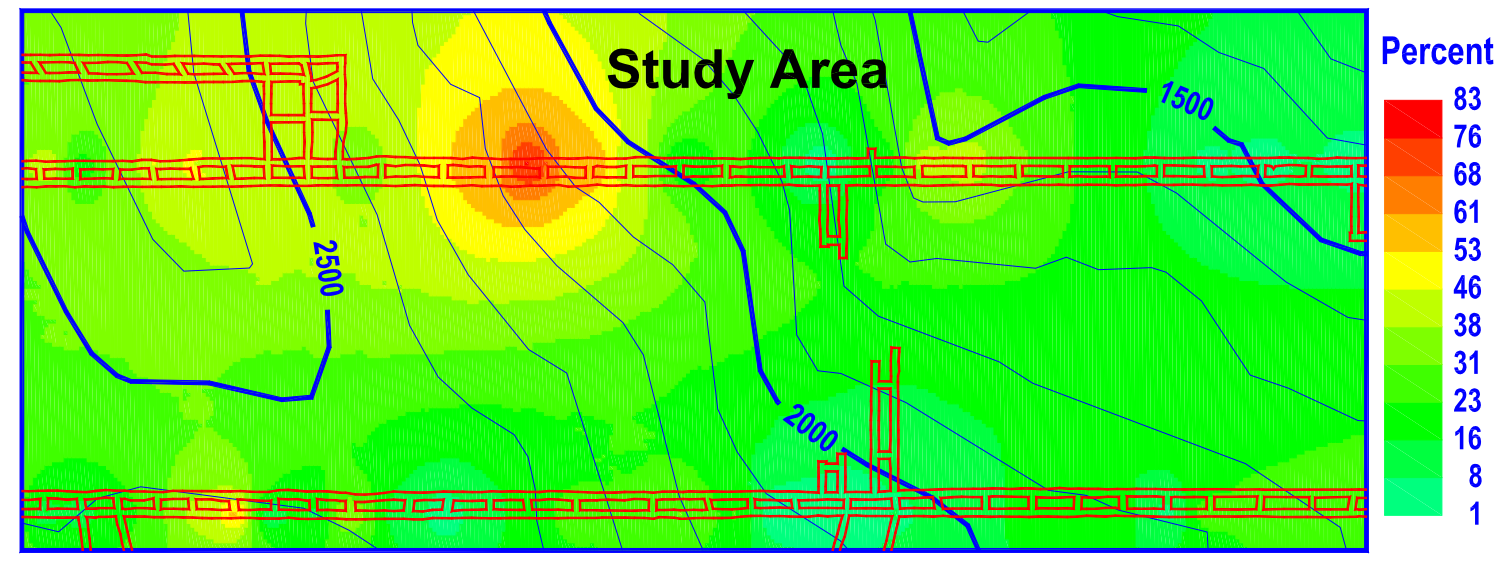

Figure 2.14 Sandstone percentage in first $10 \mathrm{ft}$. of roof (after Wang, 2005)

Because the highest percentage value was $87 \%$, this was linearly normalized to an index of 100 and the lowest percentage to an index of 0 (Wang, 2005). The next step was to find the distance between the top of the seam and the bottom of the sandstone channel, the interval distance. A grid of this interval distance was created and then transformed to an indexed plot on a scale of 0 to 100 (Figure 2.15). 


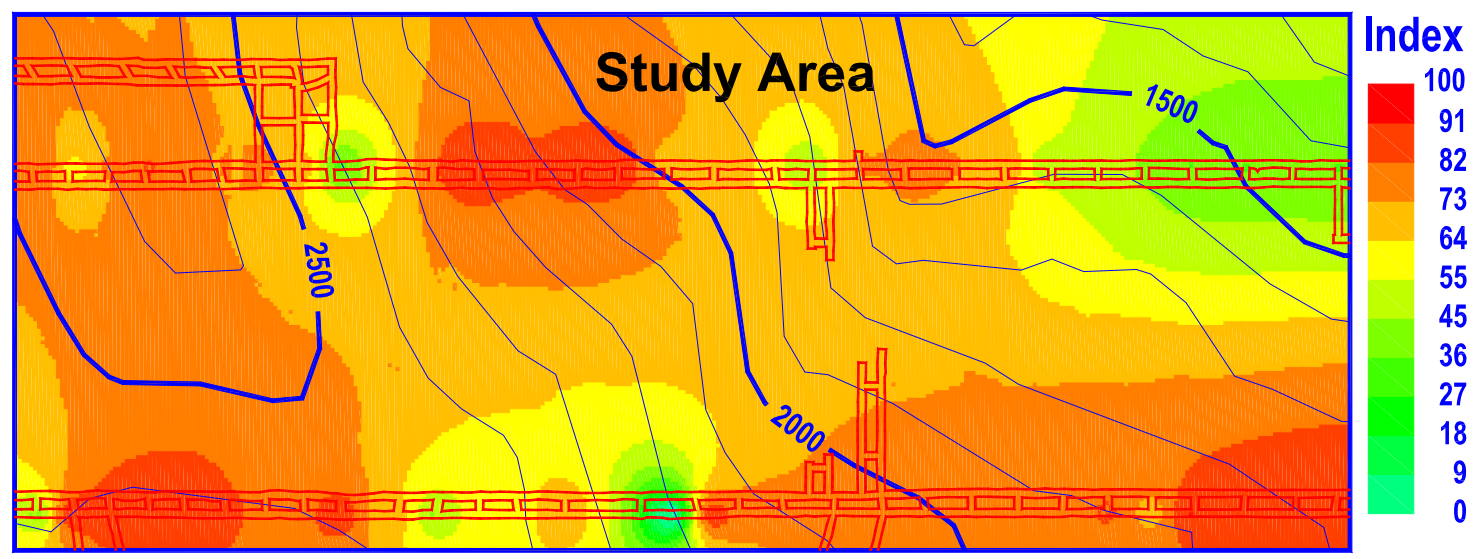

Figure 2.15 Index plot for the interval thickness (after Wang, 2005)

The last step, before the creation of the stability map, was to determine the overburden stresses by using the built-in boundary element program, LaModel (Figure 2.16). The stability mapping package has incorporated a displacement discontinuity program, LaModel, which is capable of calculating both overburden stresses due to gravity loading, and multiple seam stresses that are a result of stress concentrations from over or underlying mined areas. Finally, a stability index was created by equally weighting each of the input parameters: sandstone percentage, interval index, and overburden index. Figure 2.17 illustrates the final output of the case study.

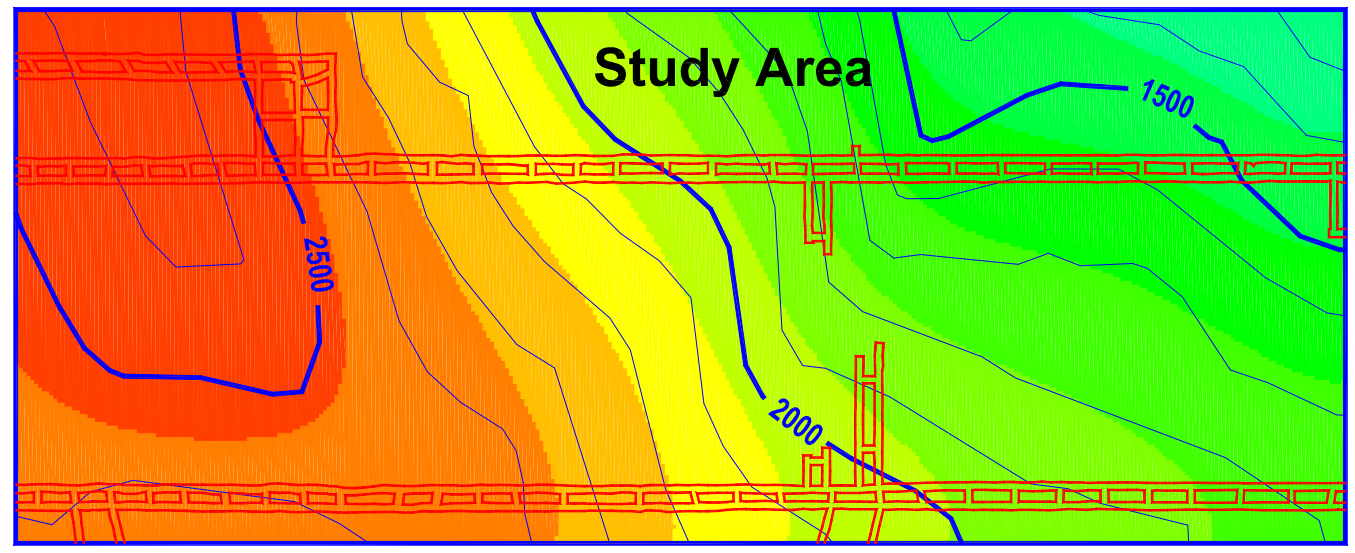

Figure 2.16 Plot of overburden stresses (after Wang, 2005) 


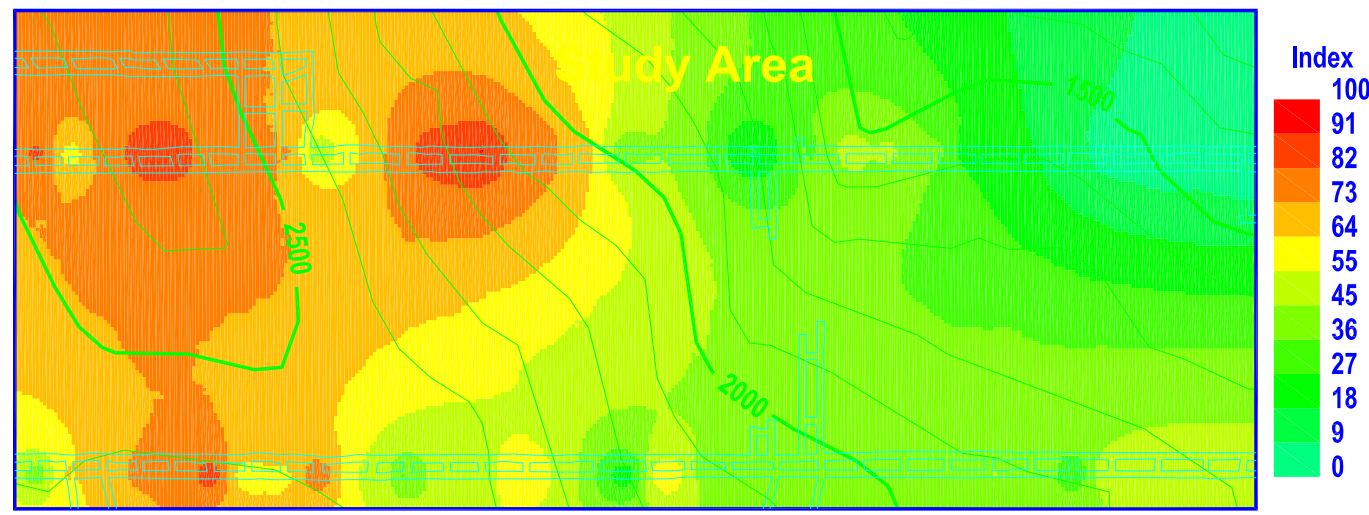

Figure 2.17 Plot of final stability index (after Wang, 2005)

Once the entire study was complete, the results were compared to the actual conditions within the mine. It was found that there was a fairly good correlation between the observed conditions underground and the calculated stability index even with the limited experience and refinement with this mine location.

The stability mapping package developed by Heasley and Wang (2005) seems to be a thorough and easy-to-use system. It allows the user to incorporate both geologic and stress components into the creation of a stability map. Geologic information can be entered as contours, points, or linear features and all of this can be done within a single program. It is also very advantageous to have data input in a format that is widely used by today’s mining industry (Richards, 2001).

The previous examples illustrate the need for and the usefulness of a comprehensive stability mapping program. One of the major drawbacks of each study was the difficult and tedious nature of the input and calculation work that needed to be done in order to reach a final result. It is evident that much of the work that has been done in the past would have benefited from a comprehensive stability mapping system. Because computer applications are becoming more prevalent in the mining industry it would make sense to assume that more work of this nature will be done in the future. 
Not needing to change between different databases and modeling programs would not only allow the mine engineer to produce a quality mine stability map, but he or she would be able to do so in a more timely manner.

The addition of the CMRR to a comprehensive stability program such as the one developed by Heasley and Wang would add another dimension to the program's capabilities. Intuitively, the more quality data that can be used to create a stability map the better the final result will be. The CMRR could be used as another variable in determining the stability ratings or it could be used in a stand alone function as it has been done in the past (Molinda and Mark, 1994). The CMRR data can be used in determining the proper bolting patterns and density along with using the numbers in the ALPS program to assess pillar size. ALPS uses the CMRR to determine a suitable stability factor for different coal pillar sizes when designing gate roads. The addition of the CMRR to the stability mapping package opens up an opportunity to increase the success rate of gate road design and overall stability mapping (Molinda and Mark, 1994).

\subsection{AutoCAD Program and Grids}

AutoCAD along with SurvCADD are two very important tools used in today's mining industry. The AutoCAD platform provides the mine engineer with basic drawing and mapping capabilities and is used in upwards of 90\% of U.S. coal mines (Heasley and Wang, 2001). Along with the AutoCAD program, many coal mines, around $80 \%$, also use the SurvCADD add-on which enables the user to carry out more mining specific applications such as surveying, geologic gridding and mine planning (Richards, 2001).

The "geologic" model of the mine that is developed in SurvCADD can be a very powerful tool for the mining engineer. Many mines store large amounts of their geologic data in a geologic model in AutoCAD/SurvCADD and in grid form files and manipulate 
it using the utilities available under the SurvCADD program. The grids are essentially a three dimensional matrix that store an $\mathrm{x}$ and $\mathrm{y}$ coordinate along with a $\mathrm{z}$ value for the data being stored at that point. Each grid has a base point that anchors the grid to some point in space on the mine map (see Appendix A.). From this origin point, each data point is spaced based on the $\mathrm{x}$ and $\mathrm{y}$ grid spacing that is specified upon creation of the grid. The $\mathrm{z}$ data type varies from application to application, storing such information as sulfur content, coal thickness, or bed strength. SurvCADD provides many utilities to manipulate and visualize the grids such as contour maps, isopachs, 3-D fishnets and other various useful displays.

During the exploration and evaluation stages of a mine, core logs are gathered to assess the coal quality and quantity. Along with this comes information on the rock which makes up the coal mine immediate roof and overburden. This information is usually evaluated through the geologic mapping software such as SurvCADD. Through the use of this software the drill core data can be displayed graphically for easy interpretation and evaluation. As the mine is developed, additional data can be gathered and added to the current geologic model. Because the CMRR is determined, in part, from these types of geologic data, it is a logical step to facilitate the calculation of minewide CMRR values based on the information stored in a mine’s geologic model. By creating this functionality, the wealth of geologic data already collected at the mine can be used to enhance the calculation of the CMRR throughout the mine, thereby improving the mine stability analysis and safety. 


\section{Chapter 3}

\section{Design of the Coal Mine Roof Rating Program}

\subsection{General}

It was determined that the CMRR program must allow the analysis of geologic data on both an areal and point basis; also it should use a currently available database structure, and be combined with the current stability mapping system. The program will be based on the AutoCAD platform and utilize the SurvCADD grid data format that is currently available. The basic idea was to design a program that allows a mining engineer to quantify the geomechanical aspects of a coal mine roof over a wide area using previously available geological data. Overall the program will expand the capabilities of the CMRR to an areal calculation.

\subsection{Data Format}

The structure of the program must be simple yet effective in calculating the CMRR and allow for the use of a widely available data format. One of the main goals of creating this program is to allow compatibility of the input and output data with one of the more widely used geologic mapping software programs, SurvCADD. So, the SurvCADD "grid” file format was chosen for storing the CMRR data. This will enable the CMRR grid files to be manipulated and viewed using all of the SurvCADD grid utilities. Using the SurvCADD grid file will also enable the output of the program to be used with a previously created stability mapping system (Wang, 2005). With the same data format, the output of the CMRR program can be analyzed and combined with other data from the stability mapping system to create a stability rating along with a CMRR grid (Figure 3.1). This can be done by manipulating the CMRR output file using the 
different modules already available within SurvCADD and the stability mapping package. If it is desired to create a stability index using the CMRR data, a transformation can be carried out using the stability factor transformation module. This enables the CMRR output to be scaled similarly to the rest of the data being used in the creation of the stability index. If it is not desired to combine the CMRR data with the rest of the geologic and stress data then the CMRR data can be plotted as an individual isopach or contour map.

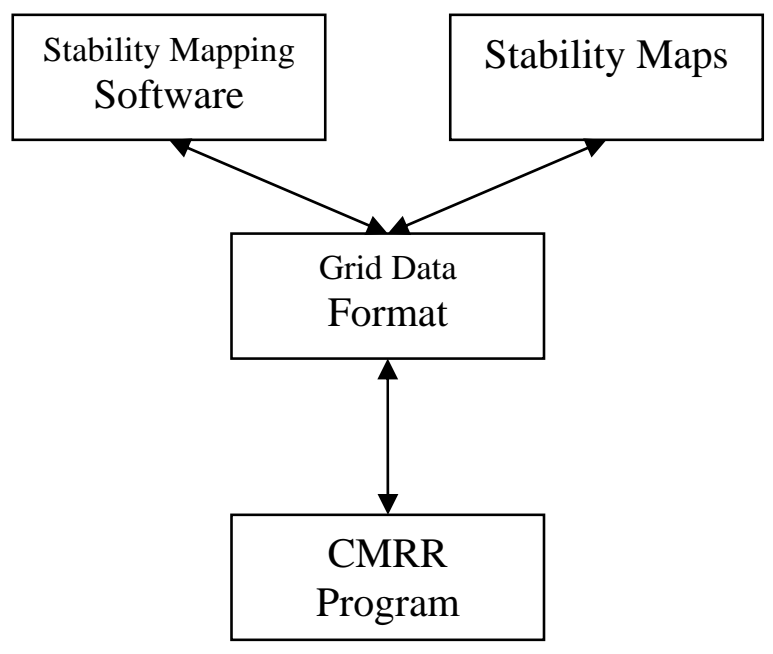

Figure 3.1 Overall structure of grid data format

Data that will be used to calculate the CMRR will need to be in a format that can be read by the SurvCADD program and converted to a grid data structure. Because SurvCADD is so widely used there should be a large bank of data already available to the mining engineer that could be used by the program. As it was previously stated, the main data format that will be used is a SurvCADD grid consisting of parameter values on an 
even grid over the area of interest within the mine area (see Appendix A). This format will be used for storing the data on disk and internally for performing the CMRR calculations. If a particular parameter is not available in a grid format from an external source, then a single value will be input by the user and used to populate a grid for that parameter. By having the capability within the program to use either a detailed grid or a constant value grid one can take advantage of having a large amount of data when available, but can still perform the calculations when these data are not available.

There are many input parameters necessary to calculate the CMRR, and as a first step in developing this program it was essential to determine which ones may be available in the grid format. Tables 3.1 through 3.3 give a list of each input parameter and what data type are possible for each one. The first and the most widely available grid input parameter is the thickness of the unit. From experience it has been found that the thickness of a unit or a geologic bed is normally one of the first geologic parameters to be recorded in a drilling program. In many instances it has been found that geologic layers such as sandstone units and the varying thickness of the unit can have a large effect on the overall stability of the immediate mine roof (Wang and Heasley, 2005). Due to the importance of these types of thicknesses, they are usually an area of interest to the mine engineer and are recorded in the mine's geologic model. If the unit data have been gathered from observations, either underground or surface, it was decided that only the unconfined strength (UCS) of a particular unit would be geologically mapped and possibly have a grid created. The strength of a unit or a geologic bed is commonly recorded when the mine personnel is interested in the mechanical properties of the immediate roof. More than likely the discontinuity data, moisture sensitivity, and unit contact would not have grid data available. As far as a CMRR created from core data, 
there are many more parameters that could possibly have data in a grid format. These include the diametral strength, fracture spacing, RQD, and axial test information. It was decided to give these parameters grid capabilities because of the nature in which the data are collected. When drill core data are collected, it is often input into geologic mapping software to be used and analyzed at a later date. Because of the data storage format, there is a greater likelihood that the data for the corehole parameters would be available in a grid format or in a format that could be used to create a grid. Along with the above four input parameters, the mine's groundwater can also be input in a grid format. The amount of groundwater within a mine is often recorded by the mine engineer through observational techniques (Stewart et al., 2006). Although the thickness, UCS, diametral strength, fracture spacing, and RQD of each unit can be input in a grid format, they will also be able to be input as single average values for an area.

Table 3.1 Unit Observation Data Types

\begin{tabular}{|l|c|c|c|}
\hline Unit Observation Data & Grid & Single Value & Menu \\
\hline Thickness & $\mathrm{X}$ & $\mathrm{X}$ & \\
\hline Unit Rating & & $\mathrm{X}$ & \\
\hline Strength Index & $\mathrm{X}$ & & $\mathrm{X}$ \\
\hline Moisture Sensitivity & & & $\mathrm{X}$ \\
\hline Contact Strength & & $\mathrm{X}$ & \\
\hline Number of Discontinuities & & $\mathrm{X}$ & \\
\hline Cohesion & & & $\mathrm{X}$ \\
\hline Roughness & & & $\mathrm{X}$ \\
\hline Spacing & & & $\mathrm{X}$ \\
\hline Persistence & & & $\mathrm{X}$ \\
\hline
\end{tabular}


Table 3.2 Unit Core Data Types

\begin{tabular}{|l|c|c|c|}
\hline Unit Core Data & Grid & Single Value & Menu \\
\hline Thickness & $\mathrm{X}$ & $\mathrm{X}$ & \\
\hline Unit Rating & & $\mathrm{X}$ & \\
\hline Diametral Is(50) & $\mathrm{X}$ & $\mathrm{X}$ & \\
\hline RQD\% & $\mathrm{X}$ & $\mathrm{X}$ & \\
\hline Discontinuity Spacing(in) & $\mathrm{X}$ & $\mathrm{X}$ & \\
\hline Axial Is(50) & $\mathrm{X}$ & $\mathrm{X}$ & \\
\hline Axial UCS & $\mathrm{X}$ & $\mathrm{X}$ & \\
\hline Moisture Sensitivity & & & $\mathrm{X}$ \\
\hline Contact Strength & & $\mathrm{X}$ & \\
\hline
\end{tabular}

Table 3.3 Overall Mine Data Types

\begin{tabular}{|l|c|c|c|}
\hline Overall Mine Data & Grid & Single Value & Menu \\
\hline Number of Units & & $\mathrm{X}$ & \\
\hline Groundwater & $\mathrm{X}$ & & $\mathrm{X}$ \\
\hline Surcharge & & & $\mathrm{X}$ \\
\hline Bolt Length & & $\mathrm{X}$ & \\
\hline
\end{tabular}

\subsection{Data Requirements}

As stated earlier, the data that are to be used for calculation of the CMRR must be available and in a format that can be properly read by the program. The main data format that is used by the program is a grid or array of points on a spatial plane. Each of these points has a location and a value representing some sort of data value such as the thickness or strength of a particular unit at that point. Along with being in the proper format, the data should also be valid and as close to the real mine conditions as possible. This is necessary because the output from the program is only as accurate and precise as the data that are used to create it.

Various sources may be used in obtaining the data. If a mine has yet to be developed, then the data source may be limited to surface drill cores and/or outcrops, but if the mine is operational then the use of underground observational data would be valid. Underground data can be taken from a number of sources such as overcasts, roof falls, and bore holes into the roof of the mine. Once the data are gathered from one or more of the above sources, it should then be converted to a grid format using the SurvCADD program or stability mapping software, given that there are adequate data to create such a 
grid. If data for certain CMRR factors are not available in sufficient quantity to create a grid, then a single number may be used as an estimated average for the extent of the area of interest.

\subsection{Program Creation}

Once the data format was determined, it was necessary to decide on a method for creating the program. Because compatibility with the AutoCAD/SurvCADD platform was desired, it was determined that Microsoft Visual C++ combined with the AutoCAD object ARX applications would be the best tool for the job. The Microsoft Visual C++ program has the capabilities to handle large quantities of data and to carry out the needed calculations that the CMRR program will require. It is also possible to create userdefined forms or dialogs using $\mathrm{C}++$ with ease. Within these forms, data entry boxes and easy to use pull-down menus can be inserted for ease of use. This will enable the creation of the interface between the user and the calculation phase of the CMRR program. Creating the CMRR program with Microsoft Visual C++ will allow for an easy to use, flexible program, which will have all of the desired capabilities. 


\section{Chapter 4}

\section{Implementation}

\subsection{General}

Since its inception, the Coal Mine Roof Rating (CMRR) has been used throughout the world including the U.S., Australia, and South Africa (Mark et al., 2002). Through this increasing popularity a need has arisen for a system that will allow the user to more effectively and efficiently calculate a CMRR over a larger area based on readily available data. Research has shown that the CMRR can be used successfully over a large area, but the process of doing this can be tedious at best (Riefenberg, 1994). Because of this need, a fast and accurate program to calculate the CMRR based on data that are readily available and in a format that is already being used has been designed. The major components for this system have already been discussed in previous chapters, but in order to facilitate the major processes each and every detail of the calculation process must be implemented. The system was developed on the widely used AutoCAD/SurvCADD platform using the AutoCAD Application Programmers Interface (API) and features a graphical user interface and fast numerical calculations. This chapter details the important algorithms, methods, and assumptions that were used in each of the major processes that make up the final program.

\subsection{User Interface}

In order to enable ease of use, the program has been designed with the user in mind. The user interface needed to be simple and self explanatory to prevent confusion or user error during the parameter input process. This was achieved by making the program forms-based and implementing many error checks throughout the program. The 
program is run within the AutoCAD platform which is also the same platform as the one used for Heasley and Wang's stability mapping system (Wang, 2005). By putting these two programs on the same platform the user is able to transfer from one application to the next with great ease. Also, if a user does not have the SurvCADD add-on to AutoCAD then they can use the stability mapping package to plot and create grids to be used in the CMRR program input and output.

The forms in the program were modeled after the forms in the CMRR program created by NIOSH. This was done because these forms were well designed, and so that users of the NIOSH program would have an easy transfer from one program to the next.

The entire program package comprises five separate dialogs or screens where data can be entered (see Appendix B). The main dialog allows the user to carry out some of the major operations of the program like opening and saving files (see Figure 4.1). The main dialog is also where the number of units is chosen and the thickness information is entered. Once the data type is selected and the thickness entered the user may click on the "Details" button. This button takes the user to either the observation data dialog, as shown in Figure 4.2, or the drill core dialog, as shown in Figure 4.4, depending on the data type that was selected in the first dialog. Within the observation data dialog there is a "sets" button which takes the user to the discontinuity data dialog shown in Figure 4.3. Whether in the observation data dialog or drill core dialog the user can enter all necessary data for the calculation of the unit ratings based on observational or core log data. Included in each dialog there is an "OK" button. When this button is clicked the user is returned to the previous dialog. For example, the "OK" button in the discontinuity dialog will take the user to the observation data dialog and the "OK" button in that dialog will return the user to the main dialog. Once complete with either set of forms, the user is 
returned to the main dialog where they can click on the "Next..." button. This button will bring up the final dialog in Figure 4.5 where all of the non-unit mine data such as the ground water and bolt length can be entered. Now that all of the data are entered the "Finish" button can be clicked and the CMRR grid or individual CMRR value will be calculated.

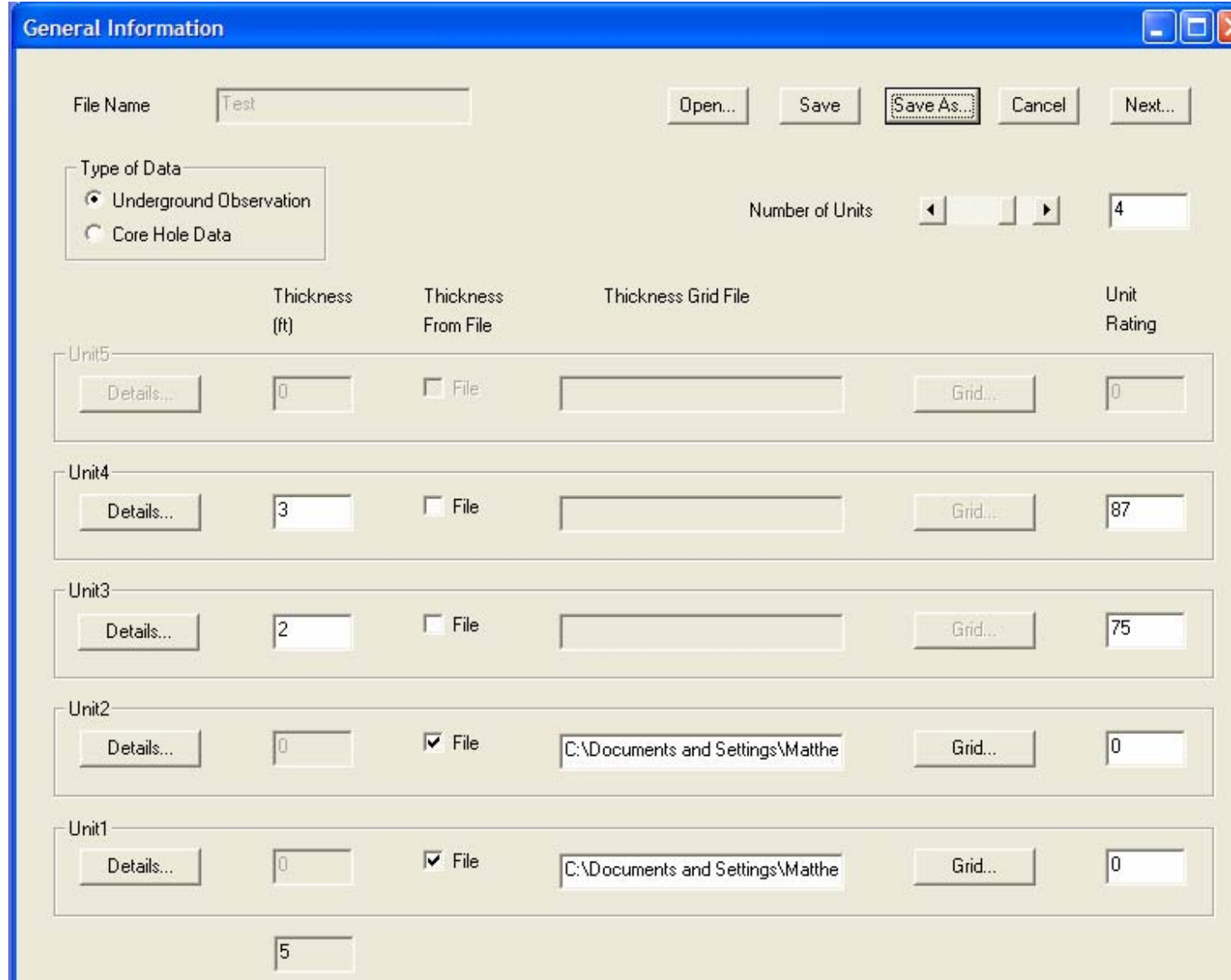

Figure 4.1 General Information form 
Strength Index

Strength Grid File

1.0 Rebounds $>1 ! \nabla$ File

Grid.

-Discontinuities

Number of Discontinuities

$\perp \perp \perp$

1

Sets...

Moisture Sensitivity Index

2.0 Slightly Sensitive
Contact at Top of the Unit-
(- Strong
$C$ Weak

Figure 4.2 Underground Observation Data form
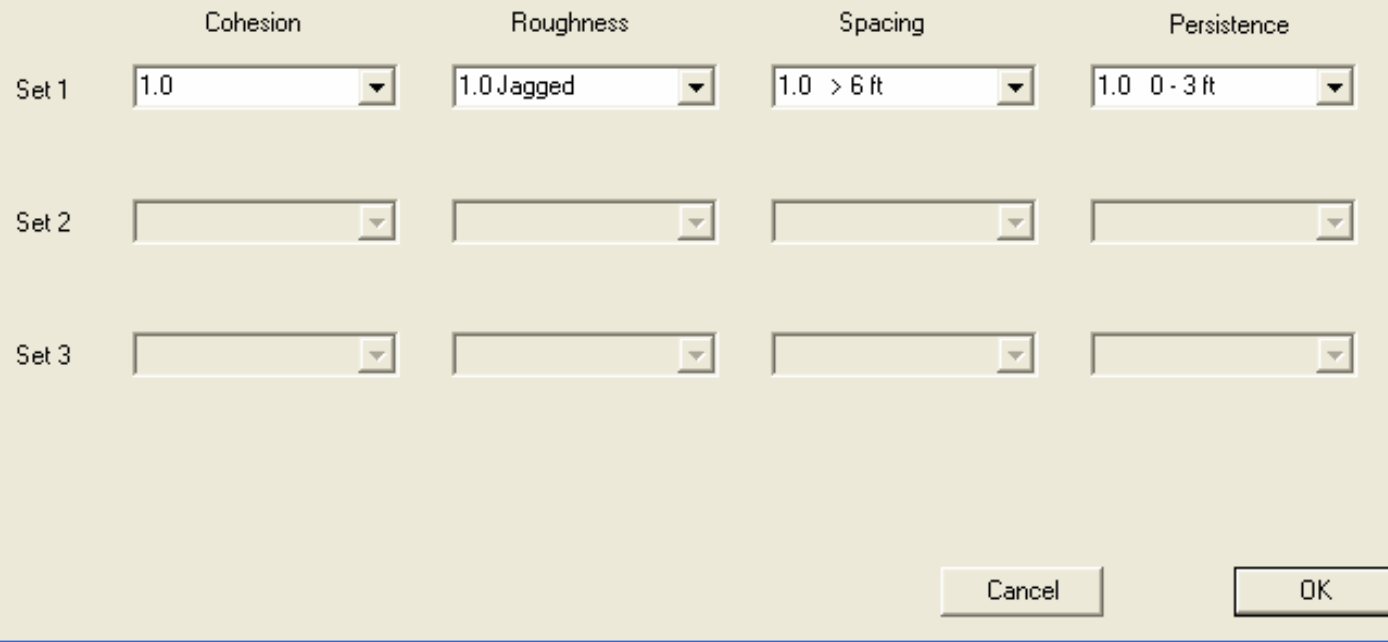

Figure 4.3 Discontinuities form 


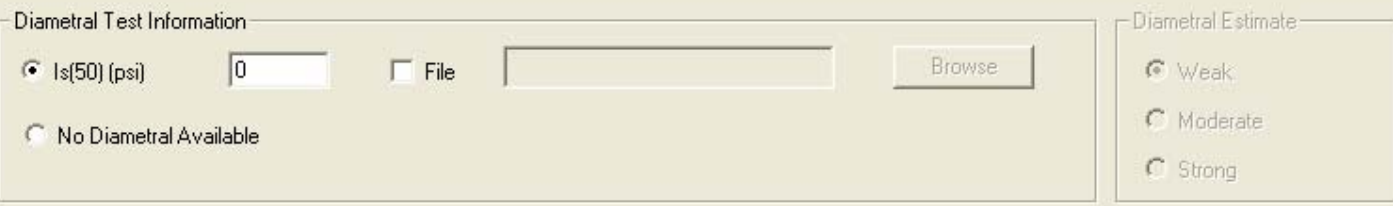

-Fracture Information
(- RQD\%
$\lceil\quad \Gamma$ File
(C Discontinuity Spacing (in)

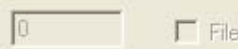
C No Fractures

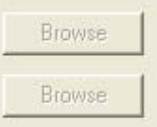

- Axial Test Information
- Is[50) (psi)
$\lceil\quad \Gamma$ File
C UCS (psi)
$\sqrt{0}$ 厂 File

Contact at Top of the Laye

- Strong

$c$ Weak

Moisture Sensitivity Index

1.0 Not Sensitive $\quad-$

Final Data Parameters

Ground Water Grid File

Ground Water Adjustment $2.0 \mathrm{Damp} \quad \Gamma$ File

Surcharge Adjustment 1.0 Unit above bolted interval is equal in strength to the bolted $u$.

Bolt Length(tet)

6

Keep Unit Grid Files

$\Gamma$ Yes

Final CMRR

$$
91
$$

$$
\text { <-. Back }
$$$$
\text { Cancel }
$$$$
\text { Finish }
$$

OK

Figure 4.5 Final Data form 


\subsection{Data Structure}

The main data structure that is used within the program is a grid of points that are spread out over a spatial plane within the mine area. Data in this grid format are used for many of the input parameters, the internal representation and the final output of the program. Each input grid is created externally, either by using other modules of the stability mapping program or SurvCADD if available. The program output is in the same format as a SurvCADD grid and can be plotted using either of the two aforementioned programs (See Appendix A).

The grid is essentially a three dimensional array or mesh of points evenly spread over an area. Each point within the grid has a corresponding $\mathrm{x}, \mathrm{y}$, and $\mathrm{z}$ value. The $\mathrm{x}$ and $\mathrm{y}$ values give the location of the point within space and the $\mathrm{z}$ dimension carries the value at that point, be it a thickness, strength, CMRR, etc. The $\mathrm{x}$ and $\mathrm{y}$ values are evenly spaced. In the SurvCADD format, the distance between the $\mathrm{x}$ and $\mathrm{y}$ values can be different. The SurvCADD grid file starts with a header section that lists the location of the lower left corner and the upper right corner of the grid along with the size of the grid in both the $\mathrm{x}$ and $\mathrm{y}$ dimension. If more than one grid is used within the program, and this is how the program is designed to be used, the grids must be of the same size and contain the same base point (See Appendix A). The program is designed to check the location and size of each grid and will not let the user try to combine grids of a different size or location within the same working program.

There are many parameters within the CMRR program that have the option to enter the database in a grid format, as can be seen in Tables 3.1-3.3. This can be very useful, but if there are insufficient data available to create a grid, the program allows a single value to be used to populate a grid for that parameter as an average value for the 
entire area of interest. Although there are often large amounts of data available for some parameters, such as thickness and strength, others parameter have much more limited data. Based on our assumptions of available data sources, some parameters that are necessary to calculate the CMRR do not have the option for a grid to be input. Instead, an individual value must be used. If there appears to be a need for increasing the number of variables which allow grid input, it can easily be incorporated into the program.

\subsection{Unit Calculations}

In order to create a CMRR grid, the major components that make up the CMRR must be calculated. One of the most important building blocks of the CMRR is the unit rating. The unit ratings are based on data specific to each unit in the bolting horizon and are made up of various parameters that affect the overall strength. The data used in the unit rating calculations can come from either observational data or from drill core data. The observational data can be obtained from various sources such as roof falls, outcrops, or overcasts, whereas the core data would be gathered either from surface drilling such as exploration drilling or from underground drilling that is carried out during or immediately after development.

Before the unit ratings can be calculated, the data source must be chosen; either observation data or drill core data. Depending on the option chosen, different data will be needed to carry out the unit rating calculation process. The calculation process varies with respect to the data source and to whether or not grid data were entered. Within the program, different dialog boxes or windows will appear based on the choice of data source. Each of the dialog boxes has various edit boxes and pull-down menus that are to be filled out before the calculation of the unit rating can be completed. Each parameter 
used in the unit rating calculation is checked to ensure that there are not any values that are outside of the range of typical data. Once all of the necessary data are entered, the unit ratings are able to be calculated based on the data type and specific data. Once the unit calculations are complete, the rest of the global CMRR parameters can be entered and the final CMRR value or grid can be computed (See Figure 4.6).

\subsubsection{Observation Routines}

As stated above, observational data can be used to calculate the unit ratings for each unit in the bolting horizon of the area of interest. There are two separate processes by which the unit rating from observational data can be calculated. The first process calculates one unit rating based on data where a single value is used for each unit parameter. The second process utilizes the ability to enter a grid of points for the strength of the unit. For the second process, instead of calculating a single unit rating, a grid of unit rating values is created and subsequently used in the calculation of the CMRR.

The first calculation process based on individual values for all unit parameters is illustrated in Figure 4.7. The calculation procedure follows what was described in Chapter 2.2.8. The first step, once all data are entered, is determining the strength rating and moisture rating. The ratings are based on the input for the strength and moisture of the unit and Tables 2.4 and 2.5. 


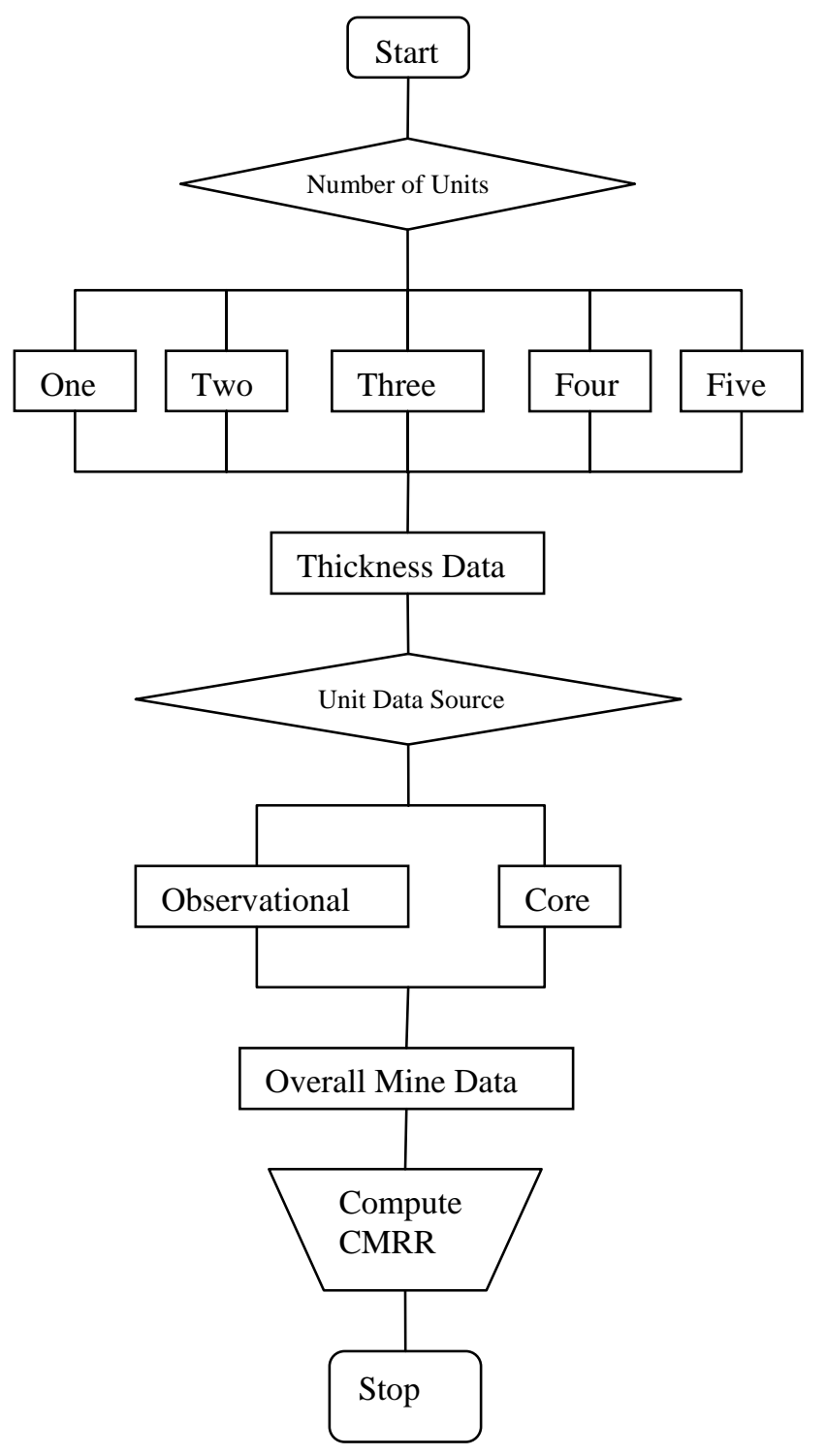

Figure 4.6 Flow chart of CMRR program

All of the tables used in the calculations are directly coded into the program and the rating and adjustment values are interpolated based on the values of the input parameters. The interpolation process will be discussed later in this chapter. When discontinuity sets are present, the adjustments for the roughness/cohesion and spacing/persistence are the next items to be calculated. Once complete, a discontinuity rating is calculated based on the two discontinuity factors for each discontinuity set. The 
discontinuity ratings are then sorted and used to determine a multiple discontinuity adjustment if more than one discontinuity set is present. Finally, the unit rating can be calculated based on the above ratings and adjustments.

If there are no discontinuity sets present, a discontinuity adjustment is determined based on the cohesion of the rock which makes up the unit. Once complete, the unit rating is calculated from the strength and moisture rating along with the discontinuity adjustment.

When a strength grid is to be used in the calculation of a unit rating, the process is similar to the above with a few exceptions (Figure 4.8). The first step, once all data are entered, is determining the strength rating. When discontinuity sets are present, the adjustments for the roughness/cohesion and spacing/persistence are the next items to be calculated. Once complete, a discontinuity rating is calculated based on the two discontinuity factors for each discontinuity set. The discontinuity ratings are then sorted and used to determine a multiple discontinuity adjustment if more than one discontinuity set is present. The next step is to loop over each of the points in the strength grid and determine a strength adjustment for each point. Finally, the unit rating can be calculated for each grid point based on the ratings and adjustments assigned to each individual point. The calculation is performed until strength ratings and unit ratings are determined for each and every point in the strength grid. The result is now a grid of unit ratings instead of one single unit rating. This grid will be used in the calculation of a grid of CMRR values later in the calculation process.

If there are no discontinuity sets present, a discontinuity adjustment is determined based on the cohesion of the rock which makes up the unit. Once complete, the strength rating is determined for each point on the strength grid and the unit rating is calculated 
for each point from the strength and moisture ratings along with the discontinuity adjustment. As in the previous paragraph, this results in a grid of unit ratings that will be used later on in the calculation process to create a grid of CMRR values.

\subsubsection{Core Data Routines}

As previously stated, drill core data can be used to calculate the unit ratings for each unit in the bolting horizon of the area of interest. There are two separate processes by which the unit rating from drill core data can be calculated. The first process calculates one unit rating based on data where a single value is used for each unit parameter. The second process utilizes the ability to enter a grid of points for one or more of the following parameters: the diametral PLT strength, RQD, discontinuity spacing, axial PLT, and axial UCS as shown in Table 3.2. Instead of calculating a single unit rating, a grid of unit rating values is created and used in calculating the CMRR.

The procedure for calculating a unit rating based on individual data values from core hole data is illustrated in Figure 4.9. The first step, once all data have been entered, is to determine the UCS rating based on either an axial PLT or a laboratory UCS. If an axial PLT has been used, this value must be multiplied by 21, as explained in Chapter 2, in order to be normalized to a UCS strength. Once the axial point load tests have been normalized, the UCS rating can be calculated either by using Eq. (2.1) if the UCS strength is less than or equal to 5,000 psi, or (2.2) if it is greater. 


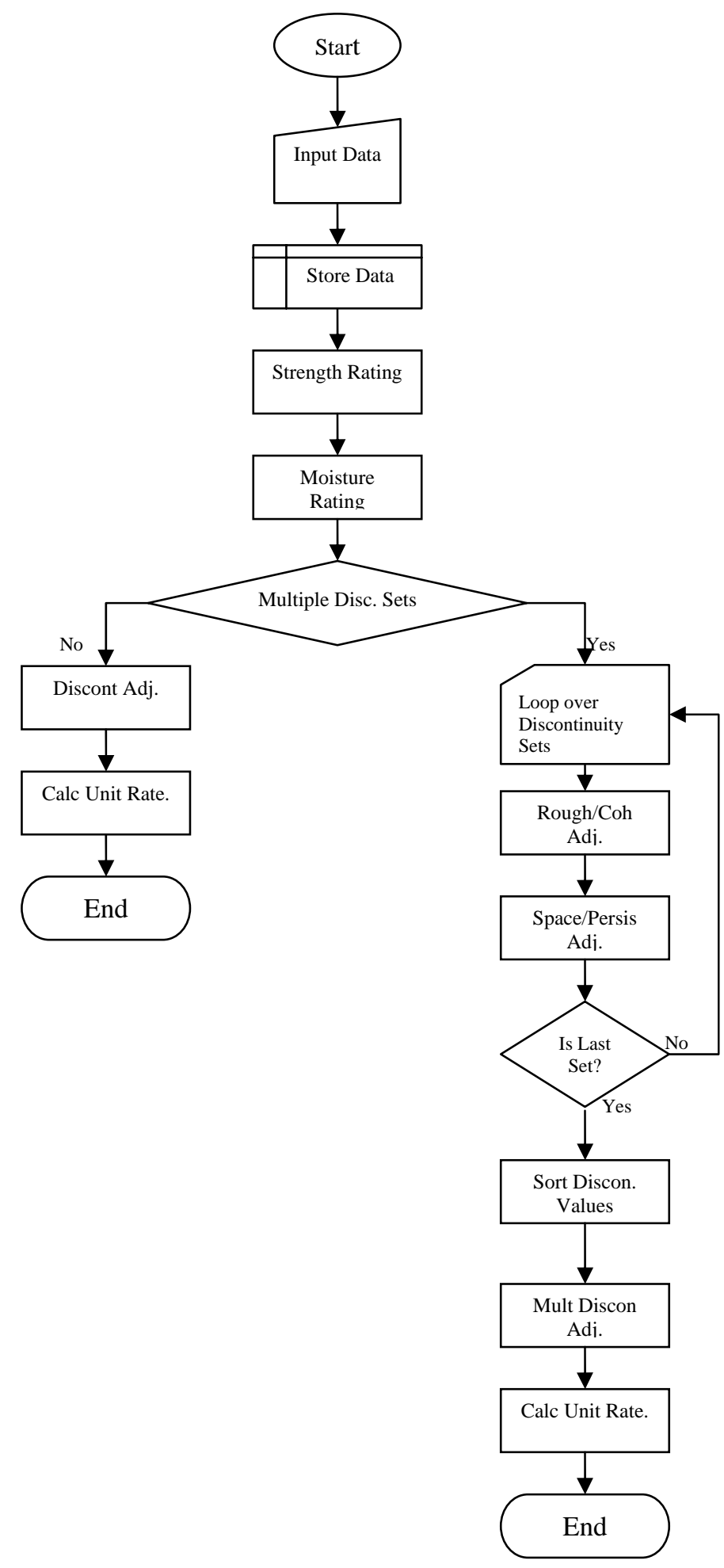

Figure 4.7 Unit rating calculation flow sheet for observation data with simple input 


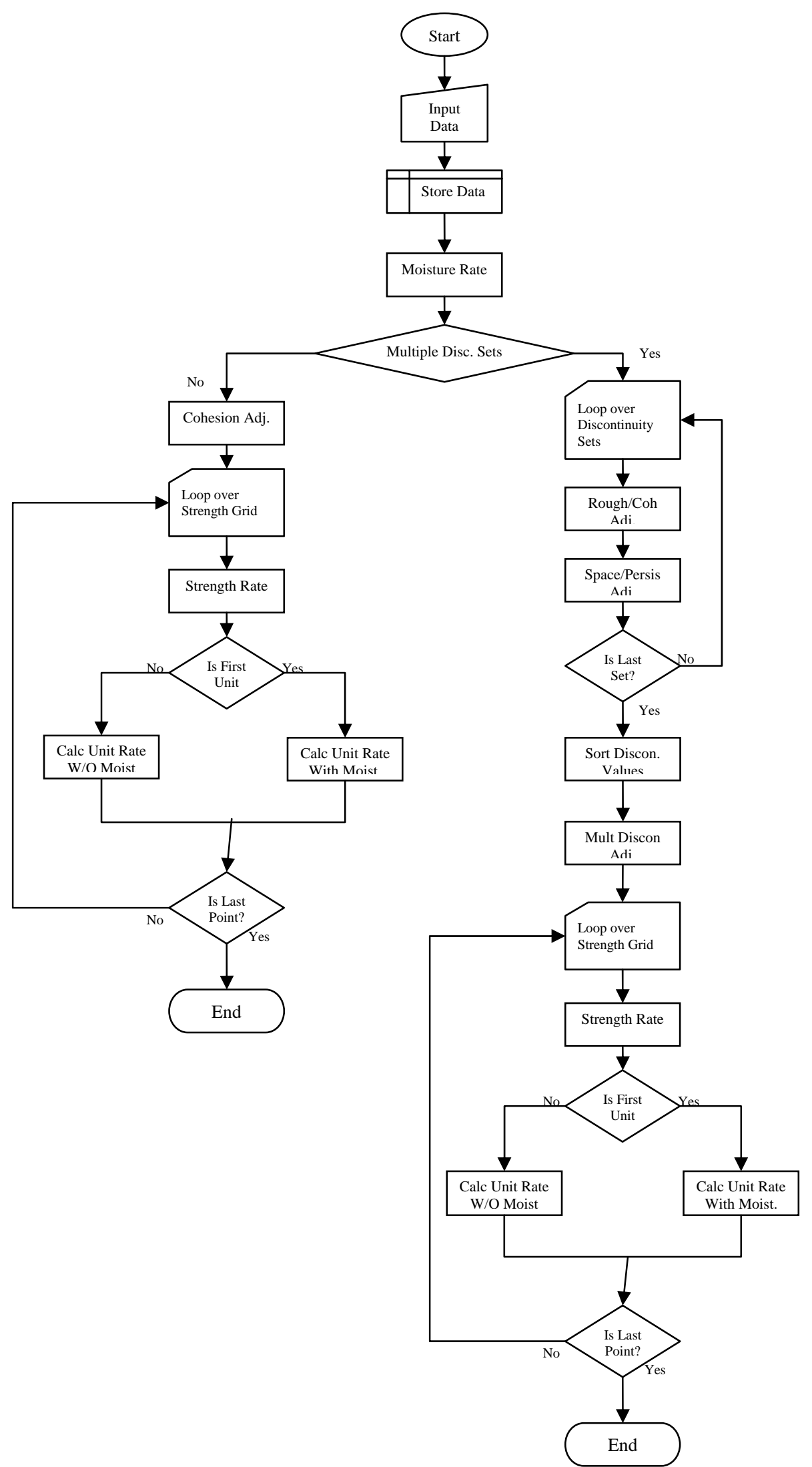

Figure 4.8 Unit rating calculation flow sheet for observation data with grid input 
Next, the discontinuity spacing rating is calculated based either on an RQD or fracture spacing. If an RQD value was given, Eq. (2.5) should be used and if a fracture spacing was given, Eq. (2.4) should be used. Once the discontinuity spacing rating is determined, the diametral rating can be found using the Equations $(2.6-2.9)$. If there are no data available for the diametral rating an estimate can be made. An estimate of weak, moderate, or strong can be input and converted to a rating value of 25, 36, or 48 respectively. The lower of both the discontinuity spacing rating and the diametral rating is used as the discontinuity rating. Finally, to calculate the unit rating, simply add the UCS rating to the discontinuity rating.

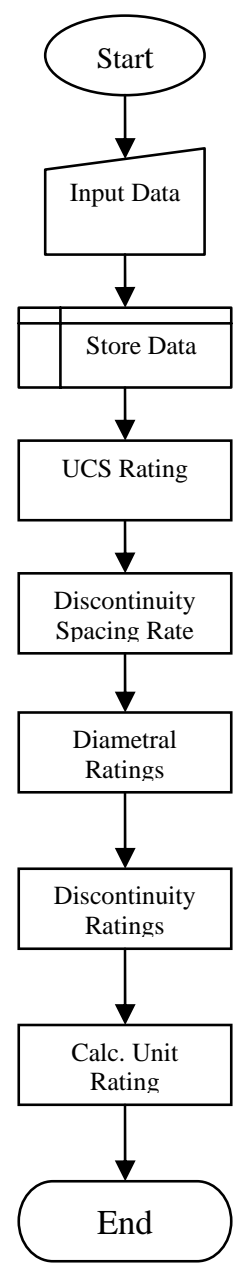

Figure 4.9 Unit rating calculation flow sheet for core hole data with simple input 
If grid values are available for any of the unit values listed in Table 3.2 under the grid column, then the calculation process must be altered from that described in the previous paragraph. Instead of calculating a unit rating for a single point one must be determined for each point on the grid as shown in Figure 4.10. If a particular factor such as the UCS rating is given an individual value but one of the other factors has a grid of data values then the single UCS rating will be used in the calculation of the unit rating for each point on the grid. Each factor that is used to calculate the unit rating is determined in the same manner as described in the previous paragraph but now it is carried out multiple times.

\subsection{CMRR Calculation Routines}

\subsubsection{CMRR Calculations for One Unit}

One of the most basic processes for calculating the CMRR is in the instance when only single point values are available and one unit is present in the bolting horizon (Figure 4.11). In this case there are only four factors that make up the CMRR. The first is the contact adjustment based on the contact strength with the rock above the unit, the second is the ground water adjustment, the third is the surcharge adjustment, and the fourth is the unit rating. These four factors are simply added together to determine the CMRR. 


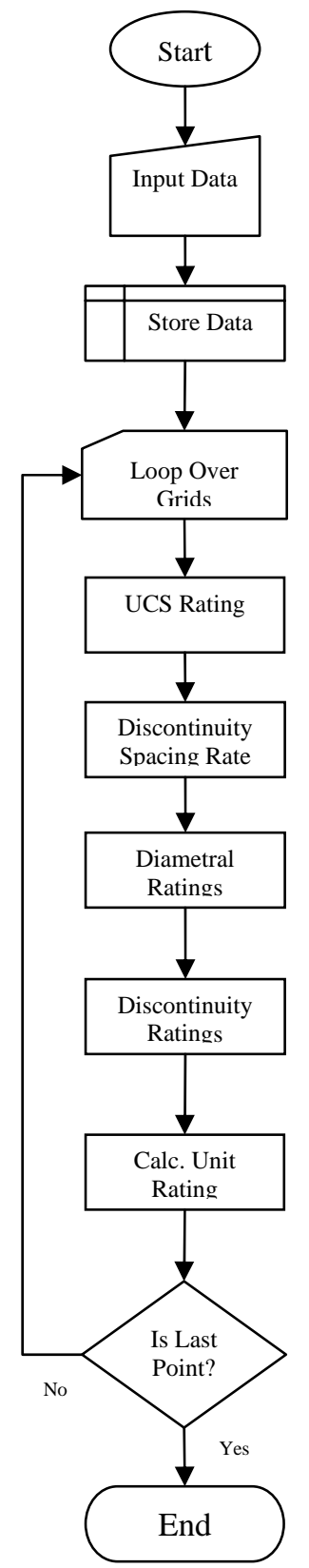

Figure 4.10 Unit rating calculation flow sheet for core hole data with grid input 


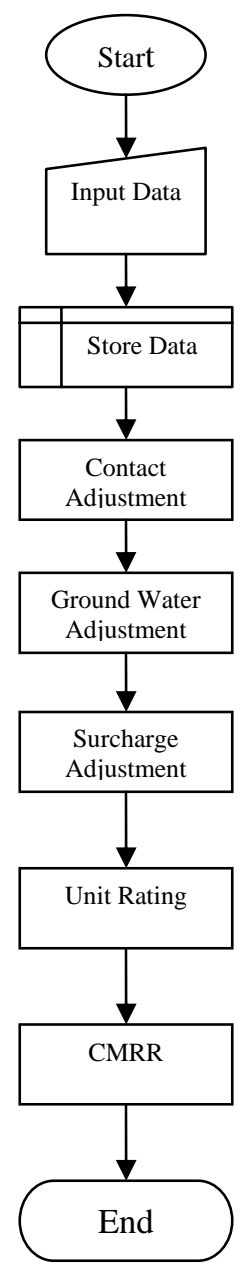

Figure 4.11 CMRR calculation flow sheet for simple input data and a single unit

When only a single unit is present but there is a grid of values for either the groundwater or the unit rating then the calculations must be looped over each of the grid points (Figure 4.12). This is similar to the unit rating calculations that were described when grid data were present. The contact adjustment, ground water adjustment, surcharge adjustment, and the unit rating are found for each point on the grid and added to determine the CMRR for that particular point. When complete, a grid of CMRR values is available for analysis. 


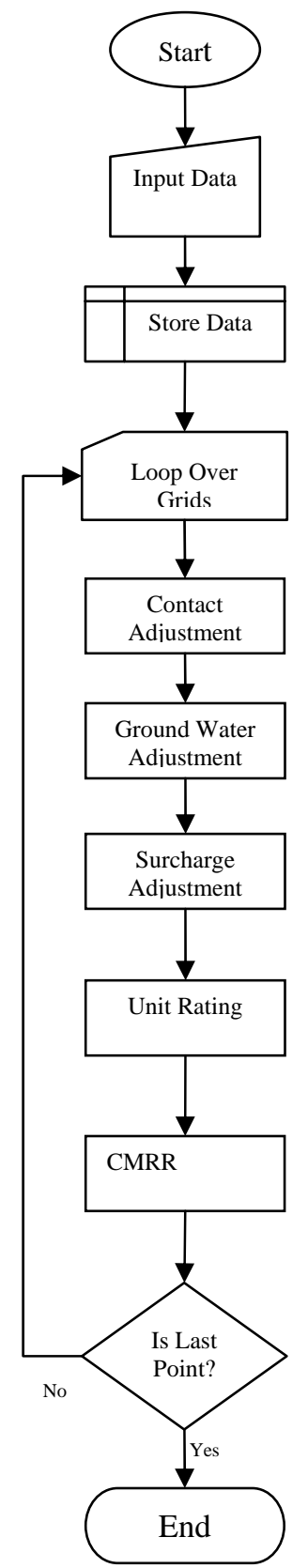

Figure 4.12 CMRR calculation flow sheet for grid input data and a single unit

\subsubsection{CMRR Calculations for Multiple Units}

When going through the process of determining a CMRR for a particular point in a mine by hand it is customary to be concerned only with the units within the bolting horizon. The length of bolt being used should end within the uppermost unit of concern. When implementing these steps into a computer program, one must account for the 
instance when the bolt is too long or too short for the total thickness of the units being used. If the bolt length is less than the total thickness of the units given, then the unit thickness used for the CMRR calculation should be modified for that particular point; the total thickness should be less in this instance. On the other hand, if the bolt is longer than the total thickness of the available units it should be assumed that the bolt is only as long as the total unit thickness. This assumption is made because when calculating a CMRR only the bolted interval is taken into consideration. For example, if data are given for 10 $\mathrm{ft}$. of roof strata and the bolt length is only $8 \mathrm{ft}$., the last two feet of rock are ignored in the calculation process. These types of occurrences need to be considered because there may not always be a case where the bolt stops in the last unit. This is particularly an item of concern when using a grid of thickness values to calculate the CMRR. The thickness of different units can vary widely over a large area and could result in many occurrences of the issues described above. Because the unit thickness for each unit and the length of bolt being used is known, it is possible to compare the two and make the appropriate changes in order to allow the calculation of the CMRR to be done correctly.

When calculating a CMRR with multiple units, either a single value is used for each factor or a grid of values is used for factors which can accept these data types. Although the two processes are similar, the first is the simpler of the two. This first process is illustrated in Figure 4.13 as a flow chart. The first step, once all data have been input and stored, is to compare the length of the bolt being used to the overall thickness of all of the units. This is done for the reasons explained in the previous paragraph. Once this is done, the unit weighted average, or RRw, can be calculated based on the determined bolt length and proper number of units to be used. Next, the strong bed difference and strong bed adjustment are found using the RRw and the 
strength and thickness of the strong bed as described in sections 2.3.4 and 2.2.9. The contact adjustment, ground water adjustment, and surcharge adjustment are then found using the tables described in section 4.4.1. Once complete, the final CMRR can be calculated by adding the RRw, strong bed adjustment, contact adjustment, ground water adjustment, and surcharge adjustment.

If a grid of unit ratings has been created or a grid of thickness values or ground water is entered into the program, the calculation process for determining the CMRR must be slightly changed. If a grid for one of the above values is used, then the CMRR must be calculated for each point on the grid. In this case, the steps described in the previous paragraph must be carried once for each point. This process is illustrated in Figure 4.14 as a flow chart. Creating a CMRR using grid data can be very useful in that it allows the user to take advantage of the best available data. Instead of interpolating between CMRR values that are created by using individual data points, the interpolation can be done on the individual factors that make up the CMRR. This helps to get a more accurate picture of CMRR values over a mine area.

\subsection{Major Secondary Support Routines}

The two previous sections describe the major calculations that are necessary to determine the unit ratings and CMRR. Although these two processes make up the main functional portion of the program, there are also smaller yet equally important functions that need to be discussed. These support functions make it possible for the unit ratings and CMRR to be calculated; without them, grid data would not be able to be used, adjustment arrays could not be interpolated, and the data that are input could not be saved. 


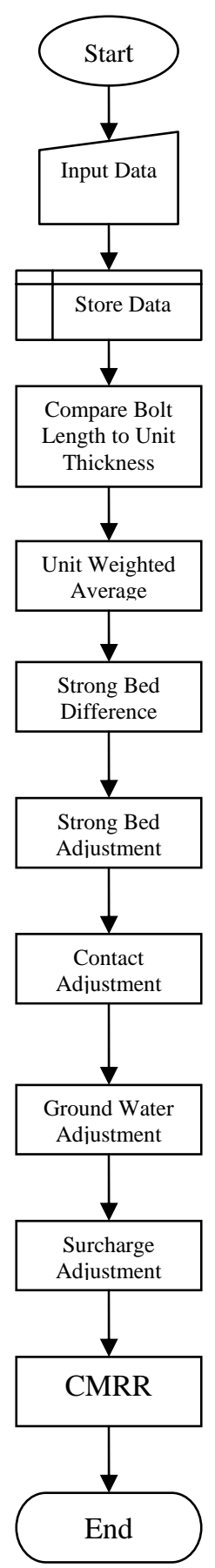

Figure 4.13 CMRR calculation flow sheet for simple input data and multiple units 


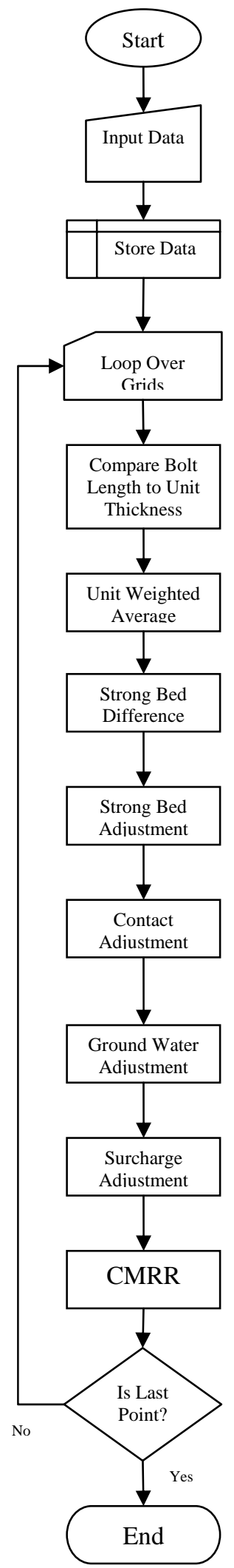

Figure 4.14 CMRR calculation flow sheet for grid input data and multiple units 
The first two support functions that will be discussed allow the program to interpolate values from both one and two dimensional arrays. Next, the process of reading and writing the grid files will be described. Finally, some information will be given regarding the working file that is used during operation of the program and that is saved to restart a previously created database.

\subsubsection{Utility Calculations}

In the previous sections, various flow sheets have been used to illustrate how each part of the CMRR is calculated. In many of these flow sheets, an adjustment or rating is determined in order to calculate some specific factor that makes up the CMRR. When the CMRR was initially designed, all of these adjustments and ratings were determined from Tables such as $2.1-2.10$ in Chapter 2. In order to use these tables in the program, each of them had to be input into either a one or two dimensional array. Tables such as 2.1, 2.2, and 2.6 were input as two dimensional arrays while the other tables were input as one dimensional arrays. The difficulty with using these tables directly is that they can only be referenced for round numbers within the table and not fractional values in between. This becomes a problem because within the program, a user can input any decimal or interpreted value for an input data factor as long as it is within the possible limits for that factor. When this full range of input occurs, the program must interpolate a value based on the known array data and the given discreet input.

For a single dimensional array, the interpolation process is very simple. A basic linear interpolation is carried out between the indexed input numbers and the associated result values by using the hard-wired one-dimensional array for whatever particular factor is needed and the number that is input by the user. The equation for the linear interpolation is given in Eq. (4.1). The equation stays the same for interpolating different 
factors, but the values that the variables reference change. The Xval variable represents the value or an interpretation of the value input by the user of the program. This value is then compared to the index data that are hard-wired into the appropriate array to obtain the values of Xmax, Xmin, Ymax, and Ymin. Xmax and Xmin are the closest index values greater than the input index and the closest index value than Xval in the correct array. Ymax and Ymin are the result values that correspond to index values of Xmax and Xmin. From these four values and the data given by the user, an interpolated adjustment or rating can be determined through the use of Eq. (4.1).

$$
Y_{v a l}=Y_{\max }-\left[\frac{\left(X_{\max }-X_{v a l}\right) *\left(Y_{\max }-Y_{\min }\right)}{X_{\max }-X_{\min }}\right]
$$

In the instance that interpolation must be done on a two dimensional array, the process is analogous, but a little more complex than that of a one dimensional array. For a two dimensional case it is assumed that we have a matrix of functional values $\mathrm{za}[1 . . \mathrm{m}][1 . . \mathrm{n}]$ and arrays $\mathrm{xa}[1 . . \mathrm{m}]$ and $\mathrm{ya}[1 . . \mathrm{n}]$ which are related to an underlying function represented by Eq. (4.2) (Vetterling et al., 1992).

$$
z a[j][k]=z(x a[j], y a[k])
$$

The goal of the interpolation is to find the value of a function $\mathrm{z}$ at some $(\mathrm{x}, \mathrm{y})$ location. In order to better understand this method the concept of the grid square can be used where the point $(\mathrm{x}, \mathrm{y})$ is the desired value and the four points surrounding that value are used to determine such value. The four points can be equated by referencing them to the value of the desired point as shown in Eq. (4.3) through (4.8) (Vettering et al., 1992). 
Equations (4.3) and (4.4) define the values of J and $\mathrm{K}$ whereas Eq. (4.5) through (4.8) define the $\mathrm{z}$ values at each of the four corner points around point $(\mathrm{x}, \mathrm{y})$.

$$
\begin{gathered}
x a[j] \leq x \leq x a[j+1] \\
y a[k] \leq y \leq y a[k+1] \\
z_{1} \equiv z a[j][k] \\
z_{2} \equiv z a[j+1][k] \\
z_{3} \equiv z a[j+1][k+1] \\
z_{4} \equiv z a[j][k+1]
\end{gathered}
$$

Once all of the values around the desired point are defined and can be referenced with regard to that point, bilinear interpolation can be used to find its value. The three equations that are used to carry out the interpolation are given in Eq. (4.9) through (4.11) (Vettering et al., 1992). In this application $\mathrm{z}_{1}, \mathrm{z}_{2}, \mathrm{z}_{3}$, and $\mathrm{z}_{4}$ are the representation of the values within the two dimensional array at a given point around the value at $(\mathrm{x}, \mathrm{y})$. The final Eq. (4.11) brings all of the previous ones together. Each of the four parts of Eq. (4.11) accounts for one of the four corner points around the desired answer. In this manner, each point is given an influence on the final interpolated value dependent upon the proximity of $(\mathrm{x}, \mathrm{y})$ to that point.

$$
t=\frac{x-x a[j]}{x a[j+1]-x a[j]}
$$




$$
\begin{gathered}
u=\frac{y-y a[k]}{y a[k+1]-y a[k]} \\
z(x, y)=\left((1-t) *(1-u) * z_{1}\right)+\left(t *(1-u) * z_{2}\right)+\left(t * u * z_{3}\right)+\left((1-t) * u * z_{4}\right)
\end{gathered}
$$

Without the ability to interpolate one and two dimensional arrays it would be impossible to write a program that allowed the user to input unlimited data values for a certain input factor within the limits of that factor. If this were the case it would limit the versatility of the program and limit the creativity of the user. In this instance the user would only be able to input data that corresponded to an exact point within one of the various adjustment or rating arrays.

\subsubsection{Grid Read and Write}

In previous sections, it was mentioned that SurvCADD grids can be used as an input data type for a number of factors. When a user desires to take advantage of this feature, each grid must be read into the program individually. In order to do this a browse window (see Appendix B), is used to choose the grid file from a specified directory to be read into the program.

The program goes through a number of steps to ensure that the grid being read is valid and the data that it contains are within the limits of the factor to which it is being applied (Figure 4.15). The first error check that is undertaken when reading a grid is to check the size and location of the grid within a spatial plane. If this is the first grid that is read into the program, the location and size will be stored and each grid thereafter will be compared to the first to ensure that each and every gird is of the same size and location. Obviously, many of the grid calculations can only be performed when the grids are the 
same size. The second error check is to analyze the data values being read into the program. Various factors such as RQD, groundwater, and thickness have upper and lower limits that cannot be breached in order for the program to run properly. Because of this, each point that is read from the grid is compared to the bounds for the type of factor to which the data are going to be applied. Along with this, each point on the grid is checked to make sure that its value is not a null value and that it is also not a negative value. If any error values are found, an error will be presented to the user, but in most instances the program will still proceed.

As the data are being checked for validity, each point is being stored in a working array. The size of the array is determined by the size of the grid and adjusted to each grid individually. The working array is not saved after the program is closed because so much information would need to be stored if multiple grids are used. Instead, when the user opens a saved data set, each grid is read into the program from its stored file location and the data are stored in a new working array. If the location of the grid file within the user's computer has changed since the program was last saved, an error will be given and the user can select a new grid file name or location.

As stated earlier, the main advantage to this program is the ability to input data in a grid format, and to also output final results in the same format. It is possible to create both a CMRR grid and a unit grid based on data that the user puts into the program. The grid files that are output by the program must be able to be read by SurvCADD; therefore they are of the same format and type. In the previous paragraphs it was mentioned that each point that is read into the program must be checked for validity and quality. The same statement holds true for the data that are contained within the grids that are output by the program. If a point from a grid is input into the program and determined to be out 
of range then a CMRR or unit rating value for that point will most likely not be able to be calculated. In this situation, a null value is assigned to the location of the out-of-range data point. The null character is capable of being read by SurvCADD and does not affect the values surrounding its location. Grids that are created by this program can be manipulated by SurvCADD like any other SurvCADD grid which allows the user to create isopachs and use other various utilities to manipulate and view the data.

The application of SurvCADD grids to the CMRR is what separates this program from those that have preceded it. Because of this, great care was taken to ensure that all data read into the program in a grid format is as accurate and valid as can be determined. By using data in this format the CMRR can be applied over a large area with less work and hopefully more accurate application.

\subsubsection{Working File Read and Write}

Like any other program, this program is capable of saving the data that are entered into it and also able to read those data back into the program at a later date. The file that the data are stored in is a simple text file that can be read by any number of word editing or processing programs. Although the working file is simple, it is dynamic in its nature. Depending on what kinds of data are being entered, be it drill core data or observation data, the structure of the file changes. Within the file itself there are flags that are saved, and when read by the program they tell the program what type of data are coming next. This dynamic type of data storage allows for a smaller data file with no null or blank values. 


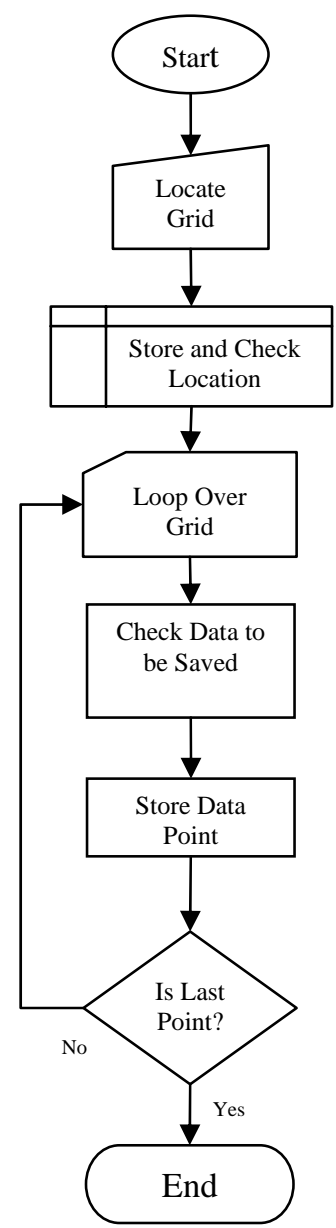

Figure 4.15 Grid read and write flow sheet

As was mentioned in the previous section, the grid files are not saved within the working file. Instead, the locations of the grid files are saved so that they may be retrieved when all of the working file data are read into the program. The reason for doing this was to limit the size of the working file in order to increase the ease and speed at which the file is read into the program. An example of a working file can be found in Figure 4.16. Here we can see the different locations of the grids used in this example along with the other data that was entered. Many of the ones and zeroes at the beginnings of each line represent the flags that tell the program what type of data are going to come next. This allows the program to know where to store each piece of information. 
Although simple, the working file is an extremely important and necessary part of any good program. Without it the user would not be able to save the work that they have completed or subsequently retrieve it in the future.

\section{SimpleGridCore1.cmr}

\section{3,1}

1,C:I TestThick.grd

1 ,

0,1,C:ITestDiam.grd

$0,1, C: I T e s t R Q D . g r d$

1,1,C:ITestAxialUCS.grd

1.0 Not Sensitive

0

1,C:ITestThick.grd

1 ,

0,1,C:ITestDiam2.grd

0,1,C:ITestRQD2.grd

1,1,C:ITestAxialUCS2.grd

1.0 Not Sensitive

0

1,C:IITestThick.grd

1 ,

0,1,C:ITestDiam3.grd

0,1,C:ITestRQD3.grd

1,1,C:I TestAxialUCS3.grd

1.0 Not Sensitive

0

0

1.0 Dry

1.0 Unit above bolted interval is equal in strength to the bolted unit

6.000000

Figure 4.16 Working file example 


\section{Chapter 5}

\section{Program Verification}

\subsection{Introduction}

With any newly developed software, a process of evaluation and testing is necessary to determine the accuracy of the output and the validity of the computer code. This chapter is a verification of the CMRR program's accuracy when compared to thorough hand calculations. More complex examples using grid input data will be covered to help ensure that there are no errors in the calculation process. Multiple data sources and data types will be entered into the program and the output checked against known values. Although tedious and time consuming, this is to ensure that the calculations being performed and the data being created by the program are true and accurate with regard to the design.

\subsection{CMRR Program Verification}

In the following section, two separate test cases will be evaluated and the output of each compared to a hand calculation for verification. The values that are used as input have been chosen so that a thorough evaluation of the program may be carried out. Because there are so many possible variations of program input for the CMRR program it was necessary to attempt to verify as many different calculations as possible in each test case. In the following sections, two test cases using both grid data and point data are evaluated. With each case, as many variables as possible are verified to ensure that the program output is accurate and detailed. Both underground and core data will be evaluated, and for each, individual data input and grid input will be used. 
The first test is to determine how well the program calculates a CMRR based on observation data. The bolting horizon will be broken into three units and grids will be used for both the thickness and the strength of each of the units. Point data will be input for all other parameters. In order to be able to calculate the CMRR by hand, individual point values from both the thickness grid and strength grid were used to determine the CMRR for that point. All of the input data used for the hand calculation are listed in Tables 5.1 and 5.2. The input factors for the strength and discontinuity data were chosen so that the programs one and two-dimensional interpolation functions would be exercised, and also evaluated through the hand calculations.

Table 5.1 Observation test data

\begin{tabular}{|l|c|c|c|}
\cline { 2 - 4 } \multicolumn{1}{c|}{} & Unit 1 & Unit 2 & Unit 3 \\
\hline Thickness(ft) & 1.00 & 2.00 & 3.00 \\
\hline Strength (UCS) & 16000 & 5000 & 10000 \\
\hline \# Discontinuities & 1 & 1 & 1 \\
\hline Cohesion & 1.75 & 2.25 & 3.25 \\
\hline Roughness & 1.75 & 2.25 & 3.00 \\
\hline Spacing & 1.75 & 2.25 & 3.25 \\
\hline Persistence & 1.75 & 2.25 & 3.00 \\
\hline Moisture Sensitivity & 1.00 & 2.25 & 1.00 \\
\hline Contact Strength & Strong & Strong & Strong \\
\hline
\end{tabular}

Table 5.2 Data for overall mine

\begin{tabular}{|l|l|}
\hline \multicolumn{2}{|c|}{ Mine Data } \\
\hline Groundwater & 1 \\
\hline Surcharge & 1 \\
\hline Bolt Length (ft) & 6 \\
\hline
\end{tabular}

Also, in this case the ground water adjustment was set to 1 or dry and the surcharge adjustment was set so that the unit above the bolted interval was stronger or equal in strength to the uppermost unit (see Table 5.2). The bolt length chosen for this test was $6 \mathrm{ft}$. The hand calculations, using Eqs. (4.1) through (4.11), resulted in the interpolated values for the roughness-cohesion and the spacing-persistence ratings shown in Tables $5.3-5.5$. The $\mathrm{z}(\mathrm{x}, \mathrm{y})$ in each table represents the adjustment factor for each 
unit in the bolting horizon. The cohesion-roughness and spacing-persistence adjustments are added together to determine the discontinuity rating for each unit (see Table 5.6).

Table 5.3 Unit 1 interpolated values

\begin{tabular}{|l|c|l|c|}
\hline \multicolumn{4}{|c|}{ Unit 1 } \\
\hline Coh-rough & & Space-Persis & \\
\hline $\mathrm{x}$ & 1.75 & $\mathrm{x}$ & 1.75 \\
\hline $\mathrm{y}$ & 1.75 & $\mathrm{y}$ & 1.75 \\
\hline $\mathrm{xa}[\mathrm{j}]$ & 1 & $\mathrm{xa}[\mathrm{j}]$ & 1 \\
\hline $\mathrm{xa}[\mathrm{j}+1]$ & 2 & $\mathrm{xa}[\mathrm{j}+1]$ & 2 \\
\hline $\mathrm{ya}[\mathrm{k}]$ & 1 & $\mathrm{ya}[\mathrm{k}]$ & 1 \\
\hline $\mathrm{ya}[\mathrm{k}+1]$ & 2 & $\mathrm{ya}[\mathrm{k}+1]$ & 2 \\
\hline $\mathrm{t}$ & 0.75 & $\mathrm{t}$ & 0.75 \\
\hline $\mathrm{u}$ & 0.75 & $\mathrm{u}$ & 0.75 \\
\hline $\mathrm{z}(\mathrm{x}, \mathrm{y})$ & $\mathbf{2 9 . 3 7 5}$ & $\mathrm{z}(\mathrm{x}, \mathrm{y})$ & $\mathbf{2 9 . 0 0 0}$ \\
\hline
\end{tabular}

Table 5.4 Unit 2 interpolated values

\begin{tabular}{|l|c|l|c|}
\hline \multicolumn{4}{|c|}{ Unit 2 } \\
\hline Coh-rough & & Space-Persis & \\
\hline $\mathrm{x}$ & 2.25 & $\mathrm{x}$ & 2.25 \\
\hline $\mathrm{y}$ & 2.25 & $\mathrm{y}$ & 2.25 \\
\hline $\mathrm{xa}[\mathrm{j}]$ & 2 & $\mathrm{xa}[\mathrm{j}]$ & 2 \\
\hline $\mathrm{xa}[\mathrm{j}+1]$ & 3 & $\mathrm{xa}[\mathrm{j}+1]$ & 3 \\
\hline $\mathrm{ya}[\mathrm{k}]$ & 2 & $\mathrm{ya}[\mathrm{k}]$ & 2 \\
\hline $\mathrm{ya}[\mathrm{k}+1]$ & 3 & $\mathrm{ya}[\mathrm{k}+1]$ & 3 \\
\hline $\mathrm{t}$ & 0.25 & $\mathrm{t}$ & 0.25 \\
\hline $\mathrm{u}$ & 0.25 & $\mathrm{u}$ & 0.25 \\
\hline $\mathrm{z}(\mathrm{x}, \mathrm{y})$ & $\mathbf{2 4 . 6 2 5}$ & $\mathrm{z}(\mathrm{x}, \mathrm{y})$ & $\mathbf{2 5 . 0 6 3}$ \\
\hline
\end{tabular}

Table 5.5 Unit 3 interpolated values

\begin{tabular}{|l|c|l|c|}
\hline \multicolumn{4}{|c|}{ Unit 3 } \\
\hline Coh-rough & & Space-Persis & \\
\hline $\mathrm{x}$ & 3.00 & $\mathrm{x}$ & 3.00 \\
\hline $\mathrm{y}$ & 3.25 & $\mathrm{y}$ & 3.25 \\
\hline $\mathrm{xa}[\mathrm{j}]$ & 3.00 & $\mathrm{xa}[\mathrm{j}]$ & 3.00 \\
\hline $\mathrm{xa}[\mathrm{j}+1]$ & 3.00 & $\mathrm{xa}[\mathrm{j}+1]$ & 3.00 \\
\hline $\mathrm{ya}[\mathrm{k}]$ & 3.00 & $\mathrm{ya}[\mathrm{k}]$ & 3.00 \\
\hline $\mathrm{ya}[\mathrm{k}+1]$ & 4.00 & $\mathrm{ya}[\mathrm{k}+1]$ & 4.00 \\
\hline $\mathrm{t}$ & 0.00 & $\mathrm{t}$ & 0.00 \\
\hline $\mathrm{u}$ & 0.25 & $\mathrm{u}$ & 0.25 \\
\hline $\mathrm{z}(\mathrm{x}, \mathrm{y})$ & $\mathbf{1 4 . 5 0 0}$ & $\mathrm{z}(\mathrm{x}, \mathrm{y})$ & $\mathbf{1 8 . 2 5 0}$ \\
\hline
\end{tabular}

Comparing each unit rating showed a perfect match between the hand calculations and the program calculations. The resulting unit ratings were 88.38, 67.59, and 58.03, respectively, as shown in Table 5.6. Due to this match it would be a fair conclusion to assume that the program is also interpolating the values in Tables $5.3-5.5$ correctly. Each of the ratings and adjustments (Table 5.6) were checked by hand to make sure that the program was using the correct logic and equations for interpolating each of the values. The CMRR program resulted in a final CMRR value of 68.64. When the same calculation was done by hand using the regression-based strong bed adjustment formula, Eq. (2.10), and the interpolation Eqs. (4.1) through (4.11), the final CMRR was also found to be 68.64 (see Table 5.7). Because the CMRR values were found to be equal it 
can be assumed that the thickness-weighted average (RRw), strong bed difference (SBD), and strong bed adjustment (SBADJ) were correctly calculated by the program.

Table 5.6 Unit adjustment values

\begin{tabular}{|l|c|c|c|}
\hline & Unit 1 & Unit 2 & Unit 3 \\
\hline Discontinuity rating & 58.38 & 49.69 & 32.75 \\
\hline Strength rating & 30.00 & 17.90 & 25.28 \\
\hline Moisture Adj. & 0.00 & 0.00 & 0.00 \\
\hline UR & $\mathbf{8 8 . 3 8}$ & $\mathbf{6 7 . 5 9}$ & $\mathbf{5 8 . 0 3}$ \\
\hline
\end{tabular}

Figure 5.7 CMRR calculation values
\begin{tabular}{|l|c|}
\hline RRW & 66.27 \\
\hline SBD & 22.10 \\
\hline SBADJ & 2.36 \\
\hline CMRR & $\mathbf{6 8 . 6 4}$ \\
\hline
\end{tabular}

The preceding example shows that the CMRR program is capable of correctly calculating both the unit ratings and CMRR values when observational data are used as input. Both point data and grid data were used in the example in an attempt to fully exercise as many functions as possible within the program. Although only one point on the grid was check by hand, the same logic and equations will be used by the program for each point, resulting in correct calculations for the entire grid area.

The second test to be performed will evaluate the program's ability to calculate a CMRR based on drill core data. The input data are similar to that of the first case in that the bolting horizon will be broken into three units and grid data will be used for the thickness, axial UCS, diametral strength, RQD, and groundwater. Point data will be used for the remaining input factors. A single grid point will be selected for the hand calculations so that the program logic may be verified. The input data that were used for the hand calculations is illustrated in Tables 5.8 and 5.9. 
Table 5.8 Core Test Data

\begin{tabular}{|l|c|c|c|}
\cline { 2 - 4 } \multicolumn{1}{c|}{} & Unit 1 & Unit 2 & Unit 3 \\
\hline Thickness(ft) & 1 & 2 & 3 \\
\hline Axial UCS & 4000 & 15000 & 25000 \\
\hline Diametral PLT & 30 & 150 & 250 \\
\hline Diametral Estimate & N/A & N/A & N/A \\
\hline Moisture Sensitivity & 1 & 1 & 1 \\
\hline RQD\% & 50 & 75 & 80 \\
\hline Discontinuity Spacing(in) & N/A & N/A & N/A \\
\hline Contact Strength & Strong & Strong & Strong \\
\hline
\end{tabular}

Table 5.9 Data for overall mine

\begin{tabular}{|l|l|}
\hline \multicolumn{2}{|c|}{ Mine Data } \\
\hline Groundwater & 2 \\
\hline Surcharge & 2 \\
\hline Bolt Length (ft) & 6 \\
\hline
\end{tabular}

In this case, the ground water adjustment value was entered as a grid of values in an effort to exercise more of the program's capabilities. Also, the surcharge adjustment was set so that the unit above the bolted interval was weaker in strength when compared to the uppermost unit. The last piece of input data, the bolt length, were once again set to $6 \mathrm{ft}$.

For each unit, the rating for the UCS, diametral strength, and discontinuity spacing was calculated by hand from Eqs. (2.1) through (2.9) (see Figure 5.10). The unit rating was then calculated by adding the lower of the diametral and discontinuity spacing rating to the UCS rating. In comparing the unit ratings calculated by hand to those calculated by the program it was found that the values matched exactly for each unit. Therefore, the program is correctly calculating the UCS rating, diametral rating, and discontinuity spacing rating, along with using the correct logic for determining the unit rating. The next step was to determine the CMRR from hand calculations and compare it to the value output by the program. Table 5.11 details the values resulting from the process of calculating the CMRR by hand. The final CMRR was then determined by 
simply adding the first five values in Table 5.12. This resulted in a CMRR value of 53.66, which matched the value calculated by the program for the grid point selected.

Table 5.10 Unit rating values

\begin{tabular}{|l|c|c|c|}
\hline & Unit 1 & Unit 2 & Unit 3 \\
\hline UCS rating & 11.00 & 23.20 & 30.00 \\
\hline Diametral rating & 25.00 & 41.60 & 53.50 \\
\hline Discontinuity spacing rating & 29.48 & 33.73 & 34.41 \\
\hline Unit rating & $\mathbf{3 6 . 0 0}$ & $\mathbf{5 6 . 9 3}$ & $\mathbf{6 4 . 4 1}$ \\
\hline
\end{tabular}

Table 5.11 CMRR calculation values

\begin{tabular}{|l|r|}
\hline RRw & 57.18 \\
\hline SBD & 7.23 \\
\hline SBADJ & 1.98 \\
\hline Groundwater & -2.00 \\
\hline Surcharge & -3.5 \\
\hline CMRR & $\mathbf{5 3 . 6 6}$ \\
\hline
\end{tabular}

\subsection{Summary}

After comparing the CMRR program to hand calculations for both underground observation data and the core hole data it would be fair to say that the program is both easy to use and accurate in its calculation. The program has the ability to properly interpolate the adjustment and rating tables within the program and to do this with both grid and point data. All of the logic and decisions that are necessary to calculate the CMRR seem to be properly programmed into the various functions within the programs $\mathrm{C}++$ code. Both the grid read and write functions operate correctly allowing the user to take advantage of data that may be stored in a geologic model and to graphically plot the output CMRR grid or use it within a stability map.

As with any geostatistical calculation, the output of the program is completely dependent on the quality of the input data. That being said, one should strive to update the input data for the program as more becomes available throughout the mining process. 


\section{Chapter 6}

\section{Case Study}

\subsection{Introduction}

In order to identify any bugs, shortcomings or additional needs of a new system or program it is desirable to evaluate it through the use of a real world example. In the following chapter, a case study example is illustrated and details how one might use the CMRR program in combination with a stability mapping program to gain additional knowledge about the mining conditions that are present at a particular location.

As has been mentioned previously, stability mapping is not a new concept, although the methods that can now be used to create a stability map have changed considerably over the years. Most recently, a stability mapping system was created by West Virginia University that allows the user to input various geologic and geotechnical data through an AutoCAD interface (Wang and Heasley, 2005). This program is capable of combining mining data such as: multiple-seam and overburden stress, through the use of a boundary element program, LaModel; influence of immediate roof and other various features that would cause mining conditions to be influenced into a stability map that is easy to calculate, read and interpret (Heasley and Agioutantis, 2001; Heasley, 1998). The following case study will use both the CMRR program as part of this thesis work and the stability mapping program created previously, in order to evaluate the mining conditions at the test mine location. 


\subsection{Case Study}

\subsubsection{Background}

The mine site chosen for this study is located in West Central CO, east of Paonia, Figure 6.1, and extracts coal from the Upper B Seam which is part of the Somerset Coal Field (Stewart et al., 2006). The Somerset Coal Field lies on the southeastern margin of the Piceance Basin, which lies north of the Gunnison Uplift, west of the Elk Mountains, east of the Uncompahgre Uplift, and south of the White River Uplift (Stewart et al., 2006). Presently there are an estimated 1.5 billion tons of bituminous coal within the Somerset Coal Field.

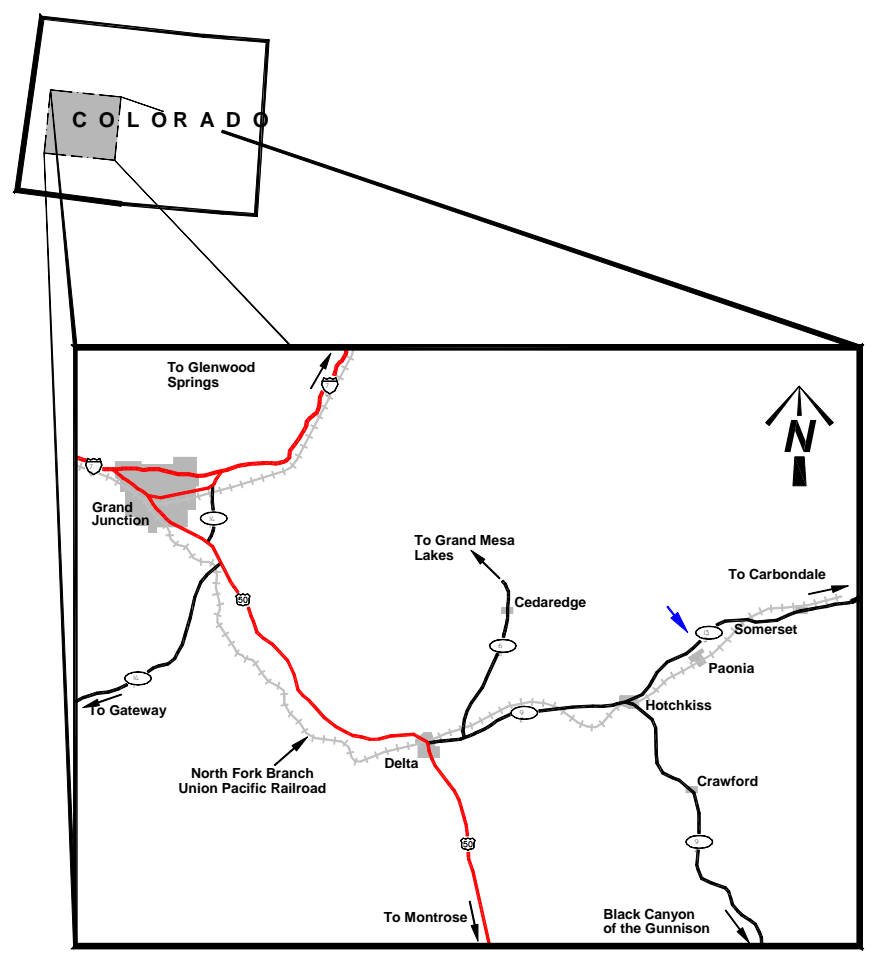

Figure 6.1 Mine location (after Stewart et al., 2006)

In preparation for development of the southwest district mine site, Figure 6.2, it was decided that a stability map, along with a CMRR map, would be created based on previously determined geotechnical data. Through their experience, the mine personnel 
had determined that there were eight major factors that influenced the mining conditions (see Table 6.1).

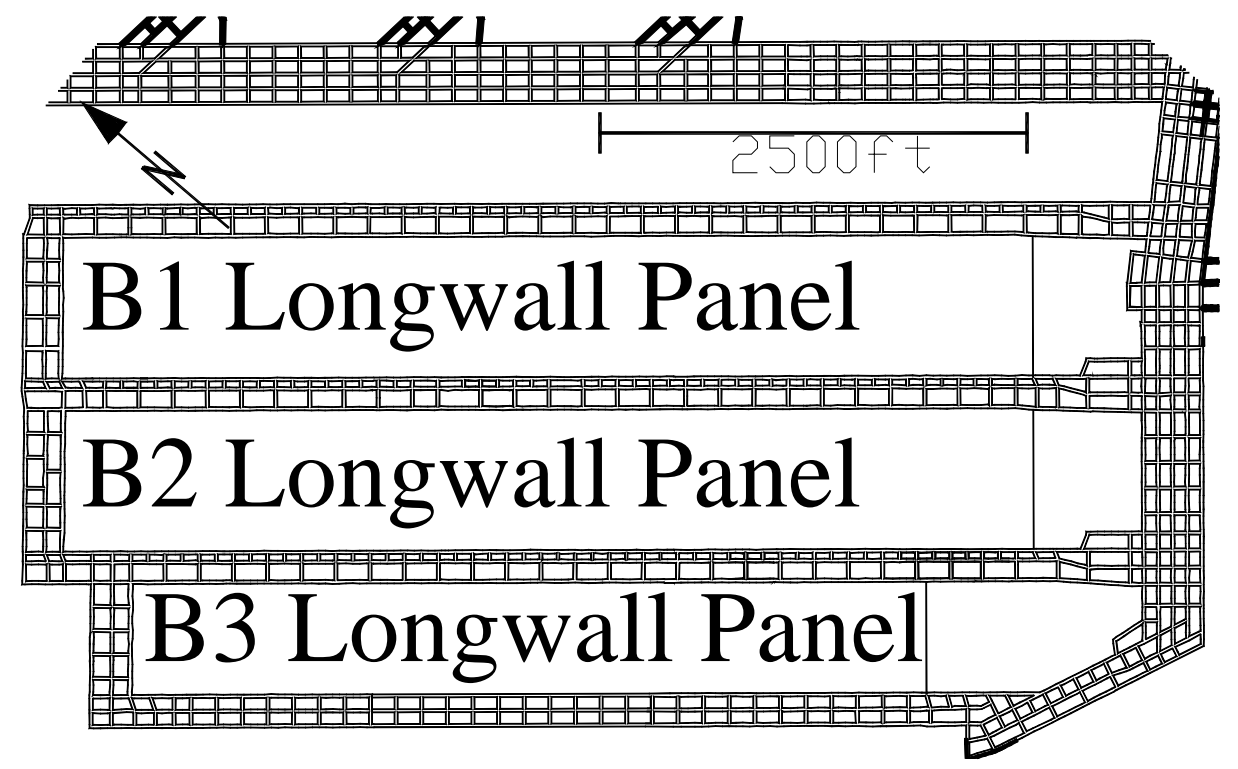

Figure 6.2 Southwest mining district longwall panels

Out of the eight critical factors, four were found to have the most influence on the mining process. These four factors include the overburden stress, CMRR, interburden thickness, and major faults.

Table 6.1 Critical Factors ( Stewart et al., 2006)
\begin{tabular}{|c|c|}
\hline Critical Factor & Final Weighting \\
\hline Overburden Stress & 20 \\
\hline Multiple-Seam Stress & 15 \\
\hline CMRR & 20 \\
\hline Sandstone Channels & 10 \\
\hline Interburden Thickness & 20 \\
\hline Faults & 20 \\
\hline Slumps & 10 \\
\hline Warps & 5 \\
\hline
\end{tabular}

The overburden in the southwest mining district varies from a minimum of $400 \mathrm{ft}$. of cover in the south to a maximum of around $1500 \mathrm{ft}$. in the north (see Figure 6.3). Prior to the development of the mine in the B seam, a longwall mine was completed in the D seam which is located approximately $250 \mathrm{ft}$. above the B seam (see Figure 6.3). Within the southwest mining district a rider coal seam exists. On the eastern side of the mine the 
rider is separated from the main B seam by interburden, Figure 6.4, but gradually becomes closer as you move to the west, until it joins with the B seam.

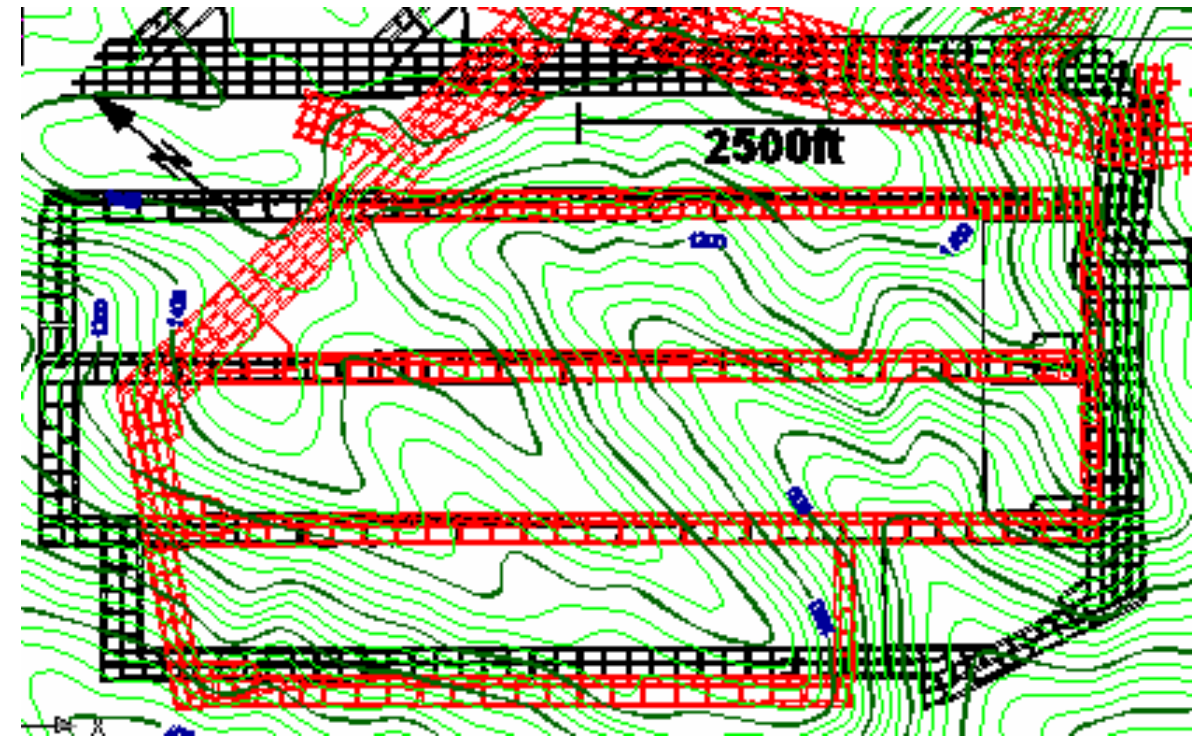

Figure 6.3 Topography over B and D seam pillars

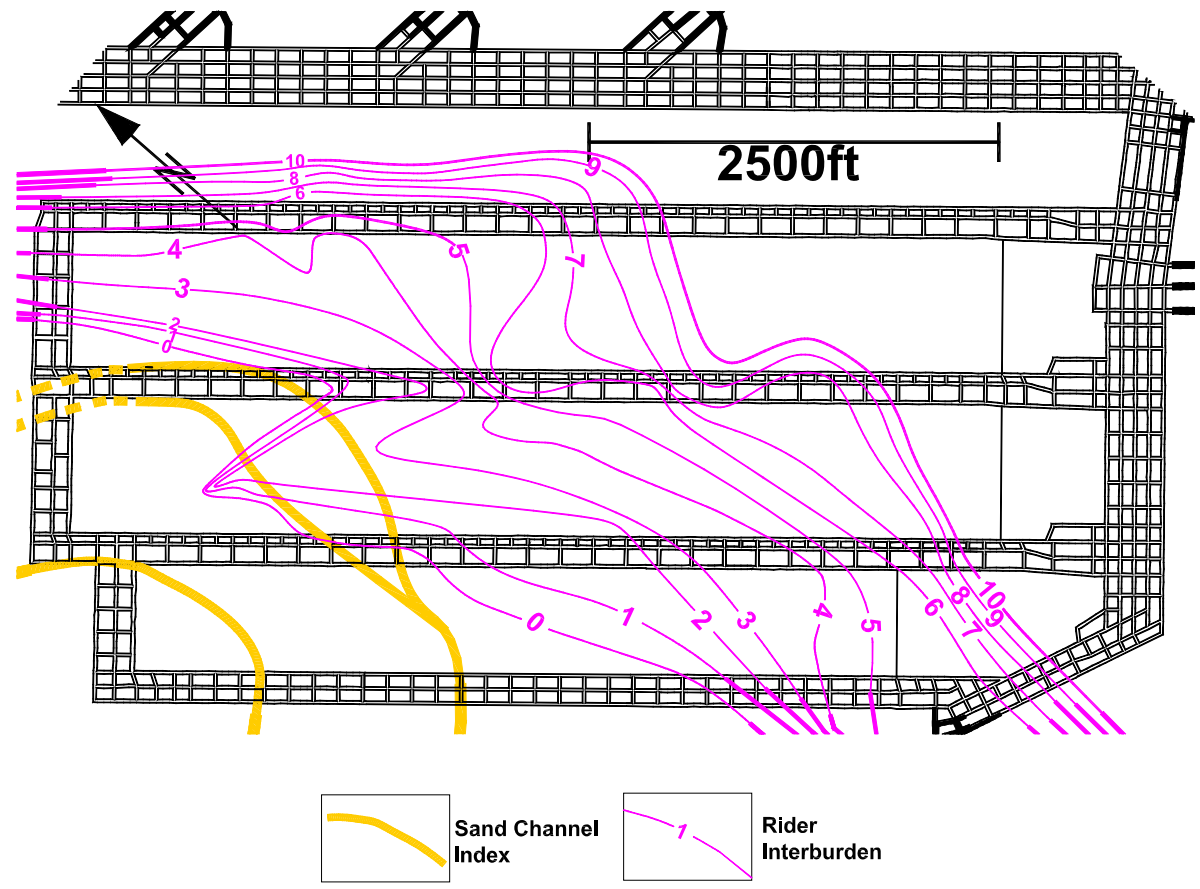

Figure 6.4 Sandstone channels and rider interburden thickness

The interburden has been found to greatly influence the stability of the mine roof, depending on its thickness. Also illustrated in Figure 6.4 are the axes of two major 
sandstone channels. These channels are usually found within the immediate roof layers, but at times come down directly on top of the coal seam. They tend to be the thickest in the center and thin towards the edges. The southwest district also has two major faults that border the longwall panels in the northeast and in the southwest. These two major faults, Figure 6.5, along with minor faults known as slumps, have been found to adversely affect the stability conditions within the mine. Along with the faults and slumps, abrupt changes in the elevation of the coal seam known as warps will also come into consideration when creating the stability map.

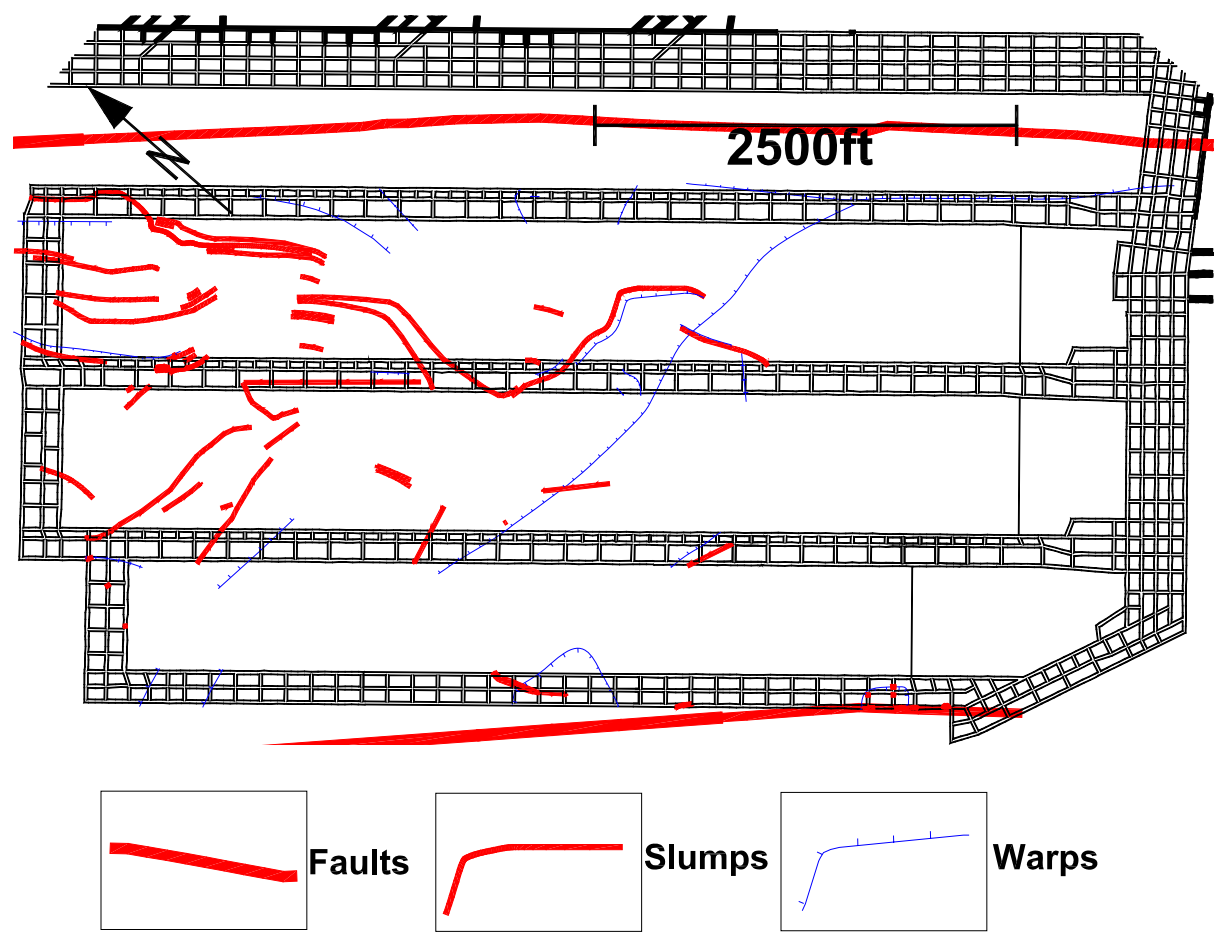

Figure 6.5 Faults, slumps, and warps in the southwest mining district

The last influence factor, and maybe one of the more important factors, is the roof strength. In this particular study the roof strength will be represented by the CMRR. Within the immediate mine roof there are up to four major units that may be present, 
depending on the location within the mine. These units include an interburden unit, which was discussed above, rider coal seam unit, sandy mudstone unit, and a sandstone unit. All four units are present in the eastern section of the southwest mining district, but both the interburden and rider go to zero in the western part of the district. In this area, the rider coal joins with the B seam and the interburden is no longer present. The sandy mudstone has an average thickness of around $10 \mathrm{ft}$. throughout the district except in the areas where the sandstone channels are located. The center of the sandstone channel axis lies directly on top of the B seam, the sandstone channel is separated from the B seam by the sandy mudstone layer moving toward the edge of the channel.

\subsubsection{CMRR Application}

As mentioned above, the stability map is to be created from eight different factors that influence the mining conditions. One of the major factors that greatly influences the stability conditions is the CMRR. In order to create a CMRR grid for the mining district, we must first have some information on the immediate mine roof geology. The mine personnel provided contour data of the thicknesses of the four most important immediate roof units and strength data for these layers were obtained from previous work (Stewart et al., 2006). These four units from the most immediate to the upper are listed as follows: interburden to the rider coal, a rider coal seam, a sandy mudstone, and a sandstone layer.

The interburden to the rider coal seam is present in the eastern part of the coal, Figure 6.4, seam but fades to zero in the western part of the seam (the zero line is marked in black in Figure 6.6). In the western part of the seam the rider coal seam comes down from the roof and joins the B seam. At the mine, the thickness of the interburden has been found to affect the quality of the roof directly without respect to the other units 
(Stewart et al., 2006). Between the interburden or rider, depending on the location, and the sandstone layer there is a sandy mudstone present. This mudstone will make up the third unit in the CMRR calculation. The fourth and uppermost unit is a sandstone unit that is found above a large majority of the mine site. This unit, although present over much of the mine, only affects the mine stability when it appears as a sandstone channel that comes in contact with the B seam or is within the immediate roof layers. The mine roof is fairly competent in the middle of the sandstone channels where the sandstone is thick, but becomes unstable near the altered edges of the sandstone channel.

For each unit, a thickness grid was created and input into the CMRR program (see Figures 6.6 - 6.8). The grids for the interburden and for the rider seam thickness were created from contours that were provided by the mine personnel. The grids were created using one of the stability mapping features that allows the user to create a grid from contours, linear features, points, etc. The thickness grid for the sandy mudstone was actually created from an initial average $10 \mathrm{ft}$. thickness and then the thickness was decreased where the known sandstone channels eroded the mudstone, using the linear feature grid module. An average thickness of the sandy mudstone was known, and where the sandstone channels were present the thickness of the mudstone was assumed to go to zero over the influence distance of the sandstone channel axis (see Figure 6.8). This was accomplished by subtracting a grid for the sandstone channel axis from the $10 \mathrm{ft}$. thick sandy mudstone grid using the grid utilities module in the stability mapping program. The sandstone unit grid was created from a grid of constant values and did not come into play with regard to the CMRR except where the combined thickness of the other units was less than the bolt length. The Sandstone grid is not illustrated since it was assigned a constant thickness of $10 \mathrm{ft}$. over the entire mine area. 

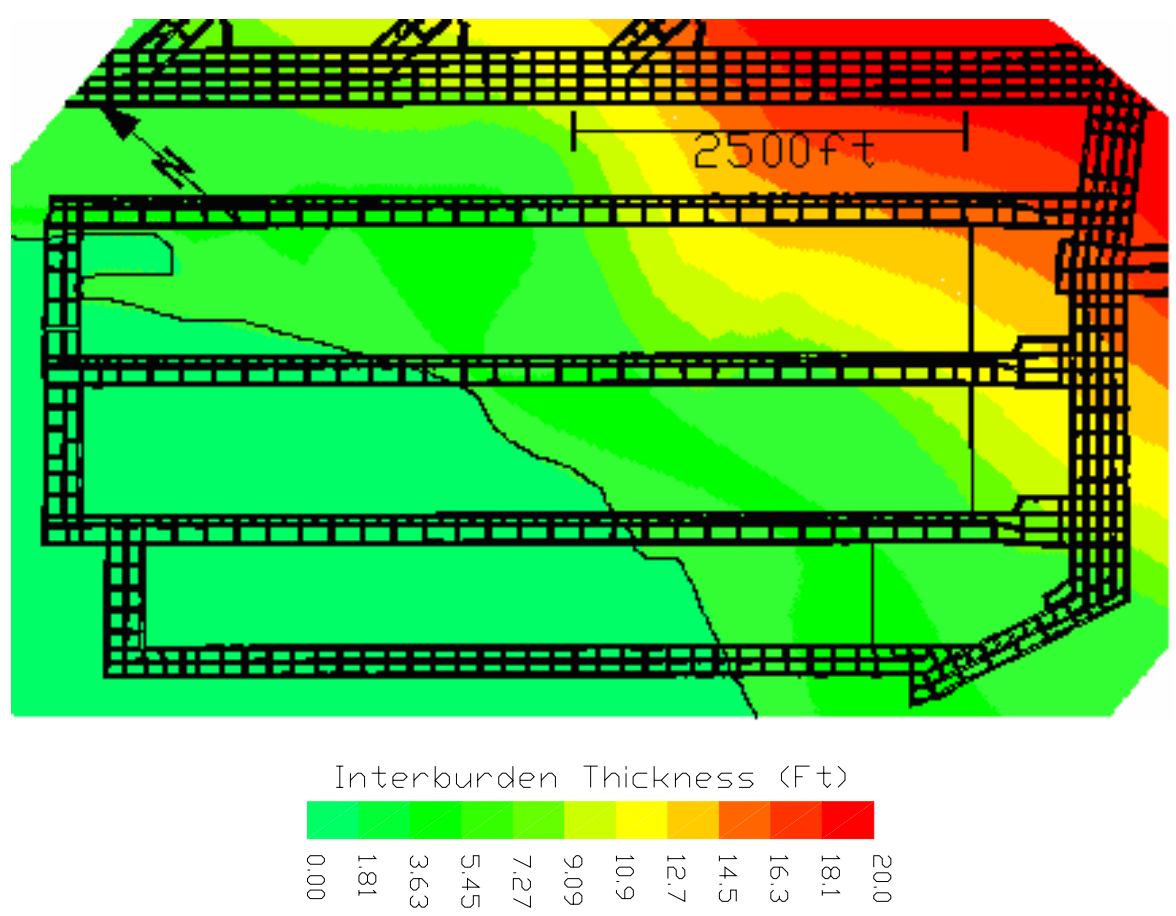

Figure 6.6 Interburden to rider coal thickness
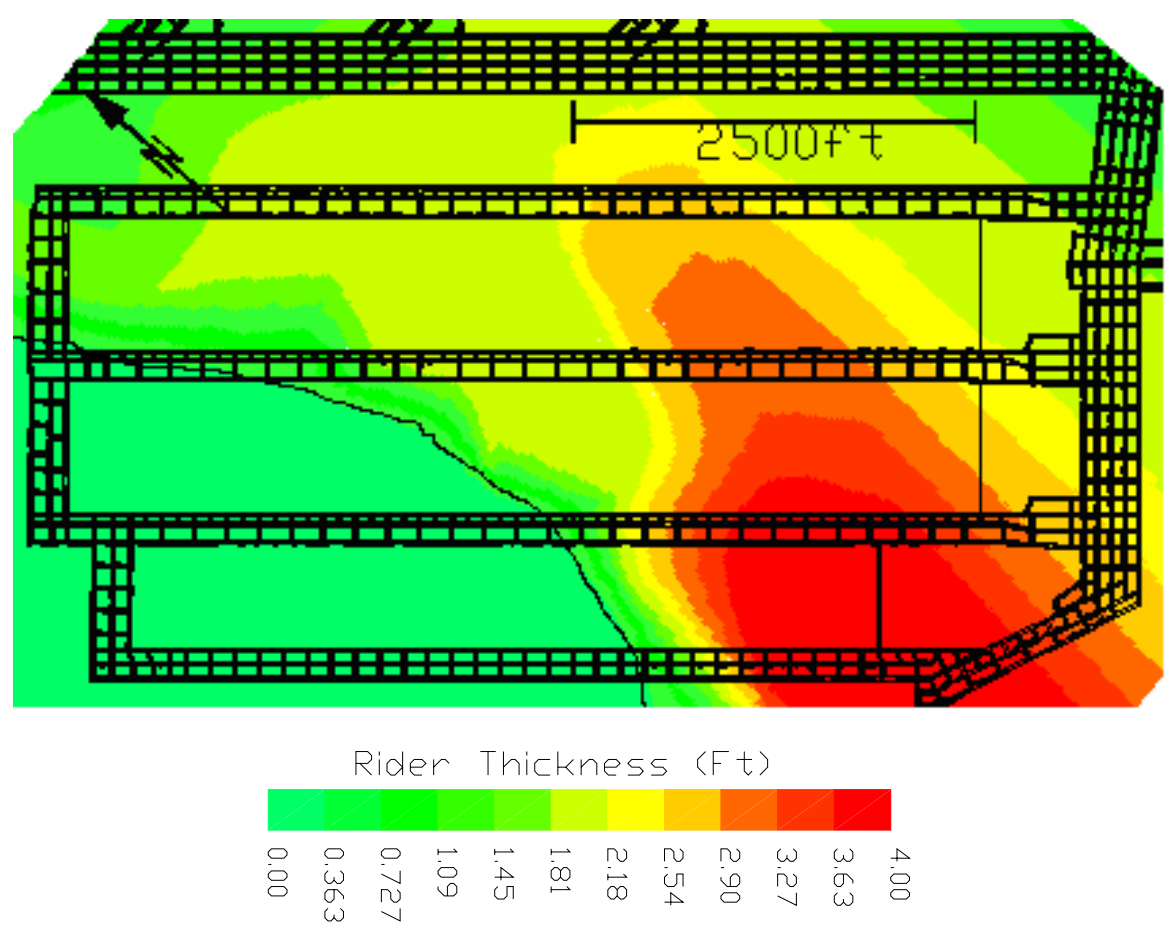

Figure 6.7 Rider thickness 


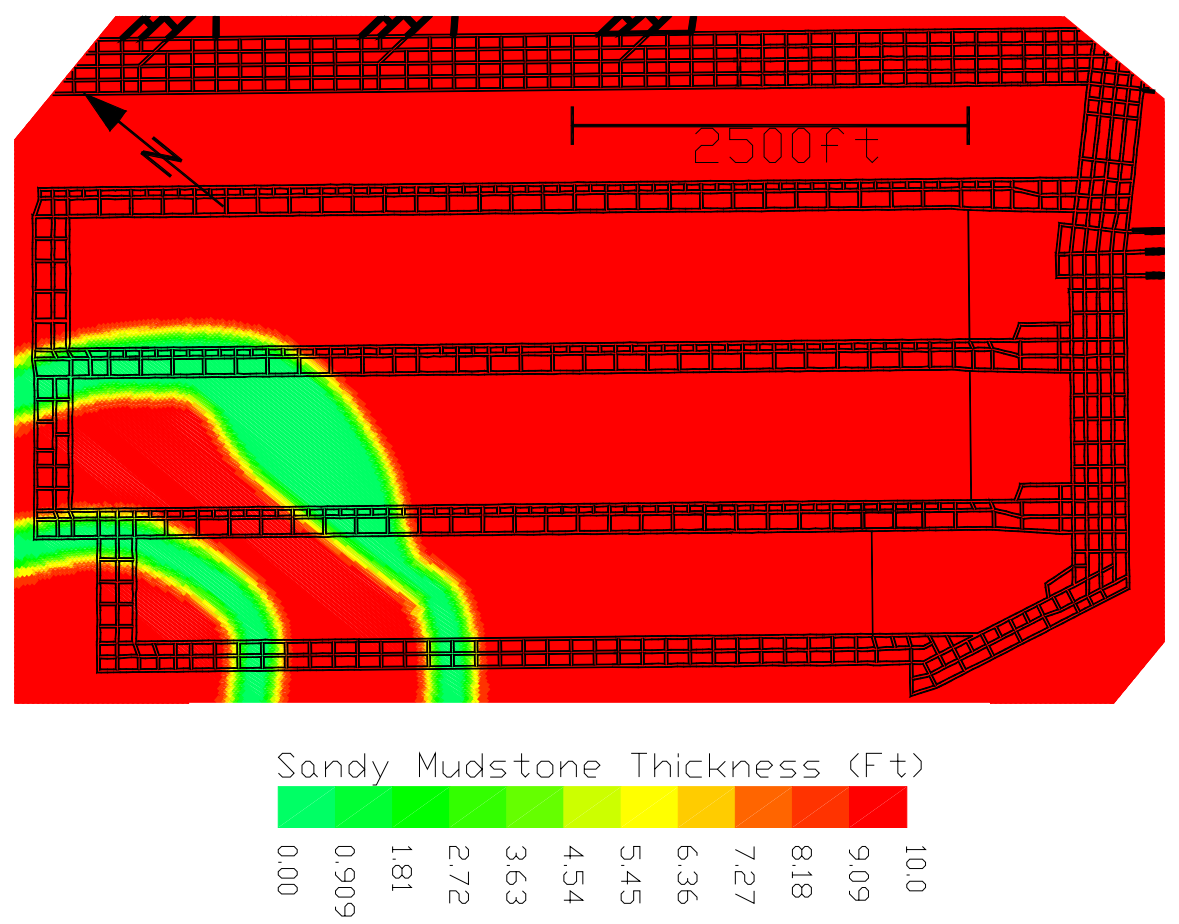

Figure 6.8 Sandy mudstone thickness

Each of the above thickness grids were input into the CMRR program along with a unit rating for each unit. These unit ratings were taken from previous research done by Mark and Molinda (1994) on unit ratings of different types of coal mine roof rock. The mine had damp conditions for the CMRR calculation and there was no surcharge because the sandstone layer above the uppermost unit was stronger than the lower units. The initial bolt length at the mine was $6 \mathrm{ft}$. and this was used in the CMRR calculations.

Once all of the data were input, the final CMRR grid could be calculated. In the CMRR grid, Figure 6.9, one can see how the different unit thickness grids that make up the CMRR affect the final values. In the eastern portion of the southwest mining district the CMRR is mostly affected by the interburden, which is the thickest in this area. Moving to the west, the interburden decreases in thickness as the rider becomes closer to the B seam, decreasing the CMRR in this area. In the western portion of the mine the two sandstone channels are present, resulting in the highest CMRR values in the southwest district. The biggest advantage to using this areal CMRR program is the ease 
at which the large amounts of available geologic data can be easily analyzed and incorporated into the CMRR values for a large mine area.

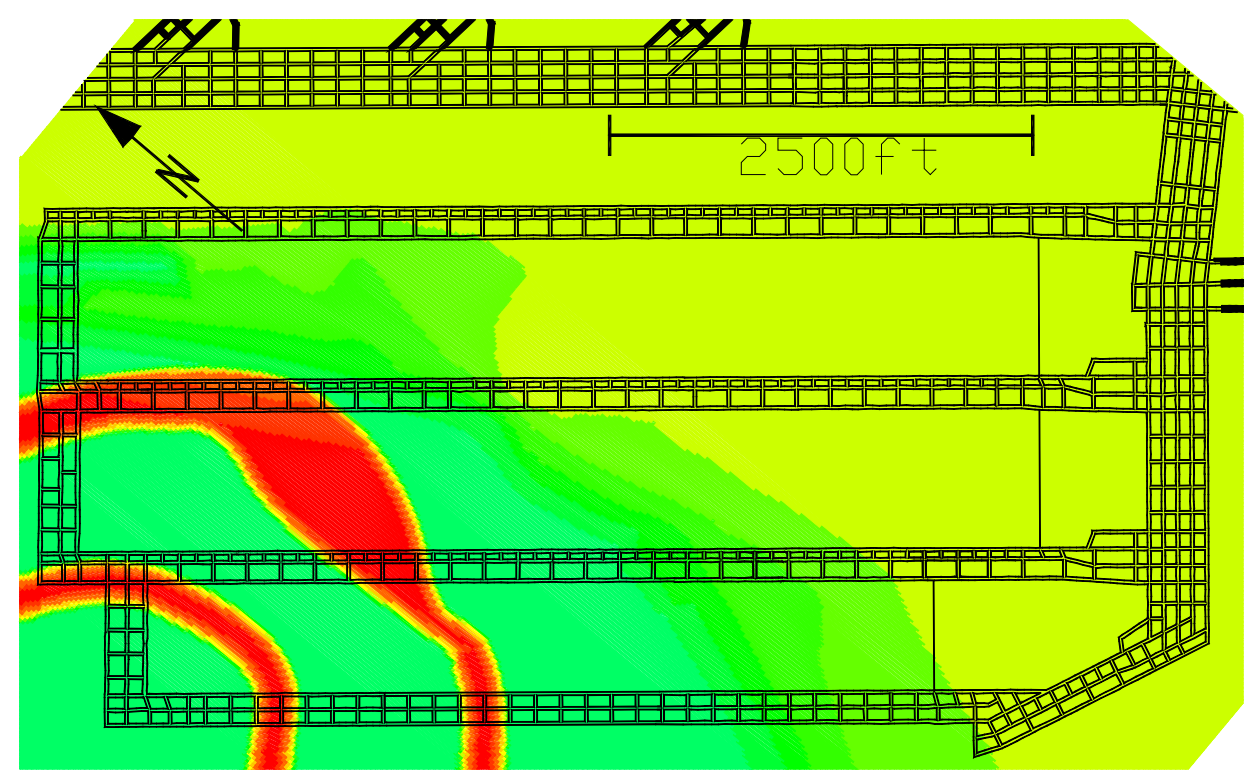

Figure 6.9 CMRR

\subsubsection{Stability Mapping}

Now that the CMRR grid has been created it can be combined with the other critical factors at the mine to create a stability index map for the mine area. Table 6.1 lists the seven other factors that were input to create the stability index map. The first two factors in the list are the overburden stress and multiple seam stress. An index grid was created for each factor so that with increasing stress the stability index also increases. This would be the logical relationship between increasing stress and decreasing mine 
stability. A linear index grid was also created for the faults, slumps and warps. The faults were linear features that were given an influence of 300 feet on either side of the fault whereas the slumps and warps are smaller seam disturbances and were only given an influence of 10 feet on either side. Both the CMRR grid and the sandstone channel grid were used to create inverse linear index grids. With increasing CMRR and sandstone thickness the stability increases, therefore with an inverse index the higher the CMRR and thicker the sandstone the lower the stability index. The last factor that was used in the creation of the stability map was the thickness of the interburden. It was found that the roof in the mine became more unstable when the interburden had a thickness of between two and six feet (Stewart et al., 2006). When the interburden was less than two feet it normally fell out during the mining process and did not cause any problems. Also, when the thickness of the interburden was greater than six feet it was found to be competent and able to support itself after roof support was installed. The major problems occurred within the two to six foot range. At this thickness, the interburden would be bolted after mining, but would fall out as mining proceeded. Therefore a parameter index of 100 was given to any thickness value between two and six feet, and a value of 0 was given to other thicknesses.

The weighting for each critical factor is given in Table 6.1 and illustrates the importance of each factor. Through experience and observation it was determined by the mine personnel that the most influential factors were the overburden stress, CMRR, interburden thickness, and major faults. Each of these factors were given a weighting of twenty. The less influential factors were given a weighting of between 15 and 5. Each of the 8 critical factors were combined using the stability mapping program to create a 
stability map of the mine area as shown in Figure 6.10. The areas of darker color are considered to be less stable and/or more difficult to mine through.
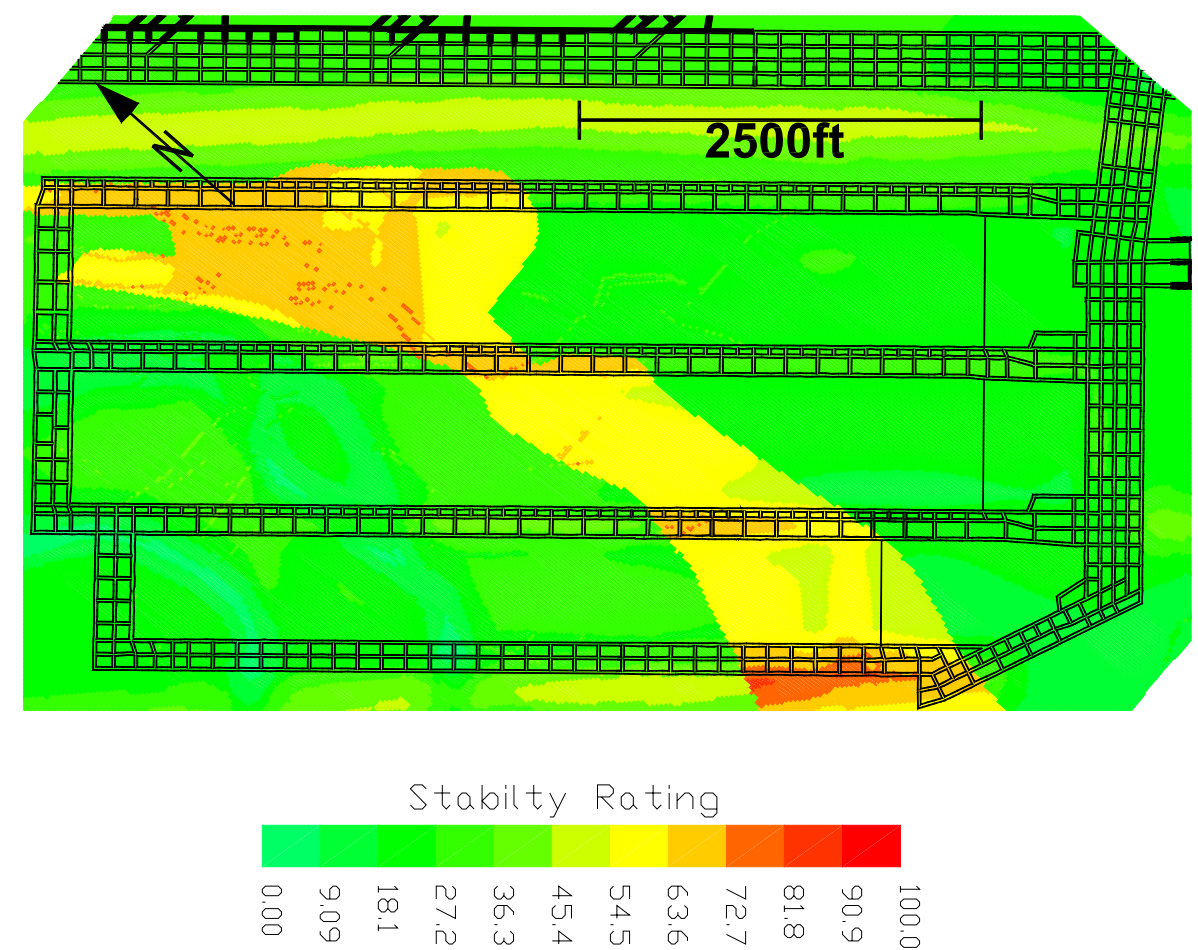

Figure 6.10 Stability Rating

Although it is desirable to develop a stability map prior to mining, it is not always possible. In this case the stability map was not complete until the B1 panel was about halfway done. The mining conditions found in the back third to half of the B1 panel were less than optimal. Roof support had to be changed from $6 \mathrm{ft}$. fully grouted bolts to $7 \mathrm{ft}$. torque tension bolts. Also, $12 \mathrm{ft}$. cable bolts and 24 in. cans were installed in the tailgate entry in an attempt to alleviate the floor heave and roof sag. In comparing the actual mining conditions with the stability map in Figure 6.10 it was found that the correlation between the two was very strong. Adverse conditions were found in both the back half of the B1 tailgate and the middle third of the B1 headgate. When looking at the stability map it can be seen that these areas have a stability index higher than much of the rest of the B1 panel. Because the stability map correlated so well with actual conditions in the B1 panel, it was decided to adjust the future roof support plans for the B2 and B3 panels 
based on the stability map data. The mine is presently working in the B2 panel and has found that the stability map results correctly predicted the adverse conditions in the B2 headgate. The adjusted roof support plans have worked well in alleviating some of the more serious affects of the predicted poor mining conditions.

\subsection{Summary}

Through the use of both the CMRR program and the stability mapping system one is able to take large amounts of data that would otherwise be difficult to analyze and display it in a manner which is easy to understand and interpret. The above case study helps to illustrate some of the possible methods of application of the CMRR program and how it could be applied in a stability mapping application. The ability to easily calculate the CMRR on an areal basis from contour data allows the user to take advantage of data that may have not been used if the program was unavailable. The addition of the CMRR to the stability mapping package also creates another input parameter that can help to increase the validity of a stability map. One of the biggest advantages to both of these programs is their ease of use and versatility. Data from many sources can be used and brought together which in turn allows the user to gain a better understanding of the overall interaction between each factor that affects mine stability. Overall, the CMRR program meshes well with the stability mapping package and is easy to use and understand. 


\section{Chapter 7}

\section{Summary and Conclusions}

\subsection{Summary}

The preceding chapters of this thesis present the design and implementation of a program that allows for the calculation of CMRR values on a large spatial scale, using data from multiple sources and different types. Both observation and drill core data can be accepted by the program and used to calculate CMRR values. Also, the data can be entered as individual values or as a grid of values for a particular area of interest in a mine. The process of calculating a CMRR starts with the data collection. The data may come from observations of an outcrop on the surface or from drill cores taken on the mine site along with many other possible sources. The data are then either entered as individual point data or are used to create input data in a grid format using either SurvCADD or the stability mapping package (Wang, 2005). Once the data are in the proper format, it can then be entered into the program to calculate an individual CMRR value or a grid of CMRR values. Once complete, the grid can be plotted on a mine map or used in a stability map as a major influence factor.

The development of the CMRR program started with identifying the easiest and most widely used format for the input data. Because the AutoCAD/SurvCADD platform is so widely used in the mining industry, the SurvCADD grid data format was the most obvious choice (Richards, 2001). The next step was to create an interface which could operate within the AutoCAD/SurvCADD environment and also cooperate with the newly developed stability mapping package (Wang, 2005). To enable this application, it was decided to build the program using Visual $\mathrm{C}++$ and the AutoCAD ObjectARX extensions. 
In order to take full advantage of the CMRR capabilities, the program was designed to be able to take input from either observation or drill core locations as mentioned above. Also, the data can be entered as an individual point value or as a grid of values (Appendix A). For a typical CMRR calculation, data are entered for anywhere between one and five units within the bolting horizon. Each specific unit has a detailed set of data that must be input in order for the CMRR to be calculated. The data can be from one of two sources; an observation data source such as an overcast, roof fall, or outcrop, or a drill core data point from a surface drill or underground sample. Regardless of the data source type, a thickness of each unit must be entered either as an average for the area of interest or as a grid of points for that particular area. If observational data are being used, data for the strength of the unit, the discontinuities, and moisture sensitivity is entered. Of these three items, the strength is the only factor that can be entered as a grid file. On the other hand, if the data have come from a core hole, then the input data set can be somewhat more complex. An axial unconfined strength or a point load test value is given in place of the unconfined strength value for the observation data, and a diametral strength and fracture spacing are given to account for the discontinuities within the sample; these factors are also able to be input as a grid file. The moisture sensitivity is input in the same manner as it is for the observation data. Each of these various factors account for the majority of the unit data that are needed for the calculation of a CMRR. The final pieces of information needed for the CMRR calculation are for the mine as a whole. Both the amount of groundwater in the mine and the strength of the rock above the uppermost unit is needed. Along with these two factors, the roof bolt length must be known in order to define the height of the bolting horizon. 
The program uses all of the above data to calculate a CMRR value for either an individual point, if point data are used, or for a grid of points, if grid data were entered. The output grid is compatible with the SurvCADD/AutoCAD platform along with the stability mapping package (Wang, 2005). Multiple functions have been developed to account for the multiple possible different scenarios of data types and formats. As stated earlier, these functions were written in the Visual $\mathrm{C}++$ with AutoCAD Object ARX extensions. All of the equations and tables needed for the CMRR calculation are hard wired into the program for proper calculation.

Once the program was completely developed, it was checked for errors in logic and calculation. Multiple validation calculations and a simple case study were undertaken to ensure the usefulness and reliability of the program. The case study used data from a deep coal mine in the western United States. Four units were included in the data set and a grid for each of the unit's thickness was input into the program. The other data points for the program were entered as individual data points. A grid of CMRR values was calculated for the mine area and combined with the stability mapping package to create a final stability index for the mine property. The two programs meshed well together and had no problems with data compatibility. The final stability index accurately correlated with observational and operational problems that were found at the mine site and illustrated the usefulness of the CMRR program.

\subsection{Conclusions}

After carrying out the program verification and case study, it appears that the CMRR program developed in this thesis can and will serve as a useful tool for the mining engineer in the evaluation of coal measure roof rock over a large spatial area. Both 
observation and core hole data can be used as input and the ability to support the gridbased data format gives great flexibility and ease of use to the program. The addition of the grid format to the CMRR calculation process furthers the usefulness of the CMRR by allowing for geostatistical calculations and depositional analysis to be performed on the input data. Performing these calculations enhances the accuracy of the CMRR over a large area by allowing individual interpolation of the geologic input data instead of just interpreting the final CMRR values. Implementation of the CMRR program in AutoCAD with SurvCADD grids increases the ease and likelihood of use and minimizes the user's learning curve for applying the application. Also, building on the AutoCAD/SurvCADD platform allows for future expansion of the program and integration with the previously created stability mapping package.

If properly supported and used, the CMRR program can be a very useful tool to the mining engineer of today. Through its application, both the mine engineer and the mine personnel can benefit from the increased geo-mechanical knowledge of the coal measure roof rock being studied and the safety which that brings.

\subsection{Ideas for Additional Research}

During the course of this research, several areas for additional research were determined that would allow for the expansion of the CMRR program. In previous chapters it was mentioned that the CMRR has been applied to both the ALPS and ARBS systems. Within the ALPS system a recommended safety factor is determined based on a simple formula, Eq. (7.1), which includes the CMRR.

$$
A_{S F}=1.76-0.014(C M R R)
$$


Also, the ARBS system incorporates the CMRR in the determination of the appropriate intersection span, bolt length, and bolt intensity as shown in Eq. (7.2) through (7.4). These two applications could be easily added to the program using the CMRR output grids as their input. This would then allow for the output of an ALPS SF grid and also grids of the various ARBS parameters to be used in the mine design process.

$$
\begin{gathered}
I s_{G}=20+.26(C M R R) \\
L_{B}=(I s / 13)\left(\log _{10} H\right)((100-C M R R) / 100)^{1.5} \\
\left.\operatorname{PRSUP}_{G}=(S F)\left(0.3\left(I s_{G}-I s\right)\right)\left(5.7 \log _{10} H\right)-0.35 C M R R+6.5\right\rfloor
\end{gathered}
$$

Given That:

$$
\begin{aligned}
& \text { Is }_{G}=\text { Intersection Span Width } \\
& \begin{array}{l}
\mathrm{L}_{\mathrm{B}}=\text { Bolt Length } \\
\mathrm{H}=\text { Depth } \\
\text { Is = Actual Intersection Span } \\
\text { PRSUP }_{\mathrm{G}}=\text { Roof Bolt Intensity } \\
\text { SF = Stability Factor (1.2 Recommended) }
\end{array}
\end{aligned}
$$

Along with the above additions there are several other areas of the program that could be expanded and improved. Within the program there are multiple parameters that can be input in a grid format. One parameter that does not have that capability is the bolt length or height of bolting horizon. Because mines may use different bolt lengths within a single mine, it would be advantageous to allow the user to input a grid of bolt lengths to be used in the CMRR calculations. Along with the bolt length, the program could be set 
up to accept data as a grid for any other parameter that is found to be readily available in a data format that can be easily converted to a grid. 


\section{REFERENCES}

Carlson Software, 2000, SurvCADD - CES, Carlson Software, Maysville, KY.

Heasley, K., and Agioutantis, Z., 2001, "LAMODEL - A boundary element program for coal mine design," Proceedings of the 10th International Conference of the International Association for Computer Methods and Advances in Geomechanics, January 7-12, 2001, Tucson, Arizona, University of Arizona, pp. 1679-1682.

Heasley, K., and Wang, Q., 2001, “Integrated Stability Mapping System for Mines,” Research Proposal submitted to National Institute for Occupational Safety and Health, Morgantown, WV.

Jiang, Y., and Wells, B., 1998, “Analysis of geologic and geotechnical conditions and their effects on longwall mining to optimize mine planning at Shoal Creek Mine," Proceedings of the 17th International Conference on Ground Control in Mining, S.S. Peng, ed., August 4-6, 1998, Morgantown, WV, West Virginia University, pp. 54-62.

Maleki, H., 1990, "Development of modeling procedures for coal mine stability evaluation," Proceedings of the 31st U.S. Rock Mechanics Symposium, Rotterdam, Netherlands, A.A. Balkema, pp. 85-92.

Mark, C., Chase, F.E., and Molinda, G.M., 1994, "Design of Longwall Gate Entry Systems Using Roof Classification,” Paper in New Technology for Longwall Ground Control: Proceedings of the USBM Technology Transfer Seminar, US Bureau of Mines, SP 94-01, pp. 5-18.

Mark, C., and Barczak, T.M., 2000, "Fundamentals of Coal Mine Roof Support," Proceedings: New Technology for Coal Mine Roof Support, National Institute for Occupational Safety and Health, Information Circular, IC 9453, pp. 23-42.

Mark, C., Molinda, G.M., and Dolinar, D.R., 2001, “Analysis of roof bolt systems," Proceedings of the 20th International Conference on Ground Control in Mining, S.S. Peng, C. Mark, A.W. Khair, eds., August 5-8, 2001, Morgantown, WV, West Virginia University, pp. 218-225.

Mark, C., Molinda, G., and Barton, T., 2002, "New developments with the coal mine roof rating," Proceedings of the 21st International Conference on Ground Control in Mining, S.S. Peng, C. Mark, A.W. Khair, K. Heasley, eds., August 6-8, 2002, Morgantown, WV, West Virginia University, pp. 294-301.

Mark, C., McWilliams, L., Pappas, D., and Rusnak, J., 2004, "Spatial trends in rock strength - can they be determined from coreholes?” Proceedings of the 23rd International Conference on Ground Control in Mining, S.S. Peng, C. Mark, G.L. Finfinger, S.C. Tadolini, K.A. Heasley and A.W. Khair, eds., August 3-5, 2004, Morgantown, WV, West Virginia University, pp. 177-182. 
Molinda, G., Heasley, K., Oyler, D., and Jones, J., 1991, “Effects of surface topography on the stability of coal mine openings," Proceedings of the 10th International Conference on Ground Control in Mining, S.S. Peng, ed., June 10-12, 1991, Morgantown, WV, West Virginia University, pp. 278-282.

Molinda, G. M., and Mark, C., 1994, “The Coal Mine Roof Rating (CMRR): A Practical Rock Mass Classification for Coal Mines,” US Bureau of Mines, Information Circular, IC 9387, 25pp.

Molinda, G. M., and Mark, C., 1996, "Rating the Strength of Coal Mine Roof Rocks,” US Bureau of Mines, Information Circular, IC 9444, 20pp.

Molinda, G.M., Mark, C., and Dolinar, D.R., 2000, “Assessing Coal Mine Roof Stability Through Roof Fall Analysis," Proceedings: New Technology for Coal Mine Roof Support, National Institute for Occupational Safety and Health, Information Circular, IC 9453, pp. 53-72.

Molinda, G.M., Mark, C., and Debasis, D., 2001, "Using the coal mine roof rating (CMRR) to assess roof stability in U.S. coal mines,” Journal of Mines, Metals, and Fuels, August-September, pp. 314-321.

Newman, D., DeCinque, J., and Dafferner, A., 2001, “The integration of geology and engineering in ground control and mine planning for a multiple-level underground limestone quarry," Proceedings of the 20th International Conference on Ground Control in Mining, S.S. Peng, C. Mark, A.W. Khair, eds., August 5-8, 2001, Morgantown, WV, West Virginia University, pp. 129-136.

Richards, 2001, Personal correspondence with Keith A. Heasley.

Riefenberg, J., 1994, "Geostatistical modeling of coal mine roof quality for hazard mapping," Proceedings of the 5th Conference on Ground Control for Midwest U.S. Coal Mines, Y.P. Chugh, G.A. Beasley, eds., June 27-30, 1994, Carbondale, IL, Southern Illinois University, pp. 31-40.

Riefenberg, J., 1994, “Hazard mapping combining geostatistical modeling of coal mine roof quality ratings with numerical modeling of stress data," Proceedings of the 13th International Conference on Ground Control in Mining, S.S. Peng, ed., August 2-4, 1994, Morgantown, WV, West Virginia University, pp. 261-268.

Rusnak, J., and Mark, C., 2000, "Using the point load test to determine the uniaxial compressive strength of coal measure rock," Proceedings of the 19th International Conference on Ground Control in Mining, S.S. Peng, C. Mark, eds, August 8-10, 2000, Morgantown, WV, West Virginia University, pp. 362-371.

Stankus, J., Wang, Y., and McCaffrey, J., 2001, "Roof instability rating (RIR) system and its application at Enlow Fork Mine," Proceedings of the 20th International Conference on Ground Control in Mining, S.S. Peng, C. Mark, A.W. Khair, eds., August 5-8, 2001, Morgantown, WV, West Virginia University, pp. 327-336. 
Stewart, C., and Heasley, K., 2006, “Mine stability mapping,” Proceedings of the 25th International Conference on Ground Control in Mining, S.S. Peng, C. Mark, G. Finfinger, S. Tadolini, A.W. Khair, K. Heasley, Y. Luo, eds., August 1-3, 2006, Morgantown, WV, West Virginia University, pp. 243-249.

Stewart, C., Hunt, G., and Mark, C., 2006, "Geology, ground control, and mine planning at Bowie Resources, Paonia, CO,” Proceedings of the 25th International Conference on Ground Control in Mining, S.S. Peng, C. Mark, G. Finfinger, S. Tadolini, A.W. Khair, K. Heasley, Y. Luo, eds., August 1-3, 2006, Morgantown, WV, West Virginia University, pp. 288-290.

Vetterling, W. T., Teukolsky, S.A., Flannery, B.P., and Press, W. H., 1992, Numerical Recipes in C: The Art of Scientific Computing, 2nd Edition, Cambridge University Press, 1020 pp.

Wang, Q., 2005, “Integrated Stability Mapping System for Mines,” Ph.D. Dissertation, West Virginia University, Morgantown, WV, 140pp.

Wang, Q., and Heasley, K.A., 2005, “Stability mapping system,” Proceedings of the 24th International Conference on Ground Control in Mining, S.S. Peng, C. Mark, G. Finfinger, S. Tadolini, A.W. Khair, K. Heasley, eds., August 2-4, 2005, Morgantown, WV, West Virginia University, pp. 243-249. 


\section{Appendix A. Grid File Example}

This appendix contains an example and explanation of a SurvCADD grid file (*.grd) that could be used in, or created by, the CMRR program.

19400.000000

25000.000000

27000.000000

32600.000000

380

380

32.000000

32.000000

32.000000

32.000000

\section{TestCMRR_CMRR}

The first four lines of the grid file contain location information for the grid file.

These values are:

- The first line is the Y coordinate of the lower left corner of the grid

- The second line is the $\mathrm{X}$ coordinate of the lower left corner of the grid

- The third line is the Y coordinate of the upper right corner of the grid

- The fourth line is the $\mathrm{X}$ coordinate of the upper right corner of the grid. 
The CMRR program uses this information to compare one grid file to the next to ensure that they are at the same location in order to be added, subtracted and multiplied together. The location values also tell SurvCADD where to place the grid in space.

The values in lines 5 and 6 give the dimensions of the grid file, respectively. In this example, the grid has a dimension of 381 values in the $\mathrm{X}$-direction and 381 values in the Y-direction. There is one extra value present in each row and column because SurvCADD stores the data points at the grid intersections and not at the center of each grid element. Therefore if you have a grid of $\mathrm{X}, \mathrm{Y}$ dimensions, the actual number of grid intersection values is $\mathrm{X}+1, \mathrm{Y}+1$.

The rest of the lines in the file represent the $\mathrm{Z}$ values at each point on the grid. In this file there would be a total of 145,161 data points (381*381). The $\mathrm{Z}$ values are arranged such that the $\mathrm{Y}$ index changes faster than the $\mathrm{X}$ index. For example, the first $\mathrm{Z}$ value is at $x=1, y=1$, and the second $Z$ value is at $x=1, y=2$. The last line in the grid file is simply the name of the grid file so that it may be identified by the CMRR program along with SurvCADD or the stability mapping program. 


\section{Appendix B. Main Input Forms}

This appendix contains screen shots of all of the six main input forms contained within the CMRR program. The functionality of each of these forms and the input parameters is described in detail.

\section{B.1 Loading the CMRR Program}

Before a user can run the CMRR program it must be loaded into the AutoCAD application. Once in AutoCAD the user should click on the Tools Menu and select the Load Application... menu item. This will bring up the Load/Unload Application form in Figure B.1.

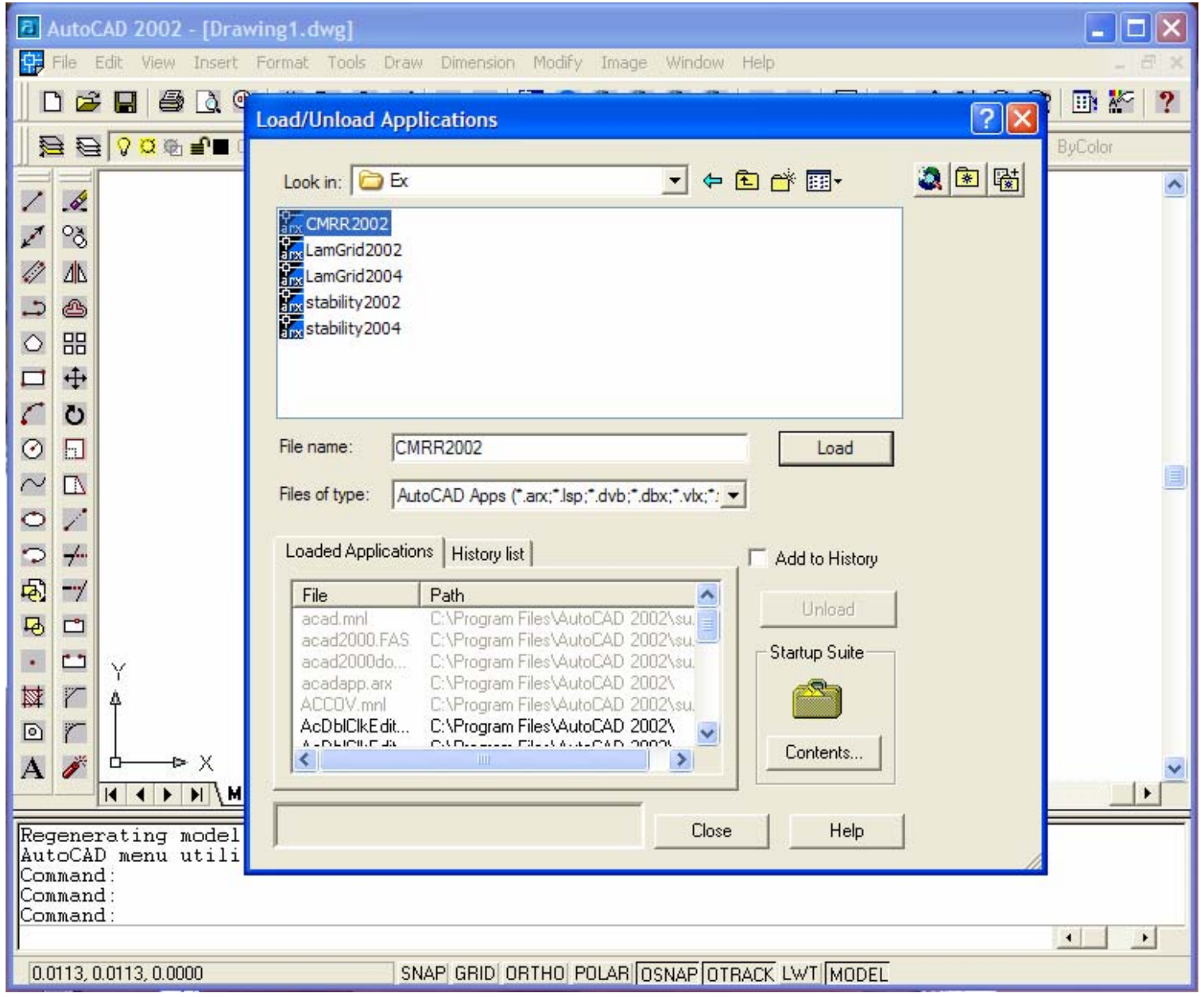

Figure B.1 Load/Unload Application form 
From here the proper directory and ObjectARX application file may be chosen and loaded using the Load button. Loading the CMRR application will add a Create CMRR Grid option to the stability mapping menu (Wang, 2005).

\section{B.2 Primary forms of the CMRR program}

\section{- General Information form}

The General Information form, as illustrated in Figure B.2, is the main form from which all other forms are accessed. When the user begins the program, this form is the first to be shown. From this form, the user is able to Open... an existing *.cmr file, Save... a file and Exit the existing file. The first step when this form appears is to select whether Underground Observations or Core Hole Data will be used using the associated radio buttons. Next, the Number of Units can be selected by either clicking on the slider or entering the desired number into the edit box. Once the Number of Units is selected (up to 5), the corresponding number of rows of unit details becomes active. For each unit, the user may choose to either input a single thickness value in the Thickness (ft) edit box or check the File check box to read a grid of thickness values into the program. If the File check box is checked, the user can then type in the grid file name in the Thickness Grid File edit box or Browse the directory structure to find the appropriate grid file using the Grid... button. After the thickness data is entered the user may either enter a known Unit Rating in the edit box or click on the Details... button. The Details... button will take you to either an Underground Observation Data form or a Core Data form, depending on which button is selected under the Type of Data group box. 


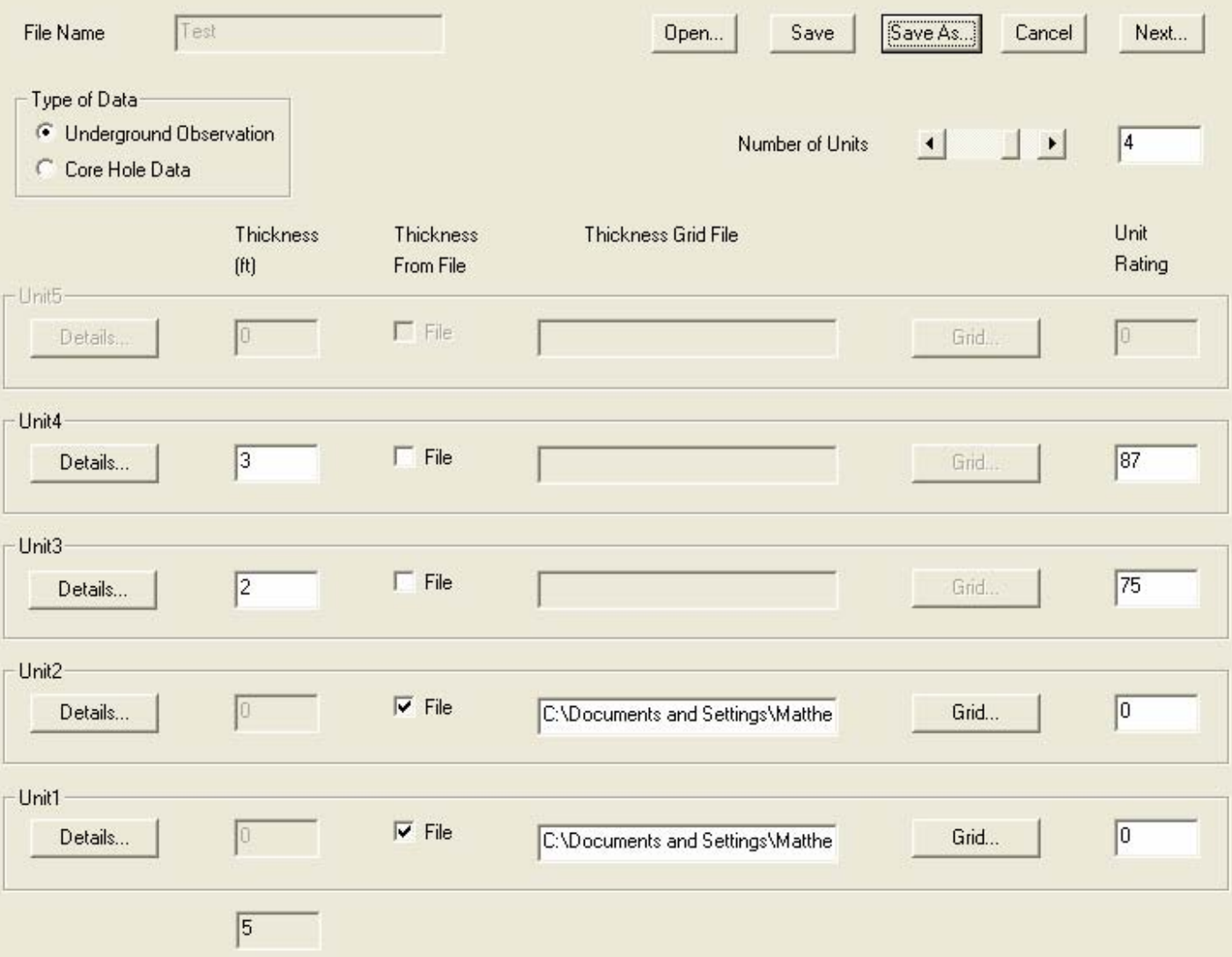

Figure B.2 General Information Form

\section{- Open form}

Throughout the program there are many instances where there is the option to enter a grid of data points from a file. If this option is chosen, the user can simply click the File check box and then the Grid... button. This will bring up the standard Windows Open form as shown in figure B.3. From here, any appropriate grid file can be chosen from the various files or directories. If the grid is of the proper format (location and size) it will be read into the program and used in the calculation process. One item that should be noted is that once the first grid is read into the program all other grids will be checked against the location and size of the first grid for compatibility. If the location and size does not match, then subsequent grid files will generate an error and will not be read into the program. 


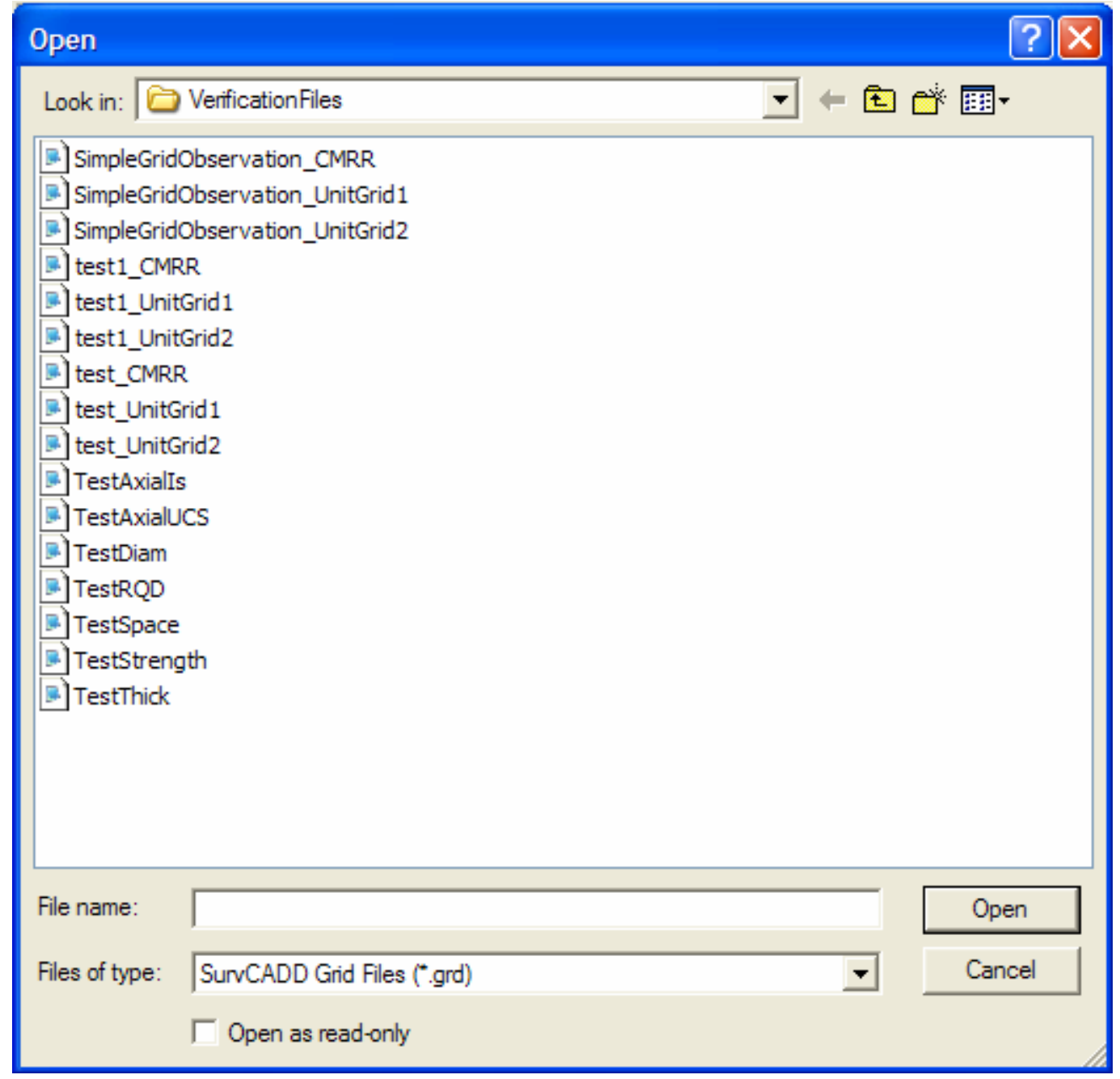

Figure B.3 Browse Window Form

- Underground Observation Data form

If the Underground Observation radio button is chosen under the type of data group box, the Underground Observation Data form in Figure B.4 will be displayed. From this form, the user may input all of the information necessary to calculate a unit rating based on observational data. The first step is to choose to enter an individual strength index in the Strength Index pull-down menu or to check the File check box to be able to enter a filename for a grid of strength values. A strength index between 1 and 5 can be entered or one of the pre-defined values may be selected from the pull-down menu. (For all of the pull-down menus in this program, an integer or real interpreted decimal value may be entered in the pull-down menus.) Or, as in the previous 
form, if the File check box is checked, the user can then type in the grid file name in the Strength Grid File edit box or Browse the directory structure to find the appropriate Strength Grid File using the Grid... button. The next step is to select the number of discontinuities that are present within the unit. The number can be changed by either using the Number of Discontinuities slider bar or by entering the number in the associated edit box. Once the number of discontinuities is entered the user should click on the Sets... button to enter all of the discontinuity data (this process will be described in the next section). The last two pieces of information that are needed in the Underground Observation Data form are the Moisture Sensitivity Index and the Contact at Top of the Unit strength. For the moisture sensitivity index, the user may enter a number between 1 and 4 or select one of the pre-defined values from the pulldown menu. The contact strength is easily defined as Weak or Strong by clicking on one of the two radio buttons under the Contact at Top of the Unit group box.

\section{Underground Observation Data}

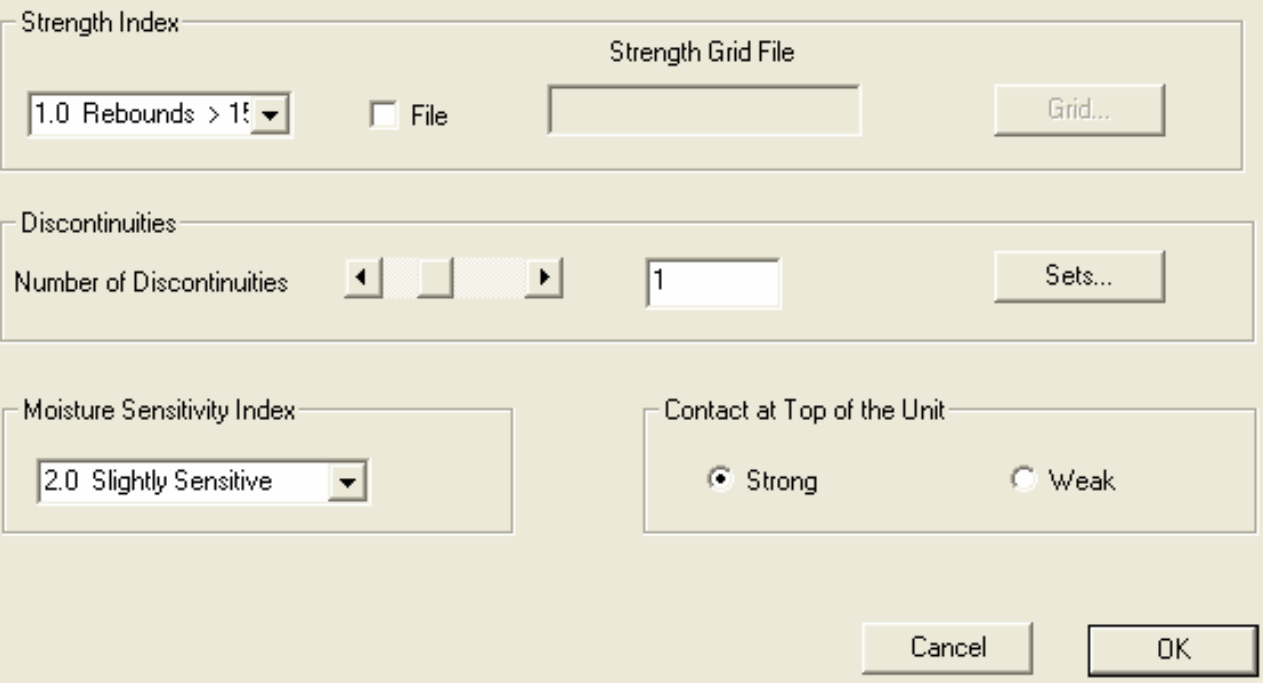

Figure B.4 Underground Observation Data Form 
- $\quad$ Discontinuities form

As mentioned in the previous section, the user must enter individual discontinuity information by clicking on the Sets... button within the Underground Observation Data form. When the Sets... button is clicked, the Discontinuities form shown in Figure B.5 will appear. In this form, the user may enter the data for the Cohesion, Roughness, Spacing, and Persistence of each set. Each different parameter can either be entered or chosen from the pull-down menu under each data type. When more than one discontinuity set is selected, the inactive areas for that set will become active as those in set 1 in figure B.5.

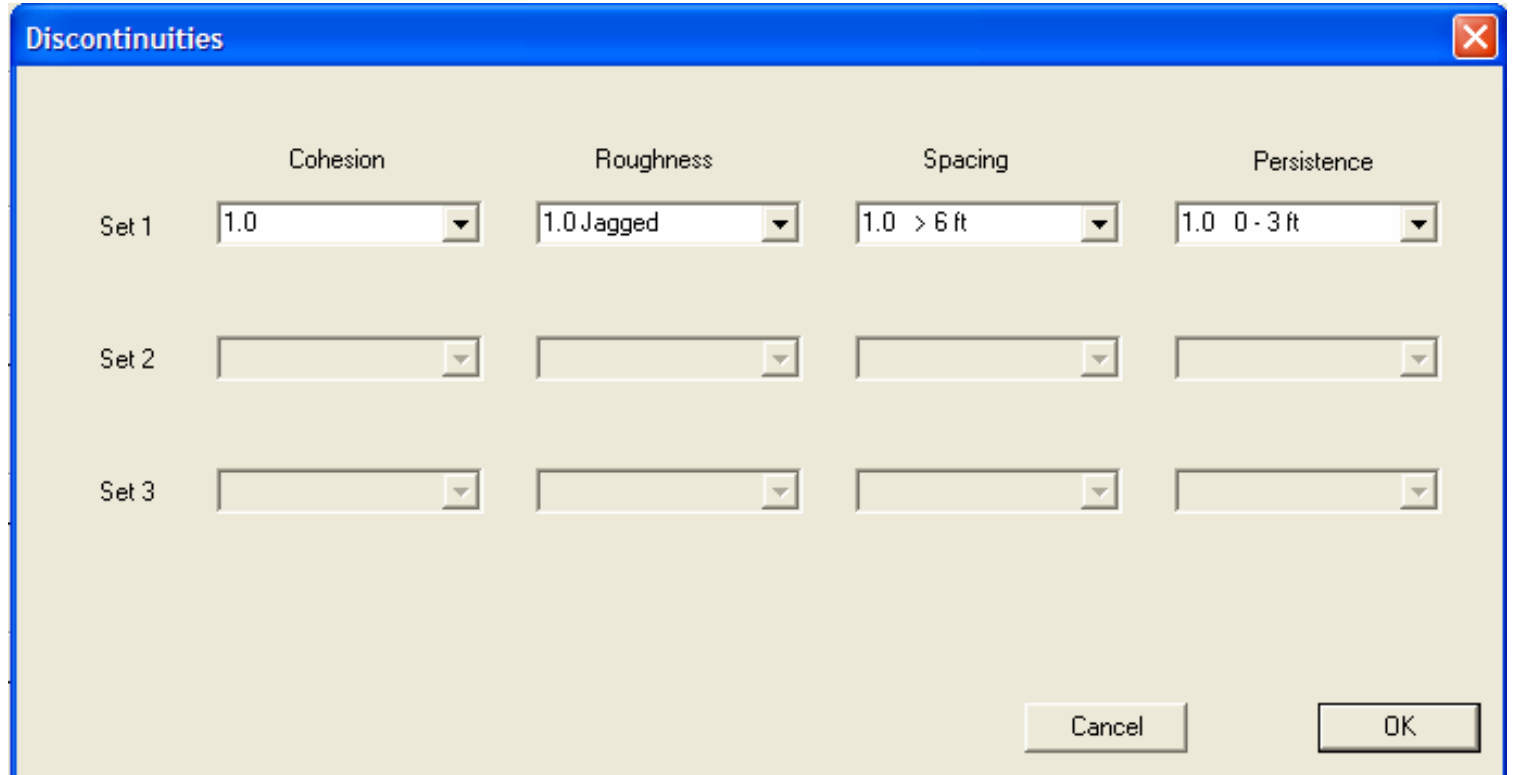

Figure B.5 Discontinuities Form

- $\quad$ Core Data form

If the Core Hole Data button is chosen under the Type of Data group box within Figure B.2, then when the Details button is pressed for a given unit in the General Information form, the Core Data form in Figure B.6 will be displayed. From this form, the user my input all of the necessary data needed to calculate the unit rating based on core hole data. The first step is to determine whether there is diametral 
strength data available or if an estimate has to be made, by selecting the radio buttons: Is(50) psi or No Diametral Available. Then, if there is data available, the data input method needs to be chosen by either entering a single average point load test strength in the Is(50) psi edit box or checking the File check box and specifying a file of grid values for this parameter. The next step is to choose which type of Fracture Information will be given. For this parameter, an RQD \%, Discontinuity Spacing (in) or No Fractures can be chosen using the Fracture Information radio button. For the RQD \% or Discontinuity Spacing(in), the values may be entered as a single data point or as a grid of points. If no fracture information is available then the user may select that radio button option. Axial Test Information is also given in this form, and for this parameter, either a point load test Is(50) or a UCS value can be selected using the radio button. For each of these Axial Test Information options, once again a single value or a grid of values can be entered here. The last two pieces of information that are needed to finish the Core Data form are the Contact at Top of Unit strength and the Moisture Sensitivity Index. These two parameters are entered in the same manner as they are entered in Figure B.4 (see previous section). 
Diametral Test Information

No Diametral Available

\section{$\lceil$ File}
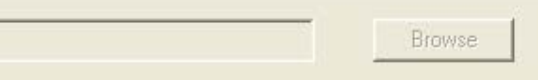

c Weak

C Moderate

C strong

-Fracture Information

( $\mathrm{RQD} \%$

C Discontinuity Spacing (in)

C No Fractures

Axial Test Information-

- Is[50) (psi)

$\sqrt{0} \quad \Gamma$ File

C UCS (psi)
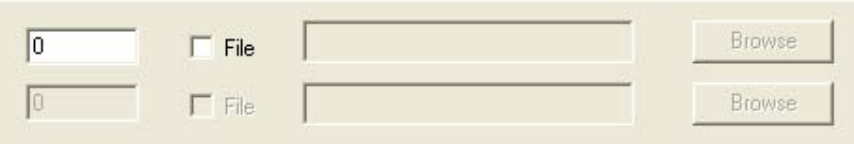

Contact at Top of the Layer

- Strong

$c$ Weak

- Moisture Sensitivity Index

1.0 Not Sensitive $\quad$ -

Cancel

Figure B.6 Core Hole Data Form

- Final Data Parameters form

Once all of the data has been entered for either the Underground Observation form or the Core Data form and the Ok button is clicked, the program will return to the General Information form shown in Figure B.2. From this form, the next step is to click the Next button which will bring up the Final Data Parameters form shown in Figure B.7. This Final Data Parameters form is where all of the mine-wide parameters for calculating the CMRR are entered. The first parameter that is to be entered is the Ground Water Adjustment. It can either be given as a single average value or as a grid of values. If a single value is chosen, then it can be entered into the edit box or picked from the pull-down menu. The Surcharge Adjustment should also be entered in this form using the Surcharge Adjustment pull-down menu. Once these two parameters are entered, the Bolt Length should be selected and the Keep Unit Grid Files box checked if the option is available and desired. The Keep Unit Grid 
Files option will only be active if the unit grid files have been calculated in the previous steps. To finish the CMRR calculation, the user simply clicks on the Finish button and either a single CMRR value will be displayed in the Final CMRR edit box, or a grid of CMRR values will be sent to the directory in which the current CMRR program, Test, is being run.

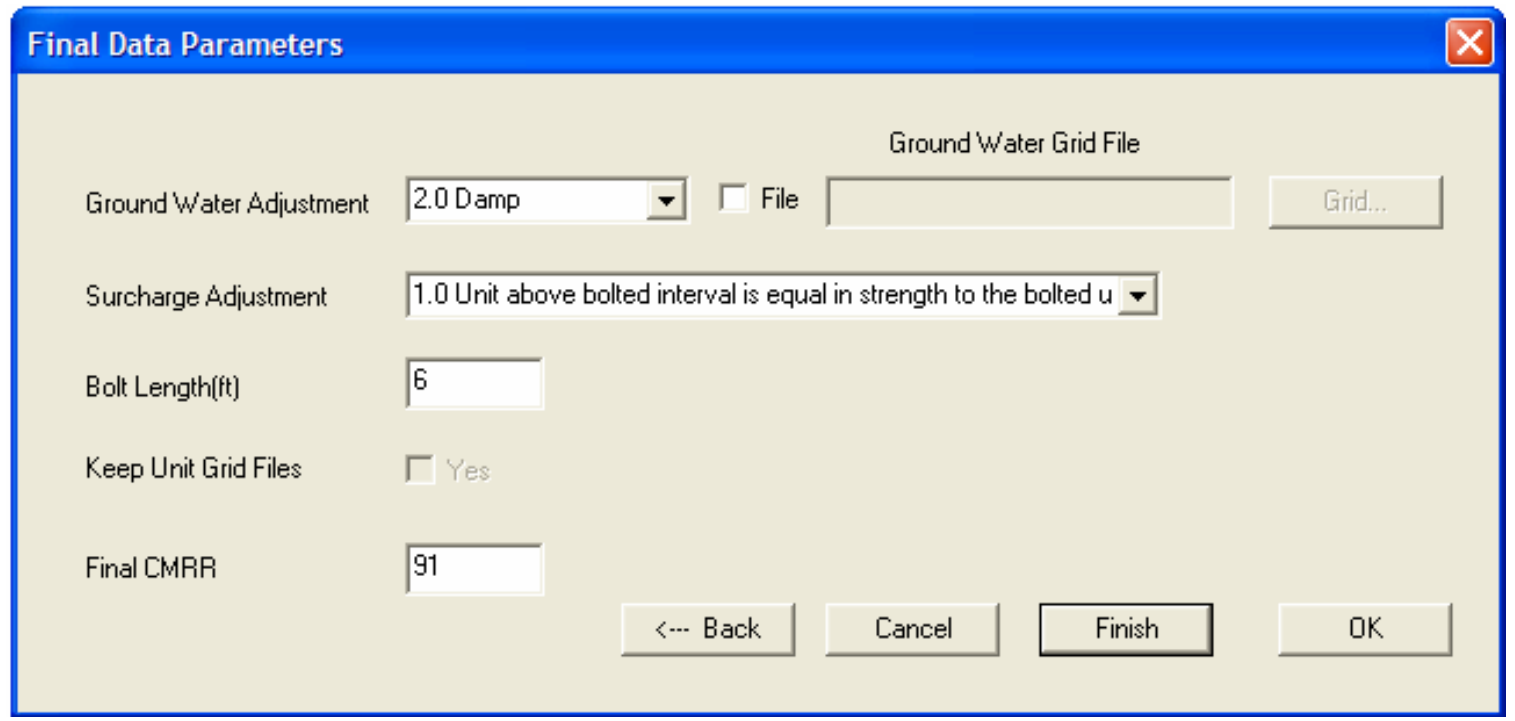

Figure B.7 Final Data Form

\section{B.3 Basic structure of the CMRR program forms}

In the previous sections each of the five major forms which make up the program are illustrated. A better way to understand the flow from one form to the other is through the flow sheet illustrated in Figure B.8. The program begins at the AutoCAD interface and moves through each form unit completion, upon which you are returned to the AutoCAD interface. 


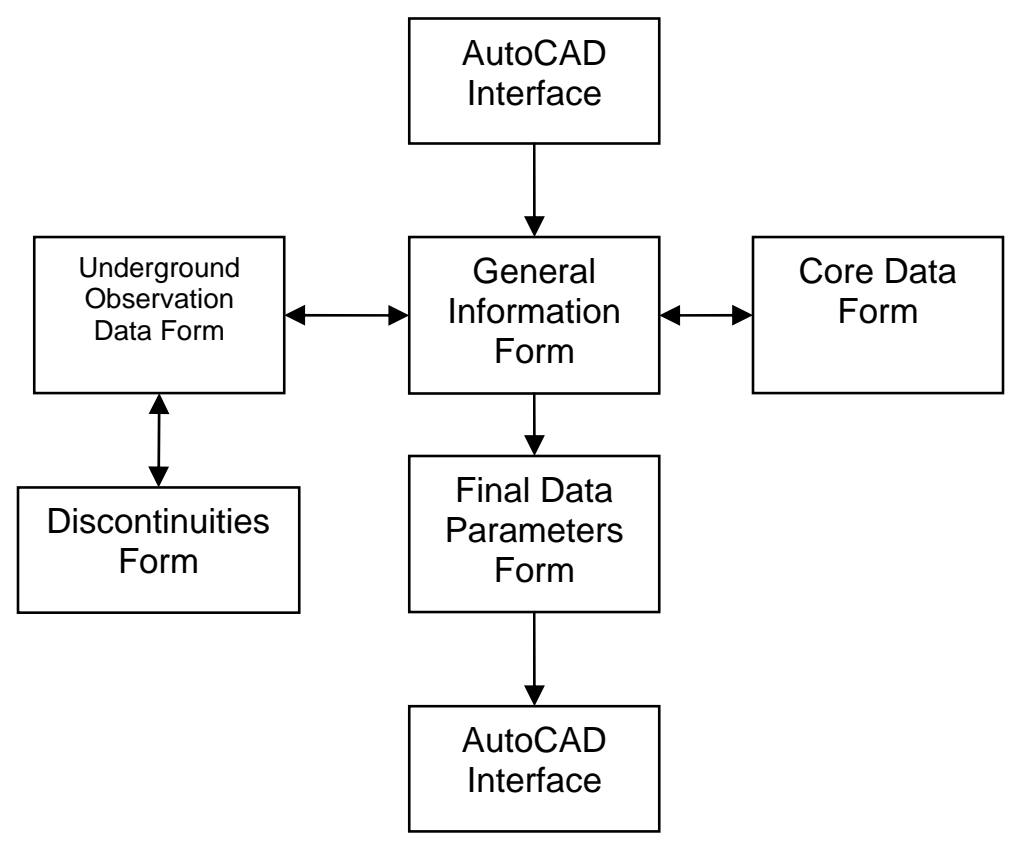

Figure B.8 General program flow sheet

\section{B.4 Details of program execution (taken from chapter 4)}

- Unit Calculations

In order to create a CMRR grid, the major components that make up the CMRR must be calculated. One of the most important building blocks of the CMRR is the unit rating. The unit ratings are based on data specific to each unit in the bolting horizon and are made up of various parameters that affect the overall strength. The data used in the unit rating calculations can come from either observational data or from drill core data. The observational data can be obtained from various sources such as roof falls, outcrops, or overcasts, whereas the core data would be gathered either from surface drilling such as exploration drilling or from underground drilling that is carried out during or immediately after development.

Before the unit ratings can be calculated, the data source must be chosen; either observation data or drill core data. Depending on the option chosen, different data will 
be needed to carry out the unit rating calculation process. The calculation process varies with respect to the data source and to whether or not grid data was entered. Within the program, different dialog boxes or windows will appear based on the choice of data source. Each of the dialog boxes has various edit boxes and pull-down menus that are to be filled out before the calculation of the unit rating can be completed. Each parameter used in the unit rating calculation is checked to ensure that there are not any values that are outside of the range of typical data. Once all of the necessary data is entered, the unit ratings are able to be calculated based on the data type and specific data. Once the unit calculations are complete, the rest of the global CMRR parameters can be entered and the final CMRR value or grid can be computed (See Figure B.9).

\section{- Observation Routines}

As stated above, observational data can be used to calculate the unit ratings for each unit in the bolting horizon of the area of interest. There are two separate processes by which the unit rating from observational data can be calculated. The first process calculates one unit rating based on data where a single value is used for each unit parameter. The second process utilizes the ability to enter a grid of points for the strength of the unit. For the second process, instead of calculating a single unit rating, a grid of unit rating values is created and subsequently used in the calculation of the CMRR.

The first calculation process based on individual values for all unit parameters is illustrated in Figure B.10. The calculation procedure follows what was described in Chapter 2.2.8. The first step, once all data is entered, is determining the strength rating and moisture rating. The ratings are based on the input for the strength and moisture of the unit and Tables 2.4 and 2.5. 


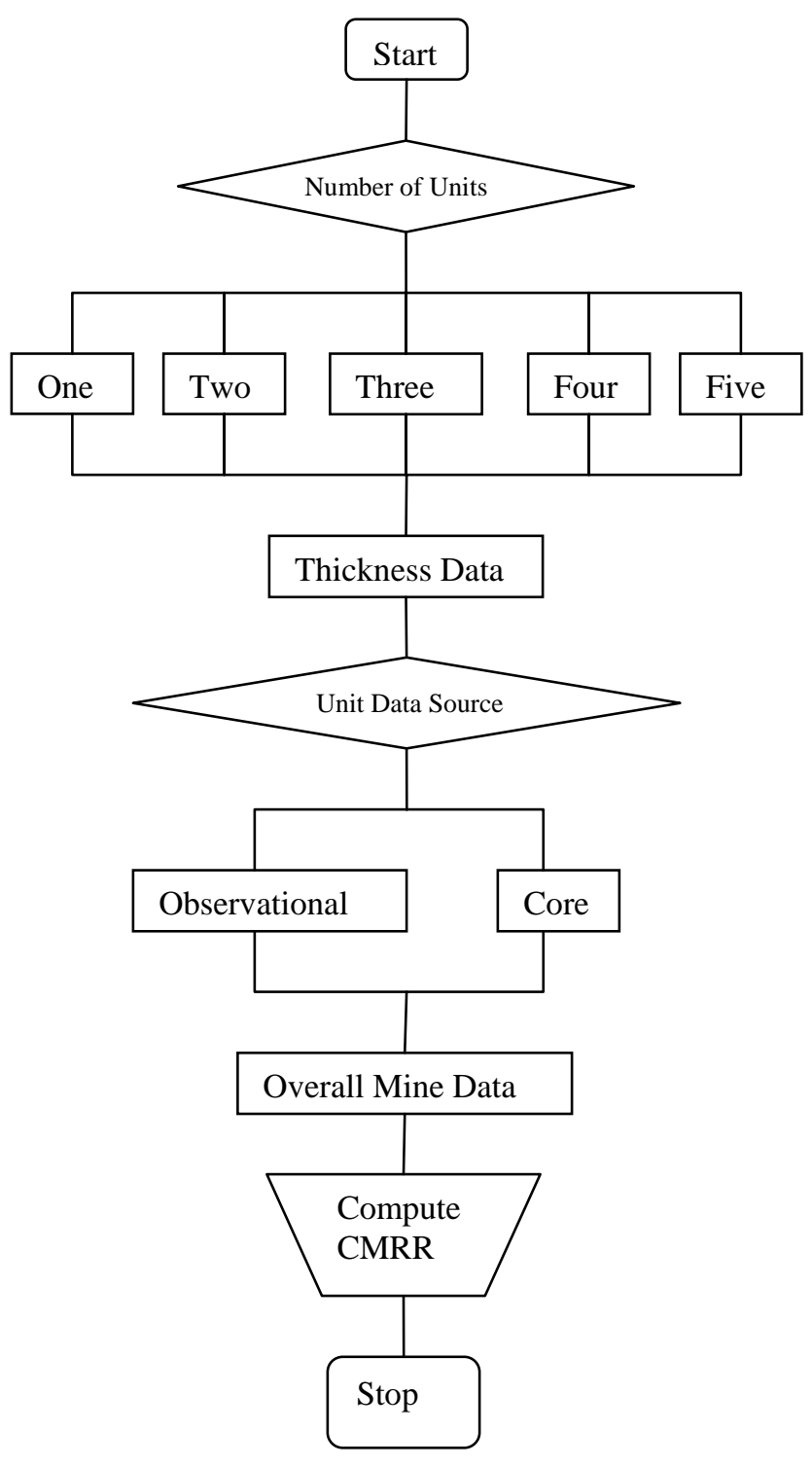

Figure B.9 Flow chart of CMRR program

All of the tables used in the calculations are directly coded into the program and the rating and adjustment values are interpolated based on the values of the input parameters. The interpolation process will be discussed later in this chapter. When discontinuity sets are present, the adjustments for the roughness/cohesion and spacing/persistence are the next items to be calculated. Once complete, a discontinuity 
rating is calculated based on the two discontinuity factors for each discontinuity set. The discontinuity ratings are then sorted and used to determine a multiple discontinuity adjustment if more than one discontinuity set is present. Finally, the unit rating can be calculated based on the above ratings and adjustments.

If there are no discontinuity sets present, a discontinuity adjustment is determined based on the cohesion of the rock which makes up the unit. Once complete, the unit rating is calculated from the strength and moisture rating along with the discontinuity adjustment.

When a strength grid is to be used in the calculation of a unit rating, the process is similar to the above, with a few exceptions (Figure B.11). The first step, once all data is entered, is determining the strength rating. When discontinuity sets are present, the adjustments for the roughness/cohesion and spacing/persistence are the next item to be calculated. Once complete a discontinuity rating is calculated based on the two discontinuity factors for each discontinuity set. The discontinuity ratings are then sorted and used to determine a multiple discontinuity adjustment if more than one discontinuity set is present. The next step is to loop over each of the points in the strength grid and determine a strength adjustment for each point. Finally, the unit rating can be calculated for each grid point based on the ratings and adjustments assigned to each individual point. The calculation is performed until strength ratings and unit ratings are determined for each and every point in the strength grid. The result is now a grid of unit ratings instead of one single unit rating. This grid will be used in the calculation of a grid of CMRR values later in the calculation process.

If there are no discontinuity sets present, a discontinuity adjustment is determined based on the cohesion of the rock which makes up the unit. Once complete, the strength 
rating is determined for each point on the strength grid and the unit rating is calculated for each point from the strength and moisture ratings along with the discontinuity adjustment. As in the previous paragraph, this results in a grid of unit ratings that will be used later on in the calculation process to create a grid of CMRR values.

\section{- Core Data Routines}

As previously stated, drill core data can be used to calculate the unit ratings for each unit in the bolting horizon of the area of interest. There are two separate processes by which the unit rating from drill core data can be calculated. The first process calculates one unit rating based on data where a single value is used for each unit parameter. The second process utilizes the ability to enter a grid of points for one or more of the following parameters: the diametral PLT strength, RQD, discontinuity spacing, axial PLT, and axial UCS as shown in Table 3.2. Instead of calculating a single unit rating, a grid of unit rating values is created and used in calculating the CMRR.

The procedure for calculating a unit rating based on individual data values from core hole data is illustrated in Figure B.12. The first step, once all data has been entered, is to determine the UCS rating based on either an axial PLT or a laboratory UCS. If an axial PLT has been used, this value must be multiplied by 21, as explained in Chapter 2, in order to be normalized to a UCS strength. Once the axial point load tests have been normalized, the UCS rating can be calculated either by using Eq. (2.1) if the UCS strength is less than or equal to 5,000 psi, or 2.2 if it is greater. 


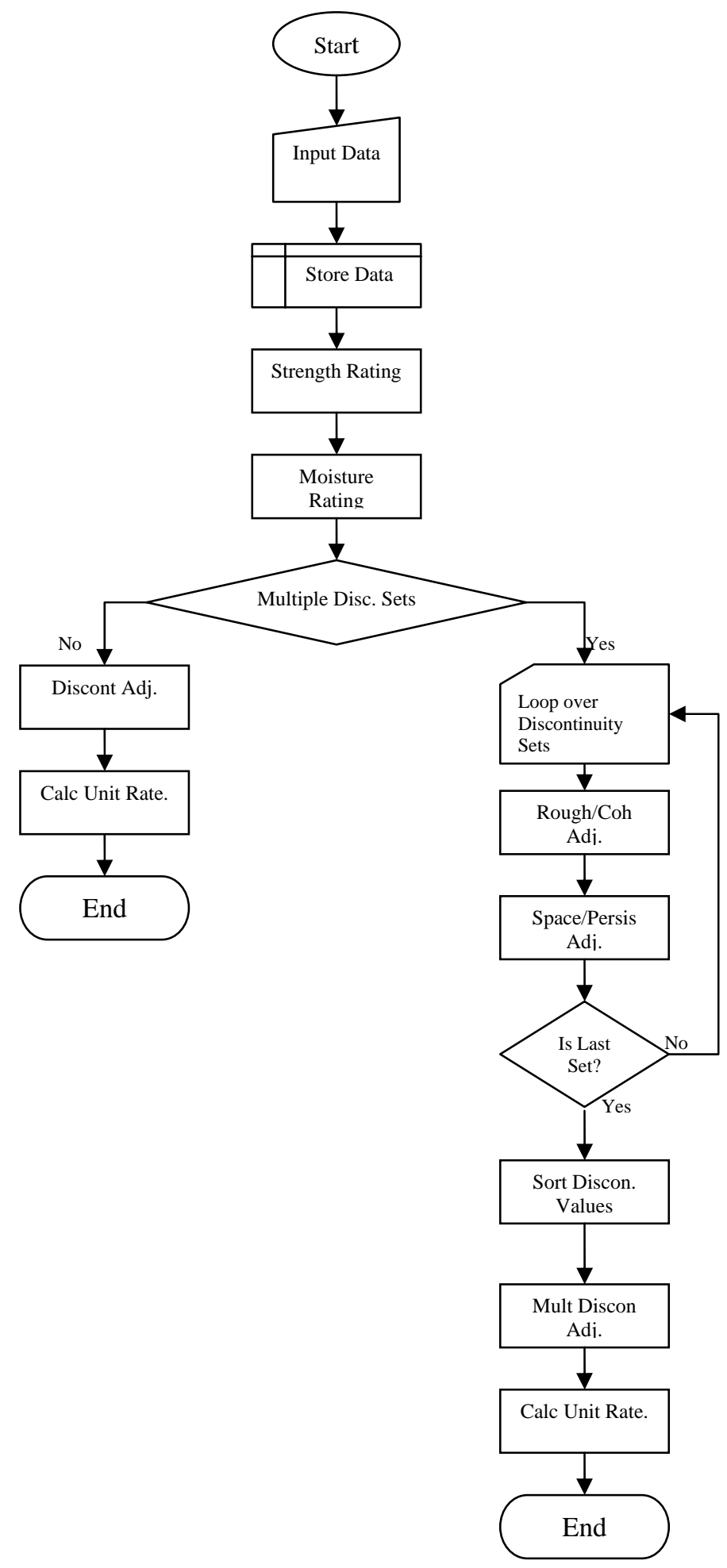

Figure B.10 Unit rating calculation flow sheet for observation data with simple input 


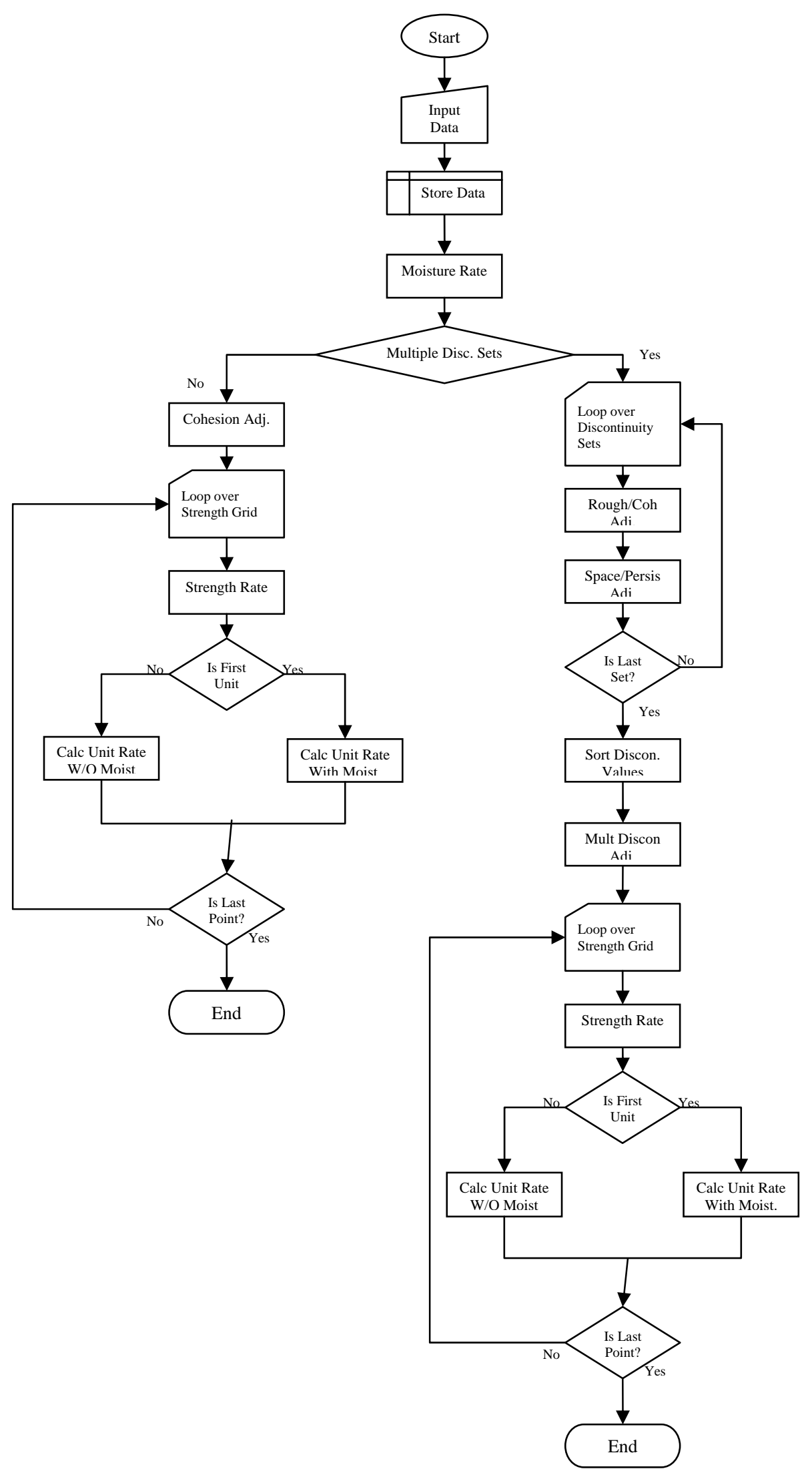

Figure B.11 Unit rating calculation flow sheet for observation data with grid input 
Next, the discontinuity spacing rating is calculated based either on an RQD or fracture spacing. If an RQD value was given, Eq. (2.5) should be used and if a fracture spacing was given Eq. (2.4) should be used. Once the discontinuity spacing rating is determined, the diametral rating can be found using the Eq. $(2.6-2.9)$. If there is no data available for the diametral rating an estimate can be made. An estimate of weak, moderate, or strong can be input and converted to a rating value of 25,36 , or 48 respectively. The lower of the discontinuity spacing rating and the diametral rating is used as the discontinuity rating. Finally, to calculate the unit rating, simply add the UCS rating to the discontinuity rating.

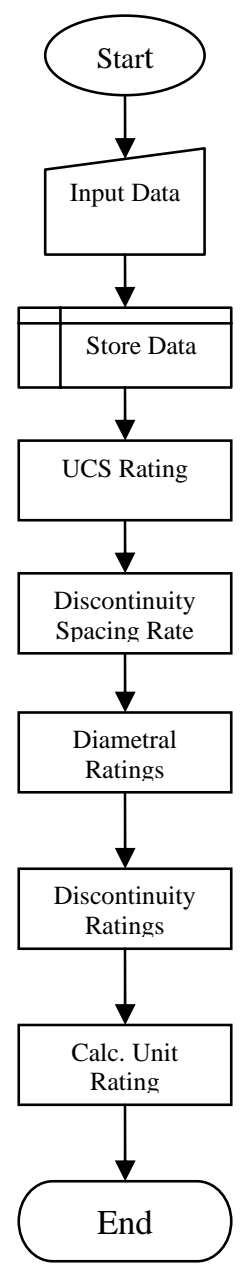

Figure B.12 Unit rating calculation flow sheet for core hole data with simple input 
If grid values are available for any of the unit values listed in Table 3.2 under the grid column, then the calculation process must be altered from that described in the previous paragraph. Instead of calculating a unit rating for a single point one must be determined for each point on the grid as shown in Figure B.13. If a particular factor such as the UCS rating is given an individual value but one of the other factors has a grid of data values then the single UCS rating will be used in the calculation of the unit rating for each point on the grid. Each factor that is used to calculate the unit rating is determined in the same manner as described in the previous paragraph but now it is carried out multiple times.

\section{- Calculations for One Unit}

One of the most basic processes for calculating the CMRR is in the instance when only single point values are available and one unit is present in the bolting horizon, Figure B.14. In this case there are only four factors that make up the CMRR. The first is the contact adjustment based on the contact strength with the rock above the unit, the second is the ground water adjustment, the third is the surcharge adjustment, and the fourth is the unit rating. These four factors are simply added together to determine the CMRR. 


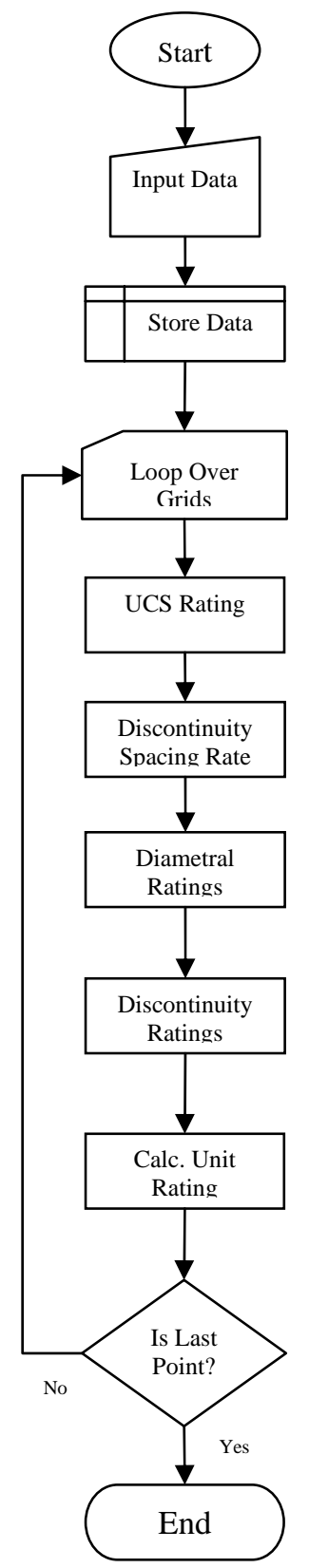

Figure B.13 Unit rating calculation flow sheet for core hole data with grid input 


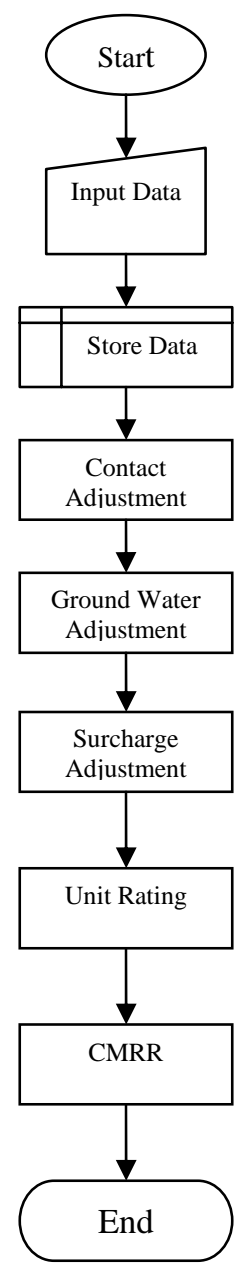

Figure B.14 CMRR calculation flow sheet for simple input data and a single unit

When only a single unit is present but there is a grid of values for either the groundwater or the unit rating then the calculations must be looped over each of the grid points, Figure B.15. This is similar to the unit rating calculations that were described when grid data was present. The contact adjustment, ground water adjustment, surcharge adjustment, and the unit rating are found for each point on the grid and added to determine the CMRR for that particular point. When complete, a grid of CMRR values is available for analysis. 


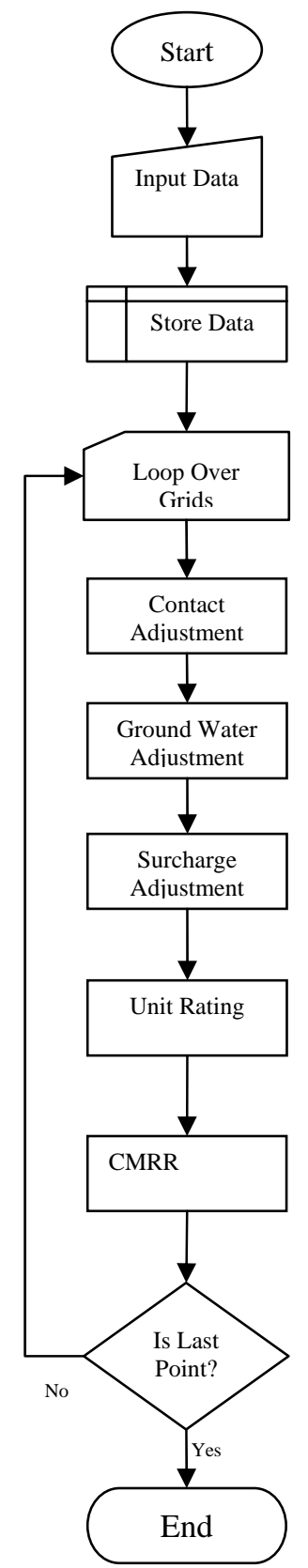

Figure B.15CMRR calculation flow sheet for grid input data and a single unit

- $\quad$ Calculations for Multiple Units

When going through the process of determining a CMRR for a particular point in a mine by hand it is customary to be concerned only with the units within the bolting horizon. The length of bolt being used should end within the uppermost unit of concern. When implementing these steps into a computer program, one must account for the 
instance when the bolt is too long or too short for the total thickness of the units being used. If the bolt length is less than the total thickness of the units given, then the unit thickness used for the CMRR calculation should be modified for that particular point; the total thickness should be less in this instance. On the other hand, if the bolt is longer than the total thickness of the available units it should be assumed that the bolt is only as long as the total unit thickness. This assumption is made because when calculating a CMRR only the bolted interval is taken into consideration. For example, if data is given for 10 $\mathrm{ft}$. of roof strata and the bolt length is only $8 \mathrm{ft}$., the last two feet of rock is ignored in the calculation process. These types of occurrences need to be considered because there may not always be a case where the bolt stops in the last unit. This is particularly an item of concern when using a grid of thickness values to calculate the CMRR. The thickness of different units can vary widely over a large area and could result in many occurrences of the issues described above. Because the unit thickness for each unit and the length of bolt being used is known, it is possible to compare the two and make the appropriate changes in order to allow the calculation of the CMRR to be done correctly.

When calculating a CMRR with multiple units, either a single value is used for each factor or a grid of values is used for factors which can accept this data type. Although the two processes are similar, the first is the simpler of the two. This first process is illustrated in Figure B.16 as a flow chart. The first step, once all data has been input and stored, is to compare the length of the bolt being used to the overall thickness of all of the units. This is done for the reasons explained in the previous paragraph. Once this is done, the unit weighted average, or RRw, can be calculated based on the determined bolt length and proper number of units to be used. Next, the strong bed difference and strong bed adjustment are found using the RRw and the strength and 
thickness of the strong bed as described in Sections 2.3.4 and 2.2.9. The contact adjustment, ground water adjustment, and surcharge adjustment are then found using the tables described in Section 4.4.1. Once complete, the final CMRR can be calculated by adding the RRw, strong bed adjustment, contact adjustment, ground water adjustment, and surcharge adjustment.

If a grid of unit ratings has been created or a grid of thickness values or ground water is entered into the program, the calculation process for determining the CMRR must be slightly changed. If a grid for one of the above values is used, then the CMRR must be calculated for each point on the grid. In this case, the steps described in the previous paragraph must be carried out once for each point. This process is illustrated in Figure B.17 as a flow chart. Creating a CMRR using grid data can be very useful in that it allows the user to take advantage of the best available data. Instead of interpolating between CMRR values that are created by using individual data points, the interpolation can be done on the individual factors that make up the CMRR. This helps to get a more accurate picture of CMRR values over a mine area.

\section{- $\quad$ Major Secondary Support Routines}

The two previous sections describe the major calculations that are necessary to determine the unit ratings and CMRR. Although these two processes make up the main functional portion of the program, there are also smaller yet equally important functions that need to be discussed. These support functions make it possible for the unit ratings and CMRR to be calculated; without them, grid data would not be able to be used, adjustment arrays could not be interpolated, and the data that is input could not be saved. 


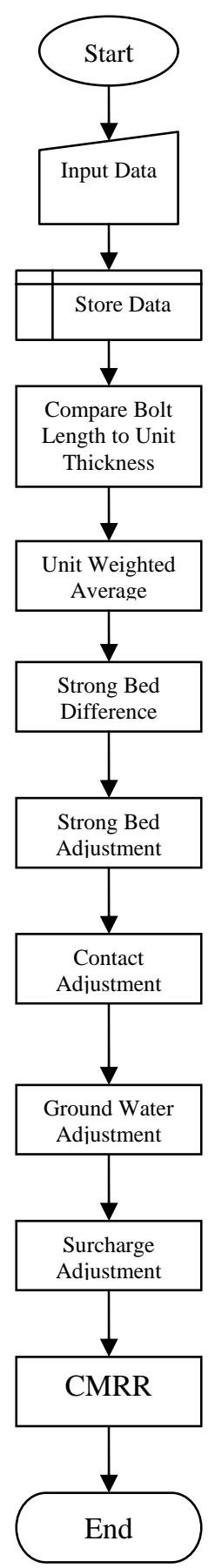

Figure B.16 CMRR calculation flow sheet for simple input data and multiple units 


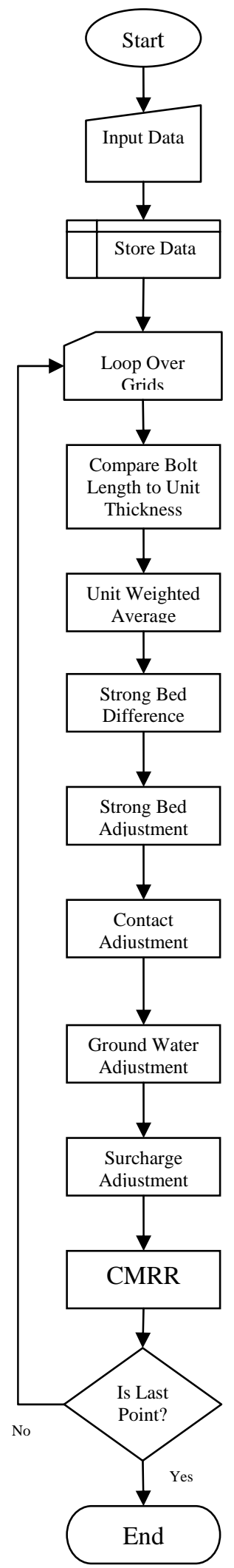

Figure B.17 CMRR calculation flow sheet for grid input data and multiple units 
The first two support functions that will be discussed allow the program to interpolate values from both one and two-dimensional arrays. Next, the process of reading and writing the grid files will be described. Finally, some information will be given regarding the working file that is used during operation of the program and that is saved to restart a previously created database.

\section{- Utility Calculations}

In the previous sections, various flow sheets have been used to illustrate how each part of the CMRR is calculated. In many of these flow sheets, an adjustment or rating is determined in order to calculate some specific factor that makes up the CMRR. When the CMRR was initially designed, all of these adjustments and ratings were determined from Tables such as $2.1-2.10$ in Chapter 2. In order to use these tables in the program, each of them had to be input into either a one or two-dimensional array. Tables such as 2.1, 2.2, and 2.6 were input as two-dimensional arrays while the other tables were input as one-dimensional arrays. The difficulty with using these tables directly is that they can only be referenced for round numbers within the table and not fractional values in between. This becomes a problem because within the program, a user can input any decimal or interpreted value for an input data factor as long as it is within the possible limits for that factor. When this full range of input occurs, the program must interpolate a value based on the known array data and the given discreet input.

For a single dimensional array, the interpolation process is very simple. A basic linear interpolation is carried out between the indexed input numbers and the associated resulting values by using the hard-wired one-dimensional array for whatever particular factor is needed and the number that is input by the user. The equation for the linear interpolation is given in Eq. (B.1). The equation stays the same for interpolating different 
factors, but the values that the variables reference change. The Xval variable represents the value or an interpretation of the value input by the user of the program. This value is then compared to the index data that is hard-wired into the appropriate array to obtain the values of Xmax, Xmin, Ymax, and Ymin. Xmax and Xmin are the closest index values greater than the input index and the closest index value than Xval in the correct array. Ymax and Ymin are the result values that correspond to index values of Xmax and Xmin. From these four values and the data given by the user, an interpolated adjustment or rating can be determined through the use of Eq. (B.1).

$$
Y_{v a l}=Y_{\max }-\left[\frac{\left(X_{\max }-X_{v a l}\right) *\left(Y_{\max }-Y_{\min }\right)}{X_{\max }-X_{\min }}\right]
$$

In the instance that interpolation must be done on a two-dimensional array, the process is analogous, but a little more complex than that of a one-dimensional array. For a two-dimensional case it is assumed that we have a matrix of functional values $\mathrm{za}[1 . . \mathrm{m}][1 . . \mathrm{n}]$ and arrays $\mathrm{xa}[1 . . \mathrm{m}]$ and $\mathrm{ya}[1 . . \mathrm{n}]$ which are related to an underlying function represented by Eq. (B.2) (Vetterling et al., 1992).

$$
z a[j][k]=z(x a[j], y a[k])
$$

The goal of the interpolation is to find the value of a function $\mathrm{z}$ at some $(\mathrm{x}, \mathrm{y})$ location. In order to better understand this method the concept of the grid square can be used where the point $(\mathrm{x}, \mathrm{y})$ is the desired value and the four points surrounding that value are used to determine such value. The four points can be equated by referencing them to the value of the desired point as shown in Eq. (B.3) through (B.8) (Vettering et al., 1992). 
Equations (B.3) and (B.4) define the values of $\mathrm{J}$ and $\mathrm{K}$ whereas Eq. (B.5) through (B.8) define the $\mathrm{z}$ values at each of the four corner points around point $(\mathrm{x}, \mathrm{y})$.

$$
\begin{gathered}
x a[j] \leq x \leq x a[j+1] \\
y a[k] \leq y \leq y a[k+1] \\
z_{1} \equiv z a[j][k] \\
z_{2} \equiv z a[j+1][k] \\
z_{3} \equiv z a[j+1][k+1] \\
z_{4} \equiv z a[j][k+1]
\end{gathered}
$$

Once all of the values around the desired point are defined and can be referenced with regard to that point, bilinear interpolation can be used to find its value. The three equations that are used to carry out the interpolation are given in Eq. (B.9) through (B.11) (Vettering et al., 1992). In this application $z_{1}, z_{2}, z_{3}$, and $z_{4}$ are the representation of the values within the two-dimensional array at a given point around the value at $(\mathrm{x}, \mathrm{y})$. The final Eq. (B.11) brings all of the previous ones together. Each of the four parts of Eq. (B.11) accounts for one of the four corner points around the desired answer. In this manner, each point is given an influence on the final interpolated value dependent upon the proximity of $(\mathrm{x}, \mathrm{y})$ to that point.

$$
t=\frac{x-x a[j]}{x a[j+1]-x a[j]}
$$




$$
\begin{gathered}
u=\frac{y-y a[k]}{y a[k+1]-y a[k]} \\
z(x, y)=\left((1-t) *(1-u) * z_{1}\right)+\left(t *(1-u) * z_{2}\right)+\left(t * u * z_{3}\right)+\left((1-t) * u * z_{4}\right)
\end{gathered}
$$

Without the ability to interpolate one and two-dimensional arrays it would be impossible to write a program that allowed the user to input unlimited data values for a certain input factor within the limits of that factor. If this were the case it would limit the versatility of the program and limit the creativity of the user. In this instance the user would only be able to input data that corresponded to an exact point within one of the various adjustment or rating arrays.

\section{- $\quad$ Grid Read and Write}

In previous sections, it was mentioned that SurvCADD grids can be used as an input data type for a number of factors. When a user desires to take advantage of this feature, each grid must be read into the program individually. In order to do this a browse window, (see Appendix B), is used to choose the grid file from a specified directory to be read into the program.

The program goes through a number of steps to ensure that the grid being read is valid and the data that it contains is within the limits of the factor to which it is being applied, Figure B.18. The first error check that is undertaken when reading a grid is to check the size and location of the grid within a spatial plane. If this is the first grid that is read into the program, the location and size will be stored and each grid thereafter will be compared to the first to ensure that each and every gird is of the same size and location. Obviously, many of the grid calculations can only be performed when the grids are the 
same size. The second error check is to analyze the data values being read into the program. Various factors such as RQD, groundwater, and thickness have upper and lower limits that cannot be breached in order for the program to run properly. Because of this, each data point that is read from the grid is compared to the bounds for the type of factor to which the data is going to be applied. Along with this, each point on the grid is checked to make sure that its value is not a null value and that it is also not a negative value. If any error values are found, an error will be presented to the user, but in most instances the program will still proceed.

As the data is being checked for validity, each point is being stored in a working array. The size of the array is determined by the size of the grid and adjusted to each grid individually. The working array is not saved after the program is closed because so much information would need to be stored if multiple grids are used. Instead, when the user opens a saved data set, each grid is read into the program from its stored file location and the data is stored in a new working array. If the location of the grid file within the user's computer has changed since the program was last saved, an error will be given and the user can select a new grid file name or location.

As stated earlier, the main advantage to this program is the ability to input data in a grid format, and to also output final results in the same format. It is possible to create both a CMRR grid and a unit grid based on data that the user puts into the program. The grid files that are output by the program must be able to be read by SurvCADD; therefore they are of the same format and type. In the previous paragraphs it was mentioned that each data point that is read into the program must be check for validity and quality. The same statement holds true for the data that is contained within the grids that are output by the program. If a data point from a grid is input into the program and determined to be 
out of range then a CMRR or unit rating value for that point will most likely not be able to be calculated. In this situation, a null value is assigned to the location of the out-ofrange data point. The null character is capable of being read by SurvCADD and does not affect the values surrounding its location. Grids that are created by this program can be manipulated by SurvCADD like any other SurvCADD grid which allows the user to create isopachs and use other various utilities to manipulate and view the data.

The application of SurvCADD grids to the CMRR is what separates this program from those that have preceded it. Because of this, great care was taken to ensure that all data read into the program in a grid format is as accurate and valid as can be determined. By using data in this format the CMRR can be applied over a large area with less work and hopefully more accurate application. 


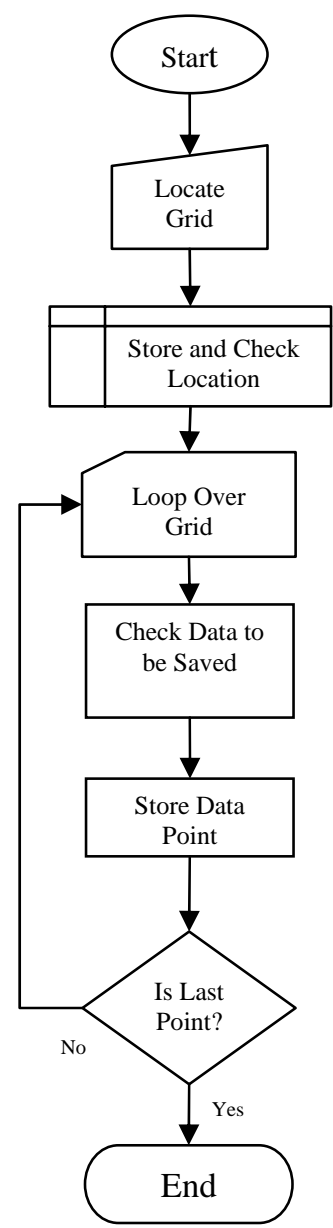

Figure B.18 Grid read and write flow sheet

\section{- Working File Read and Write}

Like any other program, this program is capable of saving the data that is entered into it and also able to read that data back into the program at a later date. The file that the data is stored in is a simple text file that can be read by any number of word editing or processing programs. Although the working file is simple, it is dynamic in its nature. Depending on what kind of data is being entered, be it drill core data or observation data, the structure of the file changes. Within the file itself there are flags that are saved, and when read by the program they tell the program what type of data is coming next. This dynamic type of data storage allows for a smaller data file with no null or blank values. 
As was mentioned in the previous section, the grid files are not saved within the working file. Instead, the locations of the grid files are saved so that they may be retrieved when all of the working file data are read into the program. The reason for doing this was to limit the size of the working file in order to increase the ease and speed at which the file is read into the program. An example of a working file can be found in Figure B19. Here we can see the different locations of the grids used in this example along with the other data that was entered. Many of the ones and zeroes at the beginning of each line represent the flags that tell the program what type of data is going to come next. This allows the program to know where to store each piece of information.

Although simple, the working file is an extremely important and necessary part of any good program. Without it the user would not be able to save the work that they have completed or subsequently retrieve it in the future.

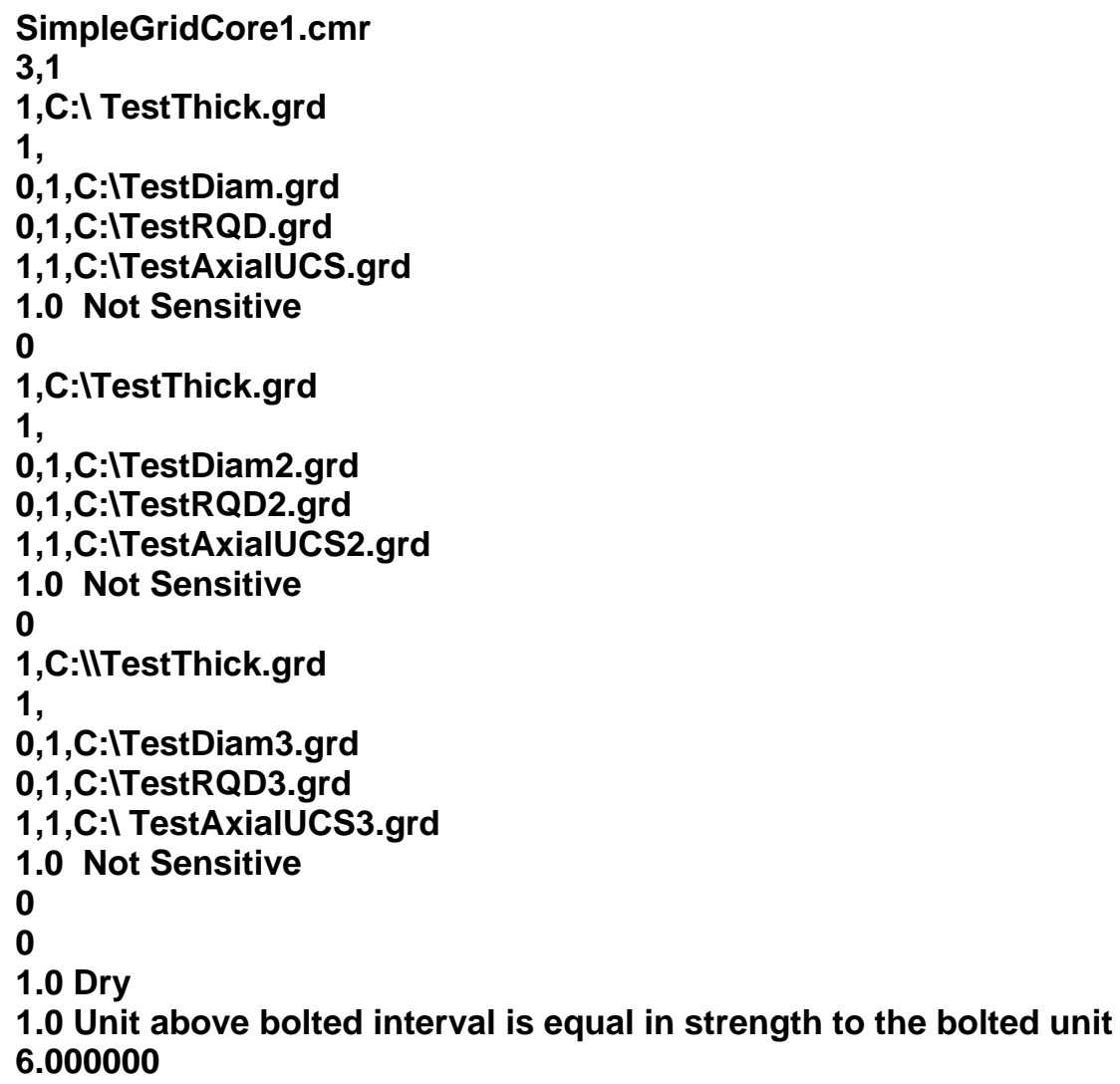

Figure B.19 Working file example 